\title{
Unveiling the Defect Structure of Lithium Niobate with Nuclear Methods
}

\author{
Andreas Kling *(D) and José G. Marques \\ Centro de Ciências e Tecnologias Nucleares, Instituto Superior Técnico, Universidade de Lisboa, Estrada \\ Nacional 10, km 139.7, P-2695-066 Bobadela, Portugal; jmarques@ctn.tecnico.ulisboa.pt \\ * Correspondence: akling@ctn.tecnico.ulisboa.pt; Tel.: +351-219-946-154
}

check for updates

Citation: Kling, A.; Marques, J.G. Unveiling the Defect Structure of Lithium Niobate with Nuclear Methods. Crystals 2021, 11, 501. https://doi.org/10.3390/ cryst11050501

Academic Editors: Gábor Corradi and László Kovács

Received: 31 March 2021

Accepted: 21 April 2021

Published: 2 May 2021

Publisher's Note: MDPI stays neutra with regard to jurisdictional claims in published maps and institutional affiliations.

Copyright: (c) 2021 by the authors. Licensee MDPI, Basel, Switzerland. This article is an open access article distributed under the terms and conditions of the Creative Commons Attribution (CC BY) license (https:// creativecommons.org/licenses/by/ $4.0 /)$.

\begin{abstract}
X-ray and neutron diffraction studies succeeded in the 1960s to determine the principal structural properties of congruent lithium niobate. However, the nature of the intrinsic defects related to the non-stoichiometry of this material remained an object of controversial discussion. In addition, the incorporation mechanism for dopants in the crystal lattice, showing a solubility range from about $0.1 \mathrm{~mol} \%$ for rare earths to $9 \mathrm{~mol} \%$ for some elements (e.g., $\mathrm{Ti}$ and $\mathrm{Mg}$ ), stayed unresolved. Various different models for the formation of these defect structures were developed and required experimental verification. In this paper, we review the outstanding role of nuclear physics based methods in the process of unveiling the kind of intrinsic defects formed in congruent lithium niobate and the rules governing the incorporation of dopants. Complementary results in the isostructural compound lithium tantalate are reviewed for the case of the ferroelectric-paraelectric phase transition. We focus especially on the use of ion beam analysis under channeling conditions for the direct determination of dopant lattice sites and intrinsic defects and on Perturbed Angular Correlation measurements probing the local environment of dopants in the host lattice yielding independent and complementary information.
\end{abstract}

Keywords: lithium niobate; intrinsic defects; extrinsic defects; lattice location; radiation damage; ion beam analysis; hyperfine interactions

\section{Introduction}

Present opto-electronic and future quantum-process based communication technologies rely strongly on optical materials with their inherent or artificially modified properties. Lithium niobate $\left(\mathrm{LiNbO}_{3}\right.$, henceforth abbreviated $\left.\mathrm{LN}\right)$ is one of the materials that has drawn most attention in this process. Its excellent linear and non-linear optical properties, facility to form waveguide using a variety of methods, ability to incorporate optically active dopants and the applications based on periodically poled crystals make it a favorite target for basic and applied research [1-4].

In order to achieve the modification of its properties with a certain goal in mind, the basic properties of LN have to be understood. Among them, the intrinsic defect structure of the congruent lithium-deficient crystals in comparison to stoichiometric ones, phenomena related with the phase ferroelectric-paraelectric phase transition, incorporation of dopants and their interaction with the lattice and lattice damage production and removal are topics for fundamental research fostering future application directed research.

Methods based on nuclear techniques played and will play an important role in materials research. Their application can clarify or-in combination with other methodsassist to clarify the topics mentioned in the preceding paragraph. While ion beam analysis methods are ideal for research on composition as well as lattice defect concentration and distribution, hyperfine interaction methods can yield complementary information on local environments in the lattice and dopant charge states. As will be demonstrated in the course of this review the combination of several of these techniques can unveil the nature of 
defects in LN. For illustration, Figure 1 shows a "periodic table of elements" for which nuclear techniques have been applied in the case of LN.

\begin{tabular}{|c|c|c|c|c|c|c|c|c|c|c|c|c|c|c|c|c|c|}
\hline $\mathrm{H}$ & & & & & IBA & & & NQI & & & & & & & & & $\mathrm{He}$ \\
\hline $\mathrm{Li}$ & $\mathrm{Be}$ & & & & PAC & & & $\mathrm{ME}$ & & & & $B$ & $\mathrm{C}$ & $\mathrm{N}$ & $\mathrm{O}$ & $\mathrm{F}$ & $\mathrm{Ne}$ \\
\hline $\mathrm{Na}$ & $\mathrm{Mg}$ & & & & NM & & & & & & & $\mathrm{Al}$ & $\mathrm{Si}$ & $\mathrm{P}$ & $\mathrm{S}$ & $\mathrm{Cl}$ & $\mathrm{Ar}$ \\
\hline $\mathrm{K}$ & $\mathrm{Ca}$ & $\mathrm{Sc}$ & $\mathrm{T} 1$ & $\mathrm{~V}$ & $\mathrm{Cr}$ & $\mathrm{Mn}$ & $\mathrm{Fe}$ & $\mathrm{Co}$ & $\mathrm{Ni}$ & $\mathrm{Cu}$ & $\mathrm{Zn}$ & $\mathrm{Ga}$ & $\mathrm{Ge}$ & As & $\mathrm{Se}$ & $\mathrm{Br}$ & $\mathrm{Kr}$ \\
\hline $\mathrm{Rb}$ & $\mathrm{Sr}$ & $\mathrm{Y}$ & $\mathrm{Zr}$ & $\mathrm{Nb}$ & $\mathrm{Mo}$ & $\mathrm{Tc}$ & $\mathrm{Ru}$ & $\mathrm{Rh}$ & $\mathrm{Pd}$ & $\mathrm{Ag}$ & Cd & $\operatorname{In}$ & $\mathrm{Sn}$ & $\mathrm{Sb}$ & $\mathrm{Te}$ & I & $\mathrm{Xe}$ \\
\hline $\mathrm{Cs}$ & $\mathrm{Ba}$ & $\mathrm{Lu}$ & $\mathrm{Hf}$ & $\mathrm{Ta}$ & W & $\operatorname{Re}$ & Os & $\mathrm{Ir}$ & $\mathrm{Pt}$ & $\mathrm{Au}$ & $\mathrm{Hg}$ & $\mathrm{Tl}$ & $\mathrm{Pb}$ & $\mathrm{Bi}$ & Po & At & $\mathrm{Rn}$ \\
\hline $\mathrm{Fr}$ & $\mathrm{Ra}$ & $\mathrm{Lr}$ & $\mathrm{Rf}$ & $\mathrm{Db}$ & $\mathrm{Sg}$ & $\mathrm{Bh}$ & Hs & $\mathrm{Mt}$ & Ds & $\mathrm{Rg}$ & $\mathrm{Cn}$ & $\mathrm{Nh}$ & $\mathrm{Fl}$ & $\mathrm{Mc}$ & $\mathrm{Lv}$ & Ts & $\mathrm{Og}$ \\
\hline
\end{tabular}

\begin{tabular}{|l|l|l|l|l|l|l|l|l|l|l|l|l|l|}
\hline $\mathrm{La}$ & $\mathrm{Ce}$ & $\mathrm{Pr}$ & $\mathrm{Nd}$ & $\mathrm{Pm}$ & $\mathrm{Sm}$ & $\mathrm{Eu}$ & $\mathrm{Gd}$ & $\mathrm{Tb}$ & $\mathrm{Dy}$ & $\mathrm{Ho}$ & $\mathrm{Er}$ & $\mathrm{Tm}$ & $\mathrm{Yb}$ \\
\hline $\mathrm{Ac}$ & $\mathrm{Th}$ & $\mathrm{Pa}$ & $\mathrm{U}$ & $\mathrm{Np}$ & $\mathrm{Pu}$ & $\mathrm{Am}$ & $\mathrm{Cm}$ & $\mathrm{Bk}$ & $\mathrm{Cf}$ & $\mathrm{Es}$ & $\mathrm{Fm}$ & $\mathrm{Md}$ & $\mathrm{No}$ \\
\hline
\end{tabular}

Figure 1. "Periodic table of elements" in LN for which one or several nuclear techniques have been applied in the investigation of their properties. IBA-Ion Beam Analysis, PAC-Perturbed Angular Correlation, NMR-Nuclear Magnetic Resonance, NQR-Nuclear Quadrupole Resonance, ME-Mössbauer Effect.

\section{Short Overview on Nuclear Methods for Materials Research}

The nuclear techniques addressed in this review are characterized shortly indicating some peculiarities with regard to their application in research on LN. References to general introductory books and reviews for further in depth study are supplied for each of the methods.

\subsection{Ion Beam Analysis}

Ion beam analysis is a group of nuclear methods that are based on the interaction of energetic ion beams (typically few $\mathrm{keV}$ to tens of $\mathrm{MeV}$ ) with materials [5-8]. Its main applications are:

- Composition determination in bulk materials, surface layers and multilayer systems. Some of the methods attain a depth resolution down to sub-monolayer range;

- Detection and quantitation of lattice damage in monocrystalline materials with high depth resolution up to a few $\mu \mathrm{m}$ from the surface;

- Characterization of intrinsic and extrinsic defects in terms of lattice site location and defect type.

The basic ion beam analysis methods applied in LN are Rutherford Backscattering Spectrometry (RBS) and Resonant Elastic Scattering (RES) [9], Nuclear Reaction Analysis (NRA) [10], Particle Induced X-ray Emission (PIXE) [11], Channeling (C) [12,13], Secondary Ion Mass Spectroscopy (SIMS) [14], Elastic Recoil Detection (ERD) and Heavy Ion Elastic Recoil Detection (HIERD) [15,16].

RBS relies on elastic backscattering of the incoming ions by the target atoms. Its origins can be traced back to the 1909 experiments performed by Geiger and Marsden [17] which led to the first modern model of the atom. The energy spectra of backscattered light ions (protons, $\mathrm{He}^{+}$and $\mathrm{He}^{++}$) in the $\mathrm{MeV}$ range provide information on the composition of the material and its depth dependence up to several $\mu \mathrm{m}$ into the bulk. Since the backscattering yield is proportional to the square of the target atomic number, this method works best for targets composed of heavy elements. Therefore, lighter elements in heavy matrices are often difficult or only indirectly determinable while the method excels in the detection of small quantities of heavy elements in light targets. Further, the difference in the maximum 
backscattering energy decreases rapidly with increasing target atom mass making it difficult to discern elements that are neighbors in the periodic table. In order to overcome the restrictions for light elements, resonant elastic scattering, i.e., deviations from the Rutherford cross section, are employed to improve the sensitivity for their detection. This technique is known as Resonant Elastics Scattering or Elastic Backscattering Spectrometry (EBS). Analysis of RBS and RES spectra is done with dedicated software, e.g., RUMP [18] and NDF [19]. As an example, Figure 2 shows a backscattering spectrum for congruent LN irradiated with $3.1 \mathrm{MeV} \mathrm{He}^{+}$demonstrating $\mathrm{Nb}-\mathrm{RBS}$ and O-RES while Li remains invisible.

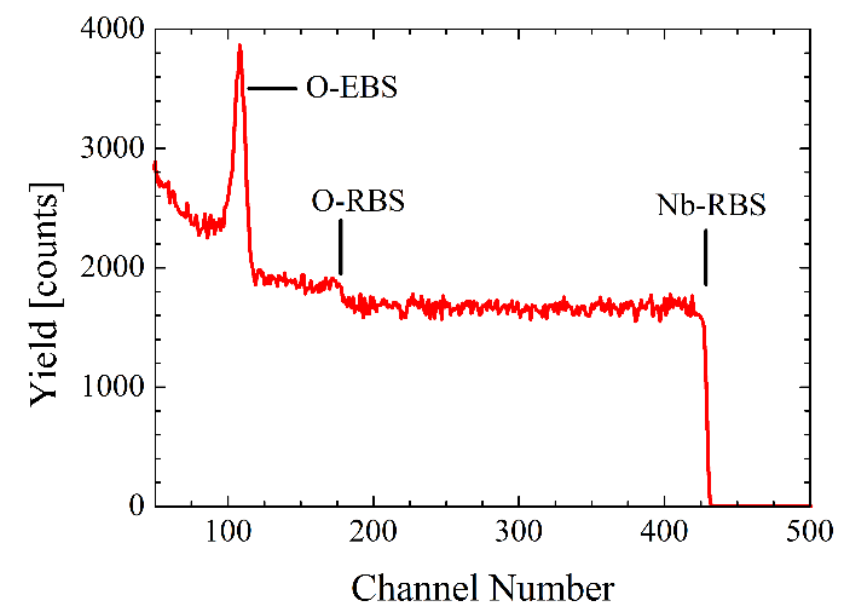

Figure 2. Backscattering spectrum (3.25 $\mathrm{MeV} \mathrm{He}^{+}$) for congruent $\mathrm{LN}$ with Rutherford Backscattering for niobium and Resonant Elastic Backscattering for oxygen using the ${ }^{16} \mathrm{O}(\alpha, \alpha){ }^{16} \mathrm{O}$ resonance (about 30 times higher than Rutherford scattering) at $3.045 \mathrm{MeV}$.

Another possibility for the detection and quantification of light elements in heavy matrices is to look for the light charged nuclei produced by ion beam induced reactions in the target material, within the so called NRA technique. Long measuring times are frequently necessary, since the reaction cross sections are typically much smaller than for backscattering. The analysis of the spectra is analogous to that of RBS and EBS. As an example, Figure 3 depicts a spectrum for $\mathrm{LN}$ irradiated with $1.75 \mathrm{MeV}$ protons. Contributions of backscattering by the target and by the alpha particles produced in the ${ }^{7} \mathrm{Li}(\mathrm{p}, \alpha)^{4} \mathrm{He}$ reaction are clearly distinguishable due to the high Q-value $(17.35 \mathrm{MeV})$ of the reaction employed.

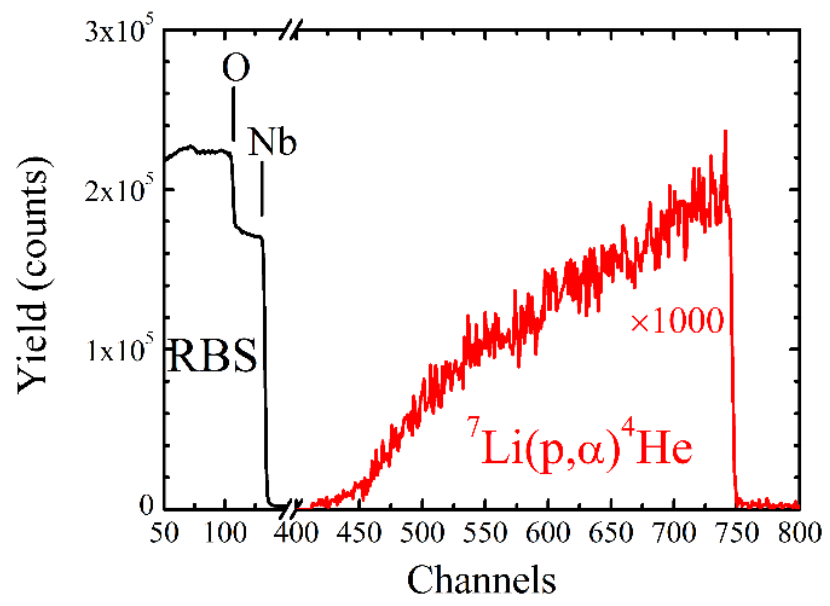

Figure 3. Backscattering spectrum for $1.75 \mathrm{MeV}$ protons on $\mathrm{LN}$ and the spectrum of the alpha particles produced in the ${ }^{7} \mathrm{Li}(\mathrm{p}, \alpha)^{4} \mathrm{He}$ reaction.

The PIXE technique relies on the production of characteristic X-rays (mainly K- and L-lines) by interaction of the incoming ion (in most cases protons, for special purposes $\mathrm{He}^{+}$) 
with inner shell electrons of the target atoms. It is most useful for the detection of medium and heavy elements in compound materials. The quantitative analysis of the elemental concentrations is significantly more complicated than in the previous cases since the technique integrates over the whole ion path in the material. This lack of depth resolution can be partially overcome by measuring the sample at different angles of incidence. Figure 4 shows an example of an X-ray energy spectrum for $\mathrm{LN}$ irradiated with $3.1 \mathrm{MeV} \mathrm{He}$ ions.

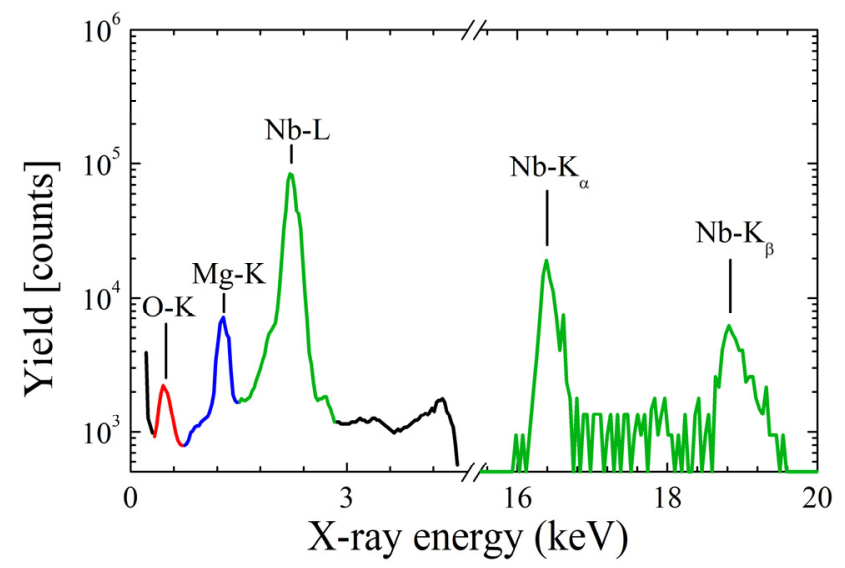

Figure 4. Characteristic X-ray spectrum induced by irradiation of $\mathrm{LN}$ by $3.1 \mathrm{MeV} \mathrm{He}^{+}$ions .

Ions incident along major crystallographic directions (axes or planes) of monocrystalline materials show the channeling effect. Along a crystallographic axis or plane, the atoms of the crystal atoms appear perfectly aligned in strings or plates, respectively. These form, due to their repellent Coulomb potential, a "channel" in which the ions are guided and the ion fluence is concentrated in the center of the channel. Due to this guiding effect the probability for close encounters with lattice atoms are reduced diminishing the yield for ion scattering, nuclear reactions and X-ray emission.

In a typical channeling experiment the yield of backscattered ions, nuclear reactions products or characteristic X-rays is measured tilting the crystal stepwise from a major crystallographic direction to one of random ion beam incidence (in which the atomic arrangement appears disordered). These "scans" are essentially characterized by two parameters, depicted in Figure 5:

- The minimum yield, $\chi_{\min }$, i.e., the ratio of the reaction yield at perfect alignment with a crystallographic direction to that at random incidence. The lower $\chi_{\min }$ the better is the crystalline quality of the sample.

- The half-width of the scan, $\psi_{1 / 2}$, that is larger the less defective the material is.

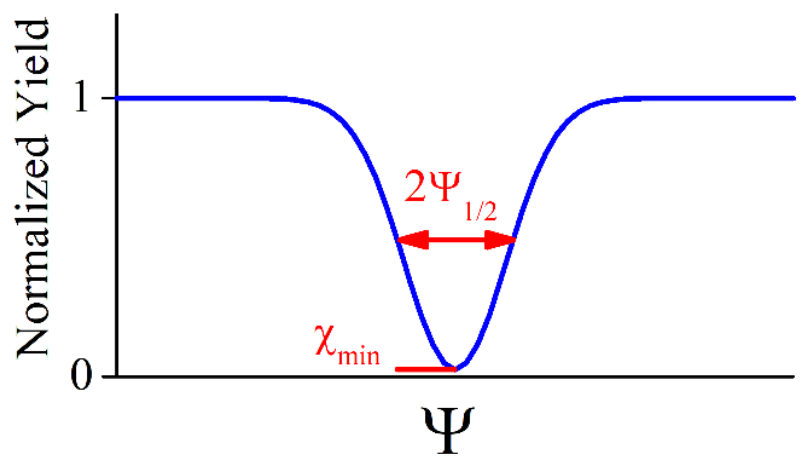

Figure 5. Typical shape and characteristic parameters of a channeling scan.

Possible applications of the channeling effect are [20]: 
- Determination of intrinsic lattice defect concentration (typically, genuine defects of the material or radiation induced defects) with high depth resolution. For the analysis, spectra are taken for the undamaged and the damaged sample aligned with a major crystallographic axis and for a random ion incidence angle. From their comparison a depth-resolved defect profile can be derived using appropriate calculation methods or programs, e.g., DICADA [21];

- Determination of intrinsic lattice defect type. Spectra are recorded in the same manner as in the item above but for different ion energies yielding a dependence of the minimum yield difference on $E^{k}$, where $E$ is the ion energy. Determining the constant $\kappa$ allows to distinguish e.g., between point defects, dislocations, inclusions, etc.

- Lattice location of dopants in the crystal. While an angular scan for a dopant located on a regular lattice site of the crystal will follow that one of the host atoms, foreign atoms on interstitial sites will show scans with distinctly different shapes, depending on their relative position in the channel (e.g., a peak instead of a dip if located in the center). Measurements for different crystallographic directions allow to determine the lattice site by triangulation.

The channeling method was initially developed for the study of simple mono- or bi-elemental cubic crystals. Therefore, an extension to materials as complex as LN was not straightforward and it was only attempted in the 1980s. In contrast to simple materials, in most axial directions of LN the channels are highly asymmetric or split in several subchannels. In all cases they are dominated by the heaviest constituent $(\mathrm{Nb})$. Figure 6 shows the projections of five important axial and a planar directions in LN indicating the regular and some interstitial lattice sites together with the respective calculated continuum potentials governing the channels.

The evaluation of the effect of a dopant on a non- $\mathrm{Nb}$ site - regular or interstitial—by simple reasoning can lead to serious errors. Therefore, the use of simulation software is mandatory for the lattice site determination of intrinsic and extrinsic defects in LN. Results presented and discussed in this review are based on two channeling simulation programs. FLUX [22,23] is a long-known code for RBS/C and NRA/C in cubic crystals that has been adapted to the trigonal LN lattice. CASSIS [24-27] is a multi-purpose code, i.e., it is applicable for all Bravais lattices and can also deal realistically with PIXE/C and high dopant concentrations. Figure 7 shows results of CASSIS for two-dimensional RBS/C calculations for the $y$-axis.

The SIMS method uses low energy heavy ions (mostly $\mathrm{Ar}^{+}$) to remove and ionize surface atoms by sputtering and analyzes these secondary ions using a mass spectrometer. This allows determining the composition of materials with very good depth resolution. The sensitivity of the method-ranging from ppm to ppb depending on the material—is its main advantage. However, this method is destructive, in contrast to those mentioned above.

ERD uses typically He-ions with $\mathrm{MeV}$ energies to remove hydrogen from a sample surface. An absorber foil in front of the detection stops the backscattered He-ions and allows pass only the protons for analysis. In contrast, HIERD uses heavy ions with specific energy of several $\mathrm{MeV} / \mathrm{amu}$ in order to sputter even heavy atoms from the surface. Various methods exist for the detection and analysis of the secondary ions emitted.

For better readability, technical details on the ion beam analysis such as ion species, charge state, current, detector geometry, installation used and provenience of samples are mostly omitted in this review. However, the information can always be recovered from the cited works. 

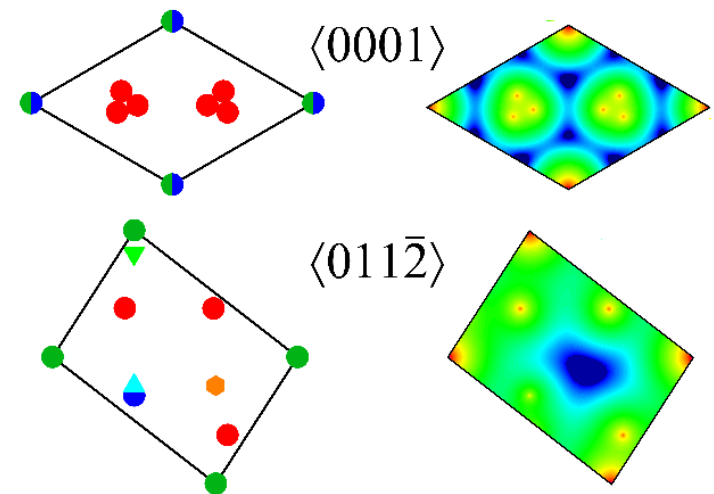

$\langle 011 \overline{2}\rangle$
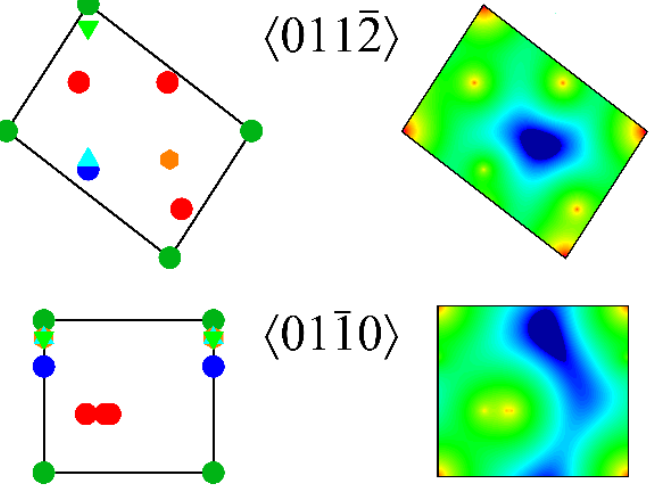

$\langle 01 \overline{1} 0\rangle$
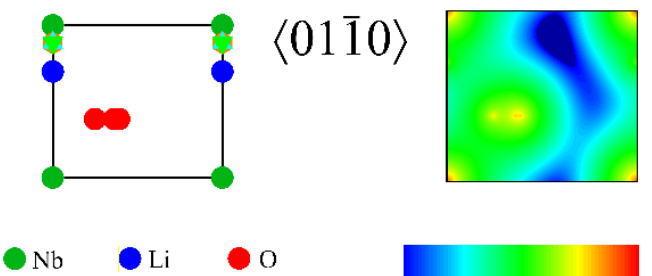

$\nabla \mathrm{Nb}$ oct $\triangle \mathrm{Li}$ oct free oct
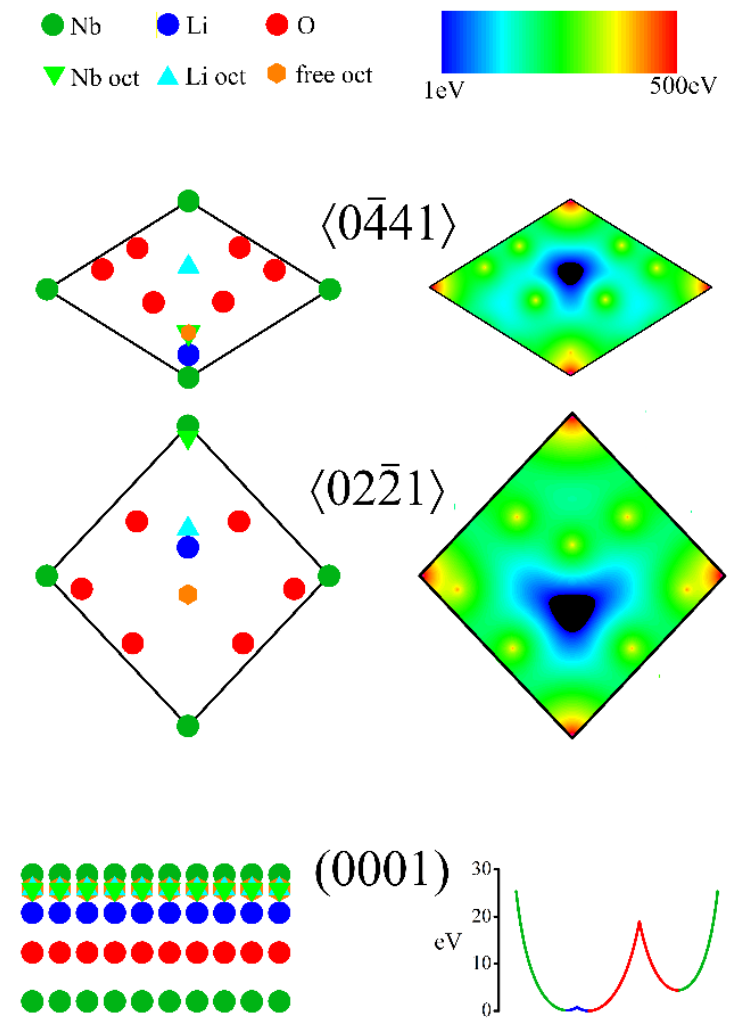

Figure 6. Channel projections with regular and some interstitial sites for important crystallographic directions and the corresponding calculated continuum potentials. The two-dimensional potentials for axial directions are plotted in logarithmic scale; the channeling occurs in the blue regions. The projection of the (0001)-plane and the corresponding one-dimensional continuum potential can be seen on the right side down. 

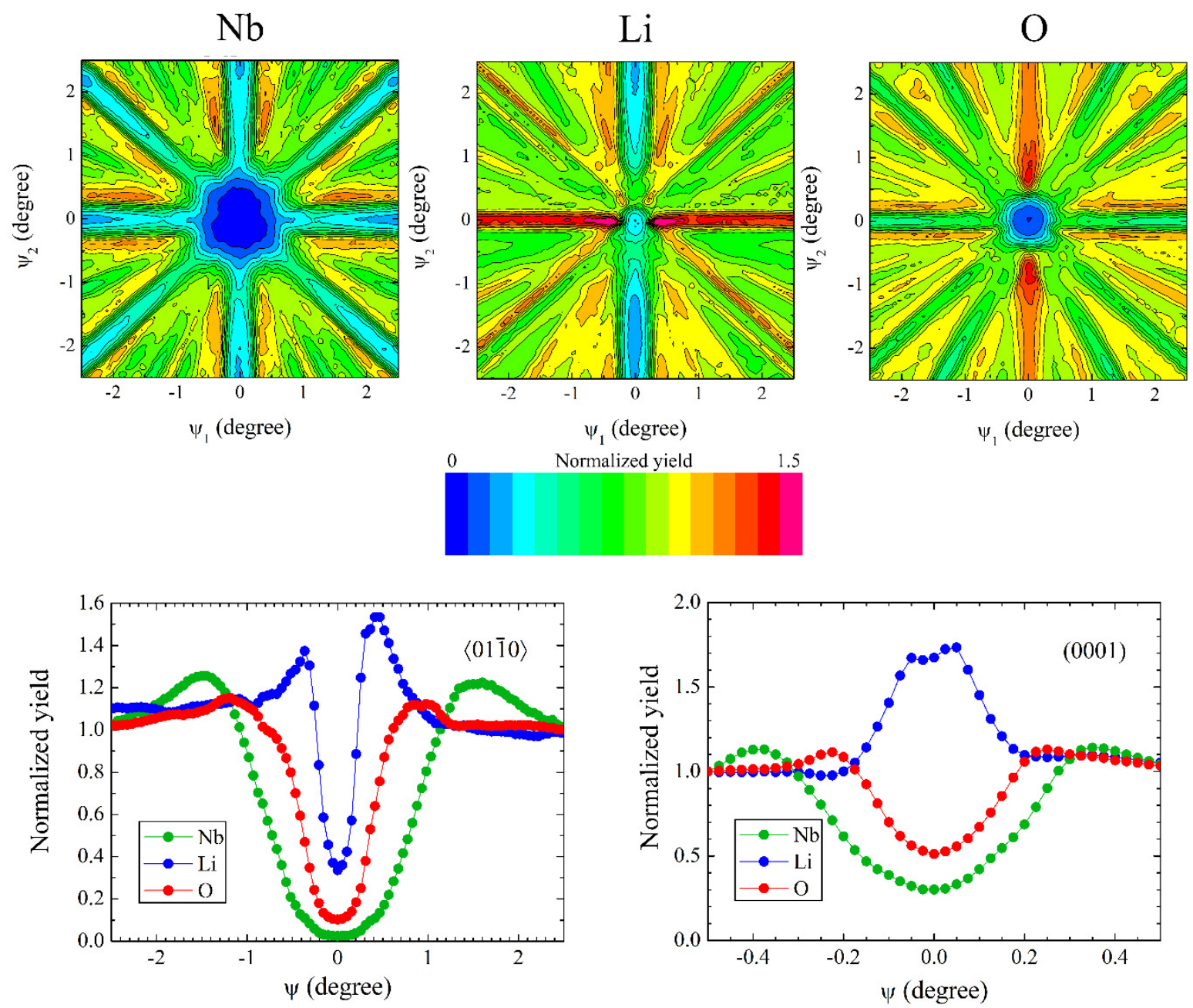

Figure 7. RBS/C calculations with CASSIS. Upper row: Two-dimensional scans for the $\langle 01 \overline{1} 0\rangle$-axis, $\psi_{1}$ corresponds to a rotation around the c-axis and $\psi_{2}$ around the a-axis of $\mathrm{LN}$. The calculated yields for $\mathrm{Li}, \mathrm{Nb}$ and $\mathrm{O}$ are shown. $\mathrm{Li}$ and $\mathrm{O}$ exhibit a yield enhancement for the (0001)- or the (1120)-plane respectively. Lower row: One-dimensional scans through $\langle 01 \overline{1} 0\rangle$ close to $(11 \overline{2} 0)$, in which Li shows the typical asymmetric yield curve, and through the (0001)-plane, in which Li acts similar to a host atom located in the center of the planar channel.

\subsection{Hyperfine Interaction Methods}

Hyperfine interaction methods such as Perturbed Angular Correlations (PAC), Mössbauer Effect (ME), Nuclear Magnetic Resonance (NMR) and Nuclear Quadrupole Resonance (NQR) are based on the interaction of a nucleus with an electric (or magnetic) field produced in a solid by the electrons and other nuclei near the nucleus. In several cases, techniques from the ion beam analysis and hyperfine interaction groups are used to study the same samples, obtaining complementary information and enlarging significantly the range of sensitivity for characterization of defects [28].

The PAC probe is an unstable nucleus decaying through a $\gamma-\gamma$ cascade that has an intermediate state with suitable half-life and nuclear quadrupole moment (or dipole moment, in case one is interested in magnetic interactions). Conversion electrons from one of the transitions of the $\gamma-\gamma$ cascade can also be used [29]. In the case of Hf-doped $\mathrm{LN}$, the PAC probe is usually produced by the neutron capture reaction ${ }^{180} \mathrm{Hf}(\mathrm{n}, \gamma){ }^{181} \mathrm{Hf}$ on natural $\mathrm{Hf}$ introduced in the samples during growth as $\mathrm{HfO}_{2}$. A typical activity of $\approx 15 \mu \mathrm{Ci}$ is obtained after reactor irradiation. Although thermal neutrons are the most important in the reactor irradiation, the LN crystal is also irradiated with fast neutrons, at a fluence 1-2 orders of magnitude smaller than the thermal flux [30] and these higher energy neutrons produce defects distinct from the ones produced by the thermal neutrons. 
Annealing in air at $700{ }^{\circ} \mathrm{C}$ is enough to restore the lattice completely [31]. The ${ }^{111}$ In probe was implanted to a typical fluence of $\approx 10^{13} \mathrm{~cm}^{-2}$ from which more than $90 \%$ were due to an unavoidable stable $\mathrm{Cd}$ contamination, resulting in a typical activity of $50 \mu \mathrm{Ci}$. The crystals were annealed at temperatures in the $700-900{ }^{\circ} \mathrm{C}$ range under flowing wet oxygen to remove the defects introduced by ion implantation. PAC measurements were made using standard spectrometers with four $\mathrm{BaF}_{2}$ detectors in a plane at $90^{\circ}$ intervals for $\gamma-\gamma$ PAC or two $\mathrm{BaF}_{2}$ detectors with two magnetic lenses in a plane at $90^{\circ}$ intervals for $\mathrm{e}^{-}-\gamma$ PAC [29].

Equation (1) is used to calculate the time differential anisotropy $R(t)$ from the coincidence spectra $N(\theta, t)$, where $\theta$ is the angle between detectors and $t$ is the time delay between events.

$$
R(t)=2 \frac{N\left(180^{\circ}, t\right)-N\left(90^{\circ}, t\right)}{N\left(180^{\circ}, t\right)+2 N\left(90^{\circ}, t\right)} \approx A_{22} G_{22}(t) .
$$

$G_{22}(t)$ is the perturbation function which describes the modulation of the angular correlation and $A_{22}$ is a parameter which depends on the nature of the radiations of the cascade [32]. For a cascade having an intermediate state with spin $I=5 / 2$, such as the ones from the decay of ${ }^{111} \mathrm{In}$ and ${ }^{181} \mathrm{Hf}$, three frequencies $\omega_{n}=C_{n}(\eta) v_{Q}$ are observed, corresponding to:

$$
G_{22}(t)=\sum_{n=0}^{3} S_{2 n} \cos \left(C_{n}(\eta) v_{Q} t\right) e^{-\delta C_{n}(\eta) v_{Q} t},
$$

The quadrupole interaction frequency (QIF), $v_{Q}=e Q V_{z z} / h$, and the asymmetry parameter $\eta=\left(V_{x x}-V_{y y}\right) / V_{z z}$, which can be deduced from the frequency factors $C_{n}(\eta)$, contain information about the magnitude of the principal component $V_{z z}$ and the asymmetry of the EFG, respectively. The exponential factor allows for a Lorentzian distribution of EFGs around a mean value. Such a distribution can be caused, e.g., by different lattice defects in the vicinity of the probe atoms. The $S_{2 n}$ coefficients, which give the amplitudes for each frequency, can be calculated for polycrystalline as well as single crystalline samples. If fractions $f_{i}$ of the total number of radioactive probes are in different but unique sites experiencing different EFGs the observed spectra is described by a sum over several perturbation functions, $f_{i} G_{22}^{i}(t)$, with the sum of the $\mathrm{f}_{\mathrm{i}}$ normalized to unity.

Figure 8 shows the PAC coincidence count rates $N(\theta, t)$ obtained with detectors at angles of $\theta=90^{\circ}$ and $\theta=180^{\circ}$ and the corresponding spectrum obtained in near-stoichiometric LN (doped with $4.6 \mathrm{wt} \% \mathrm{~K}_{2} \mathrm{O}$ ) implanted with ${ }^{111} \mathrm{In}$. The coincidence count rates $N(\theta, t)$ show the half-life of the intermediate state of the $\gamma-\gamma$ cascade from the decay of ${ }^{111} \mathrm{In}$ $\left(\mathrm{T}_{1 / 2}=80 \mathrm{~ns}\right)$ with the perturbation resulting from the interaction of the quadrupole moment of the intermediate state of the cascade and the EFG produced by the surrounding electric charges. The anisotropy ratio $R(t)$ (usually designated "PAC spectrum") calculated according to eq. 1 extracts the perturbation, exploiting the difference between minima and maxima in the experimental count rates at $90^{\circ}$ and $180^{\circ}$.

Details on the other hyperfine interaction techniques can be found, e.g., in references [8,32]. In general one can extract information on the principal component $V_{z z}$ and on the asymmetry of the EFG, although the observable frequencies are dependent on the particular nuclear method and on the nuclear properties of the probe nucleus. One must emphasize that the knowledge of the EFG is not yet enough for a direct assignment of the probe to a given lattice site. Although much progress has been made in the calculation of EFG [33] this is still time-consuming and far from generalized. Nevertheless, one can compare EFG values obtained with different probes in LN [34]. 


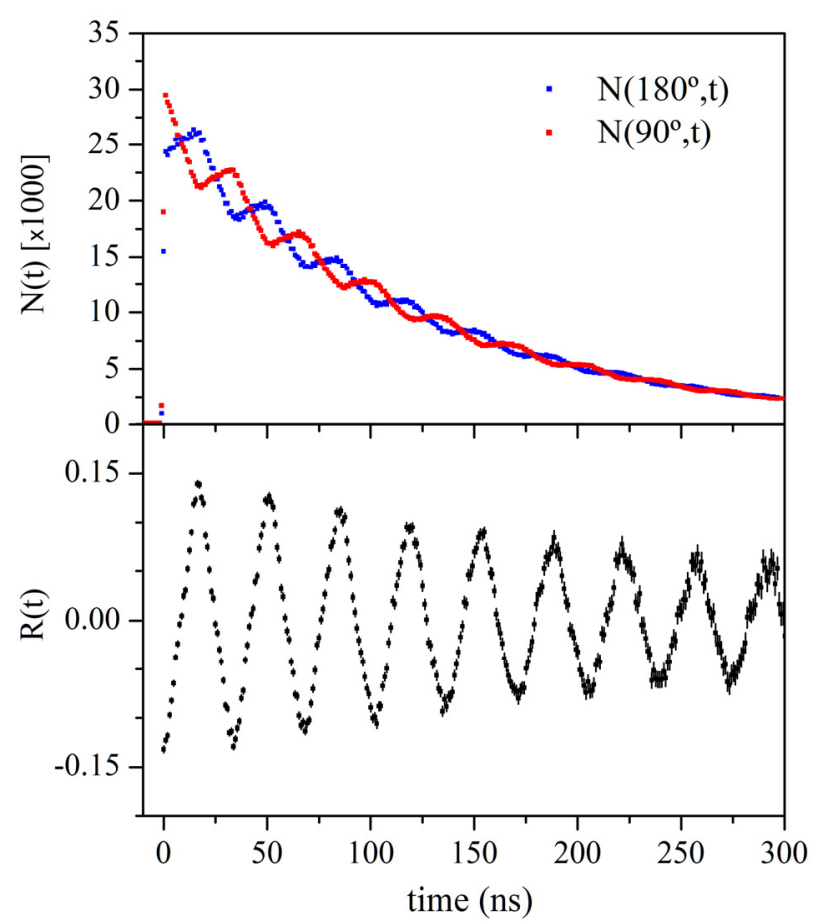

Figure 8. PAC coincidence count rates $N(\theta, t)$ obtained with detectors at angles of $\theta=90^{\circ}$ and $\theta=180^{\circ}$ (top) and corresponding spectrum obtained in near-stoichiometric $\mathrm{LN}\left(4.6 \mathrm{wt} \% \mathrm{~K}_{2} \mathrm{O}\right)$ implanted with ${ }^{111}$ In (bottom).

\section{Investigation of Intrinsic Defects}

\subsection{Congruent Versus Stoichiometric Lithium Niobate}

Already in the first growth studies it was noted that LN does not melt congruently with the first phase diagram published by Reisman and Holtzberg [35] in 1958. This nonstoichiometry implies and intrinsic defect structure and influences strongly many material properties which triggered intense research activities on the nature of the defects and the production of stoichiometric material.

Initial NMR measurements with ${ }^{7} \mathrm{Li}$ and ${ }^{93} \mathrm{Nb}$ in $\mathrm{LN}$ and lithium tantalate $\left(\mathrm{LiTaO}_{3}\right.$, henceforth abbreviated LT) were reported in the late 1960s [36-39]. Measurements were performed with the then available magnetic fields below $1 \mathrm{~T}$ [40]. These measurements were characterized by wide resonance lines, whose width could be empirically related to the material's departure from stoichiometry. Measurements with NQR [41,42] and ME [43] have also shown broader than expected interaction lines in LN. Later, Peterson et al. [44] found a second ${ }^{93} \mathrm{Nb}$ NMR signal in congruent LN crystals, with a near zero QIF and an intensity of approximately $6 \%$ of the total $\mathrm{Nb}$ signal that was assigned to $\mathrm{Nb}$ in $\mathrm{Li}$ sites $(5.9 \%)$ thus providing a strong support to the $\mathrm{Nb}$ vacancy model, even if the authors assumed later that the interpretation of their NMR spectra was not so straightforward [45]. More recent measurements by Blümel et al. [40] using a higher magnetic field of $\approx 7 \mathrm{~T}$ did not confirm a second ${ }^{93} \mathrm{Nb}$ signal with such high intensity, thus favoring instead the $\mathrm{Li}$ vacancy model. A series of experimental studies complemented with simulations assuming $\mathrm{O}-$, Li- or $\mathrm{Nb}$-vacancies (but unfortunately omitting models based on ilmenite stacking faults) was published by Yatsenko et al. [46-48], favoring the formation of Li-vacancies in the vicinity of $\mathrm{Nb}$ located on regular Li sites.

Rebouta et al. [49] reported RBS/C and ${ }^{181} \mathrm{Hf}$ PAC measurements in LN doped with $1 \mathrm{~mol} \% \mathrm{HfO}_{2}$ in the melt. The RBS/C measurements unambiguously determined that $\mathrm{Hf}$ replaced $\mathrm{Li}$, but the obtained PAC spectra could only be fitted considering two QIF around $1200 \mathrm{MHz}$. Two frequencies of the same magnitude were also observed in ${ }^{181} \mathrm{Hf}$ PAC measurements done in polycrystalline LN samples [50]. These QIF were later detailed as $v_{Q 1}=1154(12) \mathrm{MHz}$ and $v_{\mathrm{Q} 2}=1213(12) \mathrm{MHz}$, with asymmetry parameters in the 
0.2-0.3 range, from new measurements in single-crystals [34]. NMR studies [51,52] confirm an asymmetry parameter of 0.2 for congruent material. The observed frequency doublet was unexpected, as Hf was found only replacing Li and a single QIF should suffice. Significant progress was made when higher precision PAC measurements were performed using the ${ }^{111}$ In probe, also replacing Li in congruent LN crystals [53]. Again, the new spectra could not be described by a single frequency even if considering an asymmetric EFG or a broad frequency distribution, both already indicative of crystal imperfections [54]. The frequency doublet now found was $v_{Q 1}=192(2) \mathrm{MHz}$ and $v_{Q 2}=205(2) \mathrm{MHz}$, with asymmetry parameters in the 0.1-0.2 range. Since the frequencies were again very close, the simplest explanation is that the probes were in slightly different Li sites, one of them possibly linked to a defect located in the Li-Octahedron. Since the fraction of PAC probe atoms located at this additional site is significant (about one third) it should be energetically favorable for the inclusion of atoms causing a charge excess relative to Li. It is therefore unlikely that this defect is identical to a Li-position distorted by a nearby excess $\mathrm{Nb}$ atom, since the occupation of such a site by a dopant with a higher charge state than Li would increase further the local charge imbalance. A far more reasonable assumption is to identify this defect with a site, shifted form the regular lithium site that actually incorporates the excess $\mathrm{Nb}$ (or dopants) in congruent material. The broadening of quadrupole interaction lines seen by other techniques is also compatible with the existence of two nearby frequencies that cannot be resolved.

Growth procedures developed in the 1990s [55-58] made available high-quality crystals with stoichiometric composition, allowing a direct comparison of the two compositions.

The possible impacts of the Li- and the $\mathrm{Nb}$-vacancy models on axial and planar channeling can be easily estimated qualitatively from the channel projections presented above. Eventually existing vacancies on regular $\mathrm{Nb}$-sites should have only small effects on the $\mathrm{Nb}$-channeling since even in the case of $5.9 \mathrm{~mol} \%$ vacancies the steering effect is hardly diminished. On the other hand, anti-site $\mathrm{Nb}$-atoms located on regular Li-sites should lower the minimum yields for Li-NRA measurements for congruent material in axial directions clearly since the channeling effect on the Li-rows is enhanced by the $\mathrm{Nb}$. For a $1.2 \%$ fraction the average atomic number of the row increases from 3 (stoichiometric) to 3.5 ( $\mathrm{Nb}$-vacancy model). For planar channeling in the (0001)-direction Li-NRA-scans should show clear peaks in the aligned direction; but for the congruent case, it should be lower and narrower than for the stoichiometric.

Measurements with congruent and near-stoichiometric LN, grown with $4.6 \mathrm{wt} \%$ $\mathrm{K}_{2} \mathrm{O}$ in the melt $([\mathrm{Li}] /[\mathrm{Nb}]=0.979$ [59]), reported by Kling et al. [60,61] showed contrary effects. NRA/C using the ${ }^{7} \mathrm{Li}(\mathrm{p}, \alpha)^{4} \mathrm{He}$ nuclear reaction and $\mathrm{RBS} / \mathrm{C}$ scans were performed simultaneously in order to study differences in $\mathrm{Li}$ - and $\mathrm{Nb}$-sublattice between the two crystals. Several crystallographic axes and planes were investigated, as shown in Figure 9. The Li-NRA data corresponding to the (0001) plane, perpendicular to the c-axis, were particularly interesting. They showed a prominent flux peak that is considerably broadened in the congruent crystal in comparison to the near-stoichiometric one. The NRA-Li broadening suggests either a disordered Li sublattice or several well-defined defect sites for the $\mathrm{Li}$ ions. For the $\langle 02 \overline{2} 1\rangle$-axis, in which $\mathrm{Li}$ is located in the center of the channel, the minimum yield for $\mathrm{Li}-\mathrm{NRA} / \mathrm{C}$ drops drastically ruling out the possibility of simple $\mathrm{Nb}_{\mathrm{Li}}$ antisites, i.e., the Li- and the $\mathrm{Nb}$-vacancy model [60] Besides the stronger reduction of the ${ }^{7} \mathrm{Li}(\mathrm{p}, \alpha)^{4} \mathrm{He}$ reaction yield at the surface the spectra for the stoichiometric extend also to higher depth indicating a reduced stopping power due to a diminished number of lattice defects in the channel compared to congruent material [61].

Further, a strong broadening of $\mathrm{Nb}$-RBS/C in the $\langle 01 \overline{1} 0\rangle$-axis of the near-stoichiometric sample has been observed indicating an improvement of the $\mathrm{Nb}$-sublattice structural ordering with regard to the congruent case [60]. These observations indicate that the excess $\mathrm{Nb}$ cannot be located in regular Li lattice sites, favoring the ilmenite stacking fault model but not ruling out the formation of small non-crystalline or Li-deficient (e.g., ilmenite-type 
$\mathrm{LN}$ or monoclinic lithium $\mathrm{LiNb}_{3} \mathrm{O}_{8}$ ) regions in the material and on the other extreme, point defects with inversed cation occupation.

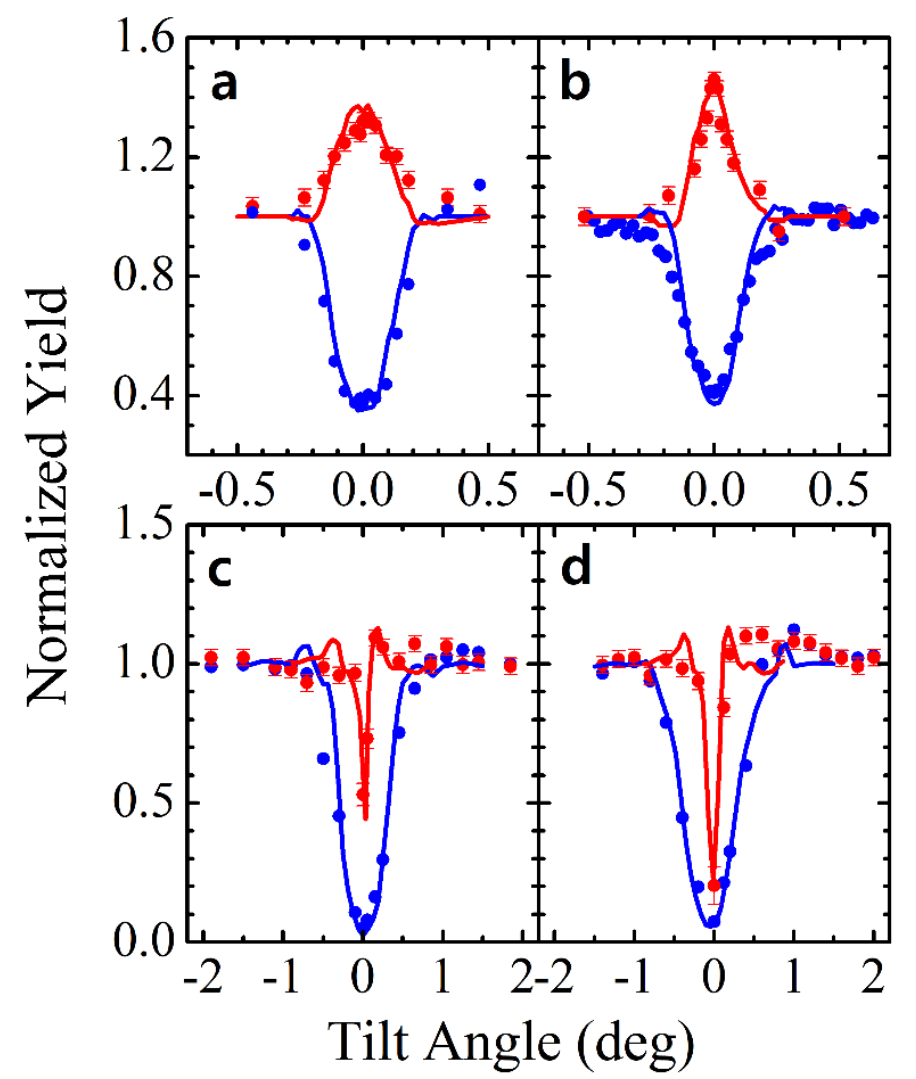

Figure 9. RBS/C dips obtained for the (0001) plane in (a) congruent and (b) near-stoichiometric $\mathrm{LiNbO}_{3}$, as well as for the $\langle 02 \overline{2} 1\rangle$ axis in (c) congruent and (d) near-stoichiometric $\mathrm{LiNbO}_{3}$. The $\mathrm{Li}$ data are plotted as red circles and were obtained using NRA via the ${ }^{7} \mathrm{Li}(\mathrm{p}, \alpha)^{4} \mathrm{He}$ reaction and the $\mathrm{Nb}$ data are plotted as blue circles and were obtained using Rutherford Backscattering. The uncertainty bars for Nb-RBS are smaller than symbols. Adapted from Kling et al. [59,61].

This point can be clarified by studying the $\mathrm{Nb}$ sublattice measuring the energy dependence of axial dechanneling induced by defects along several crystallographic directions. The difference in the minimum yields between near-stoichiometric and congruent, $\Delta X_{\min }$, at a fixed depth interval yields information about the type and size of defects in a nonperfect crystal [62]. The observed values for $k$ range between 0.69 to 0.78 falls between the values for true point defects $(\kappa=1)$ and extended defect clusters $(\kappa=0.5)$ which indicates defects should have a size in the order of nanometers (as expected for local stacking fault sequences). However, a small admixture of true point defects cannot be excluded. In addition, the possibility that microcrystals of ilmenite-type or $\mathrm{LiNb}_{3} \mathrm{O}_{8}(\mathrm{~K}=0)$ or dislocations $(\kappa=-0.5)$ exist can be rejected.

A comparison was also made with PAC. Figure 10 shows PAC spectra obtained with the ${ }^{111} \mathrm{In}$ probe in the same near-stoichiometric crystal grown with $4.6 \mathrm{wt} \% \mathrm{~K}_{2} \mathrm{O}$ after implantation and annealing [63], compared with a spectrum previously obtained in a congruent crystal [53]. It is clear that the spectrum with the highest attenuation is the one obtained in the congruent crystal. The spectrum obtained in the near-stoichiometric crystal is described by a single QIF, $v_{Q}=191(2) \mathrm{MHz}$, i.e., only one of the two QIF previously found, and with a zero asymmetry parameter. It can also be seen that the pattern from the congruent crystal is not in phase with the one from the near-stoichiometric crystal, with the maxima in the congruent crystal occurring progressively a few nanoseconds after the corresponding ones for the stoichiometric crystal, due to the modulation imposed by the frequency doublet, which is also responsible for a higher attenuation. As the QIF have 
almost identical values, the PAC measurements suggest the existence of two non-equivalent Li sites in congruent crystals and only one Li site in stoichiometric material. No conclusions can be drawn on the $\mathrm{Nb}$ sublattice from these measurements, as ${ }^{111}$ In replaces Li only [53].

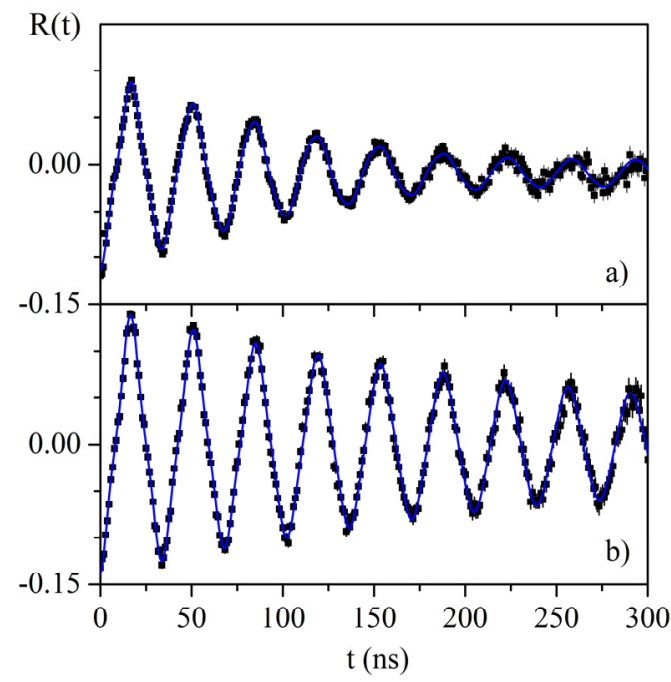

Figure 10. Perturbed Angular Correlation spectra obtained (a) in a congruent LN crystal, and (b) a near-stoichiometric LN crystal grown with $4.6 \mathrm{wt} \% \mathrm{~K}_{2} \mathrm{O}$ in the melt. Drawn using data from references $[53,63]$.

The joint analysis of the NRA and PAC data thus suggest the existence of two distinct Li sites in a congruent crystal, while only one of them remains in a stoichiometric crystal. Natural candidates for such defects are stacking faults. Several models have been proposed for $\mathrm{LN}$ in the literature. Both the $\mathrm{Li}$ and the $\mathrm{Nb}$ vacancy models include $\mathrm{Nb}$ on $\mathrm{Li}$ sites and thus a sequence of three $\mathrm{Nb}$ consecutive atoms along the c-axis would be created. Nassau et al. [64] proposed different stacking sequences in order to avoid such improbable arrangements and Smyth $[65,66]$ proposed short stacking sequences with the ilmenite structure, which were later found energetically plausible [67]. The stacking sequence along the c-axis of ilmenite-like $\mathrm{LN}$ would be $\mathrm{Nb}, \mathrm{Li}, \mathrm{V}, \mathrm{Li}, \mathrm{Nb}, \ldots$, where $\mathrm{V}$ denotes the intrinsic vacancy. Since these inverse stacking sequences accommodate no $\mathrm{Nb}$ excess themselves they have to accompanied by Li vacancies. The "inverted" Li site in the ilmenite sequence is generally assumed to be one of this vacancies leading to the "complex defect" model. This defect structure can be regarded as a Li-vacancy model in which the $\mathrm{Nb}$ is shifted from the regular Li-site and the inconvenient stacking of three consecutive $\mathrm{Nb}$ atoms along the c-axis is avoided. Further, it furnishes a straightforward explanation for the occurrence of the second electric field gradient in the Li-Octahedron observed in hyperfine interaction measurements. Figure 11 compares the regular LN stacking with other sequences, including short ilmenite stacking sequences and the "complex defect".

The channel projections of the lattice sites corresponding to the "inverted" $\mathrm{Li}$ and $\mathrm{Nb}$ sites in ilmenite stacking faults are plotted in Figure 12. The $\mathrm{Nb}$ on inverted locations shows up close but shifted from the regular Li sites and therefore should induce dechanneling near the Li-rows instead of an enhancement of the channeling effect for regular Li-site occupation. This effect is expected to be most visible in the case of the $\langle 02 \overline{2} 1\rangle$-axis and the (0001)-plane where these sites are located close to center of the channel. 

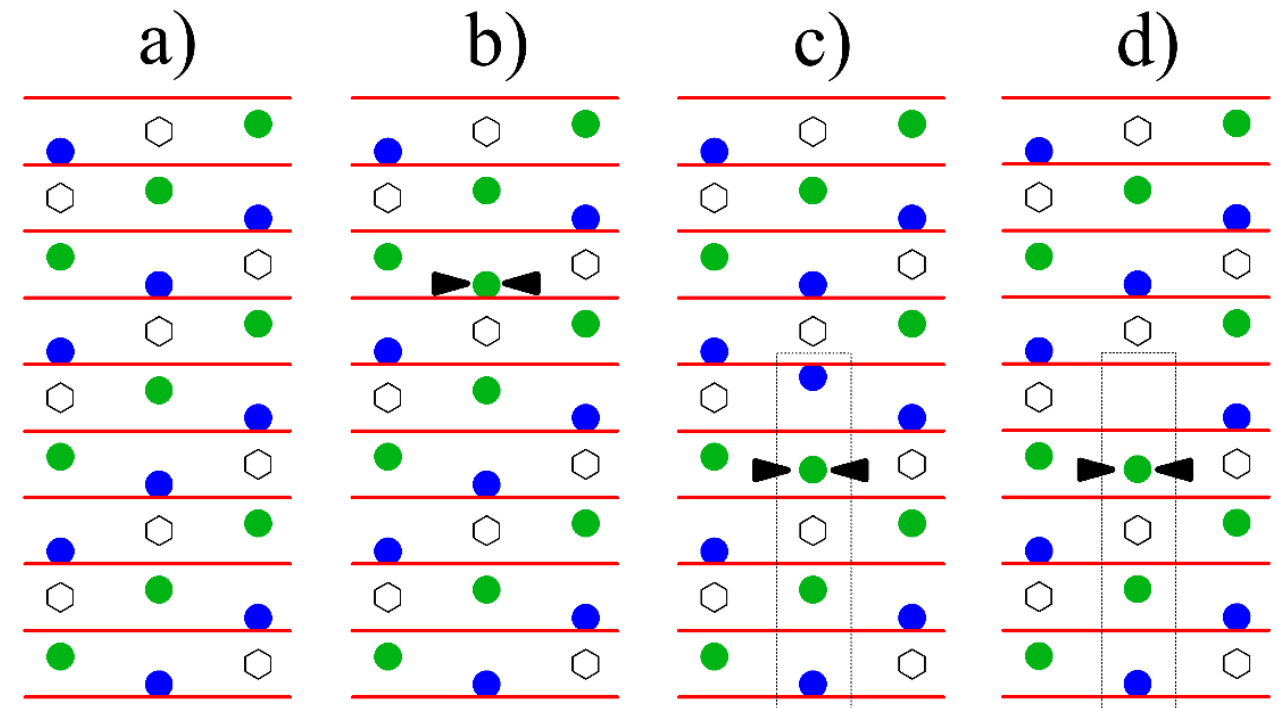

Figure 11. Stacking models for $\mathrm{LiNbO}_{3}$ : (a) regular stacking, (b) $\mathrm{Nb}$-antisites (extra $\mathrm{Nb}$ indicated by arrows), (c) ilmenite stacking faults (boxed area) and (d) like (c) but with Li vacancy ("complex defect"). Nb is represented by green, Li by blue and free octahedral positions by white symbols and the oxygen layers are depicted as red lines.

$\langle 01 \overline{1} 0\rangle$
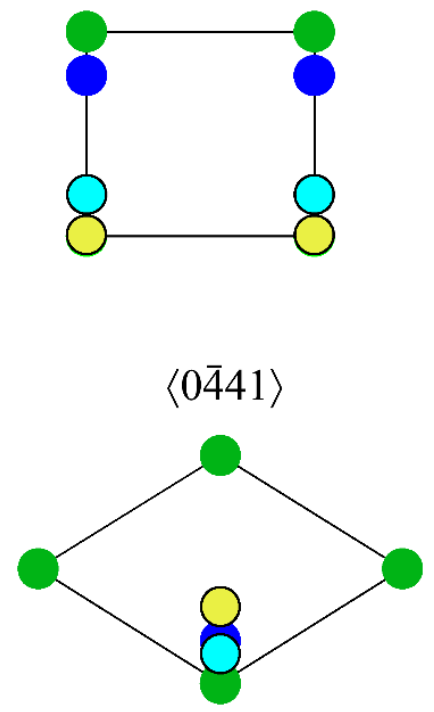

(0001)

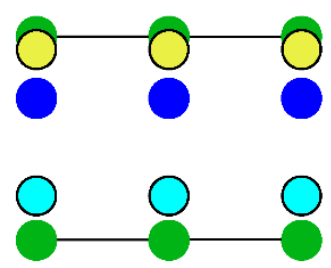

$\langle 02 \overline{2} 1\rangle$

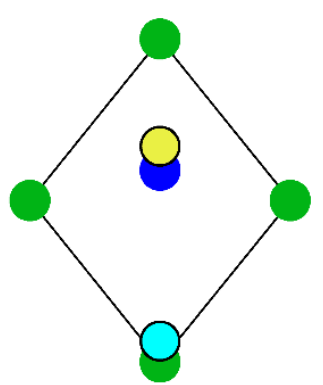

$\mathrm{Nb}$ - regular

$\mathrm{Nb}$ - ilmenite

Li - regular

Li - ilmenite

Figure 12. Channel projections with regular and ilmenite type lattice site for $\mathrm{Li}$ and $\mathrm{Nb}$ for important crystallographic direction.

These results can be related to the lattice structure looking at the interaction potential in the (0001) plane seen by the incoming ions, shown in Figure 13, which was calculated using Molière's approximation to the Thomas-Fermi potential under the assumption of a static lattice [68]. Two pronounced minima are visible, showing the existence of two channels for the incoming ions, separated by a potential barrier associated to $\mathrm{O}$ ions. One of those minima, designated as Li-I, corresponds to the regular Li position, whereas the other one, named as $\mathrm{Li}-\mathrm{II}$, lies close to a regular $\mathrm{Nb}$ location. It could be considered as a $\mathrm{Li}$ that substitutes for an $\mathrm{Nb}$ and then shifts towards the nearest oxygen plane up to a position symmetrical to that of Li. The existence of those defective Li sites is a key result that provides a confirmation of theoretical analyses [67] proposing the occurrence of inverted $\mathrm{Li}-\mathrm{Nb}$ sequences as they appear in the related ilmenite structure. 


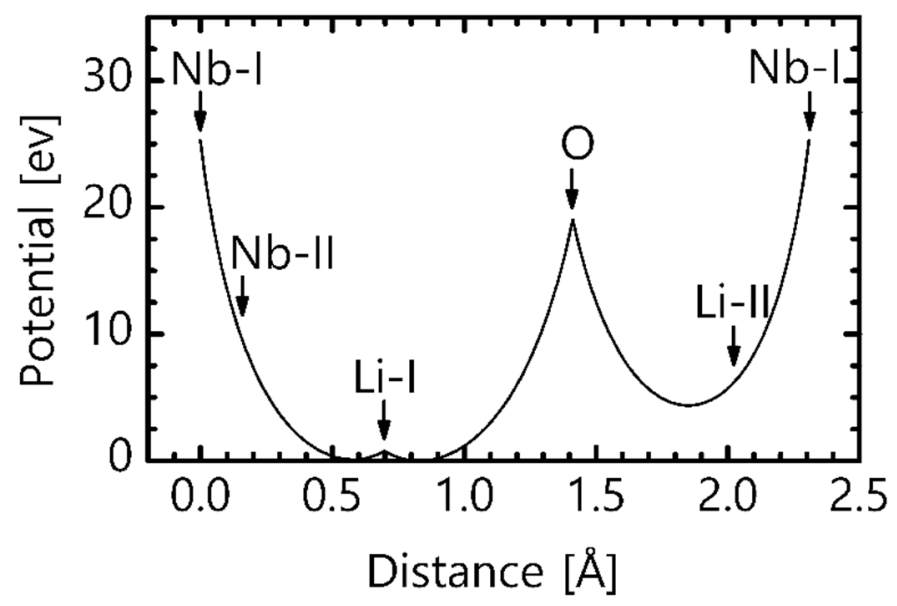

Figure 13. Interaction potential in the (0001) plane of $\mathrm{LiNbO}_{3}$ seen by the incoming protons, calculated using a Molière's approximation to the Thomas-Fermi potential. The positions of $\mathrm{Li}$ and $\mathrm{Nb}$ in the regular lattice as Li-I and $\mathrm{Nb}-\mathrm{I}$ as well as in the ilmenite stacking fault as $\mathrm{Li}$-II and $\mathrm{Nb}-\mathrm{II}$ are marked.

Taking as a basis this local ilmenite structure, the broadened flux peak in the NRA/ channeling spectra has been simulated using the CASSIS code. The peak shape and particularly the broadening of the Li-NRA signal is reasonably well explained. The best fit is obtained assuming $2 \%$ of dispersed ilmenite stacking faults, $\mathrm{Li}-\mathrm{Nb}-\mathrm{Nb}-\mathrm{Li}$. On the contrary, other models exclusively involving $\mathrm{Nb}$ antisites and cation vacancies cannot account for this key experimental feature, as shown in Figure 14.

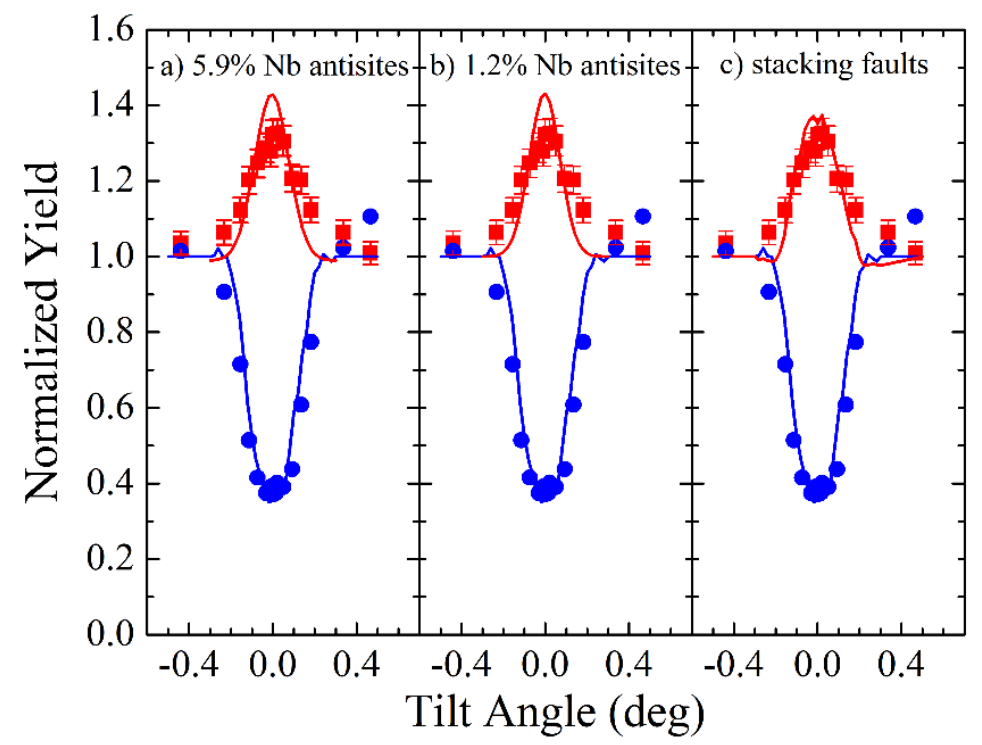

Figure 14. Comparison of experimental results and Monte Carlo simulations for the (0001) Li-NRA angular scan assuming different defect models for congruent lithium niobate: (a) 5.9\% niobium antisites, (b) 1.2\% niobium antisites, and (c) $2 \%$ ilmenite type stacking faults. The Li data are plotted as red circles and were obtained using NRA via the ${ }^{7} \mathrm{Li}(\mathrm{p}, \alpha)^{4} \mathrm{He}$ reaction and the $\mathrm{Nb}$ data are plotted as blue circles and were obtained using Rutherford Backscattering. The uncertainty bars for Nb-RBS are smaller than symbols. Redrawn from Kling et al. [61].

The energy dependence of the axial dechanneling reported in [60] has also been simulated using CASSIS. Figure 15 shows a comparison of the experimentally observed energy dependence of the minimum yield $\mathrm{X}_{\min }$ in several axes for protons together with CASSIS simulations for (a) a defect free stoichiometric crystal; (b) congruent crystal containing 5.9 and $1.2 \% \mathrm{Nb}$ antisites and (c) congruent cristal containing 2.0\% ilmenite stacking inversions with and without $1.2 \% \mathrm{Nb}$ antisites, from Kling at al. [26]. The best fit to the $\mathrm{Nb}$ data is 
obtained when the ilmenite stacking inversions with $1.2 \% \mathrm{Nb}$ antisites, i.e., within the $\mathrm{Li}$ vacancy model.

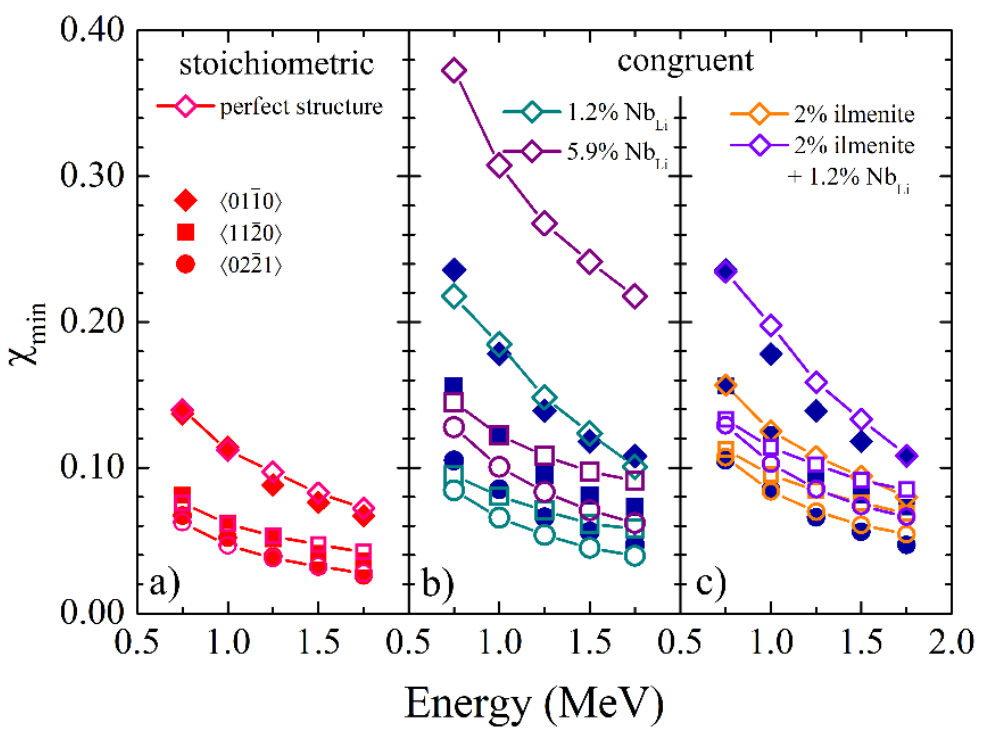

Figure 15. Comparison of the experimentally observed energy dependence of $\boldsymbol{X}_{\min }$ for protons (full symbols) with CASSIS simulations (open symbols) for (a) a defect free stoichiometric crystal; (b) congruent crystal containing 5.9 and $1.2 \% \mathrm{Nb}$ antisites and (c) congruent cristal containing $2.0 \%$ ilmenite stacking inversions with and without $1.2 \% \mathrm{Nb}$ antisites. Redrawn from Kling et al. [26].

The crystal structures of $\mathrm{LiNbO}_{3}$, perovskite and ilmenite are interrelated and some transitions between them are possible $[69,70]$. The ilmenite form of LN has been synthetized by ion-exchange from the ilmenite form of sodium niobate, $\mathrm{NaNbO}_{3}$ [71-73]. This $\mathrm{LN}$ form transforms back to the regular structure above $900 \mathrm{~K}$. The estimated enthalpy difference between the two LN forms [73] is in good agreement with the calculated difference of $0.1 \mathrm{eV}$ in their lattice energies [67].

The channeling studies on near-stoichiometric LN clearly indicate the absence of any intrinsic disorder-including the occurrence of ilmenite stacking faults-suggesting that in this case the small energy difference is sufficient to suppress their existence. However, LN has a strong tendency to grow non-stoichiometric with the congruent melt showing an excess of $\mathrm{Nb}$. The resulting need for an intrinsic defect structure may locally outbalance the extra energy needed for the formation of ilmenite-type stacking to accommodate the excess $\mathrm{Nb}$ and the Li vacancies leaving the "stoichiometric" remainder of the crystal virtually defect-free. This arrangement may result in a global energy minimum for the congruent material.

The current knowledge on the properties of ilmenite-like LN is still limited. Wiegel et al. [74] have reported the UV optical absorption edge in ilmenite-like LN moved towards longer wavelengths when compared to a congruent crystal. For comparison purposes, the UV absorption edge of LN moves towards shorter wavelengths when approaching stoichiometric composition [75]. Baran et al. [76] have reported a very strong Raman scattering peak at about $735 \mathrm{~cm}^{-1}$ for ilmenite-like LN. Kong et al. [77] have reported a weak peak at $738 \mathrm{~cm}^{-1}$ in congruent LN that is absent in near-stoichiometric crystals, in congruent crystals doped with $\mathrm{MgO}$ above $2 \mathrm{~mol} \%$, and in congruent crystals doped with $2.5 \mathrm{~mol}_{\mathrm{O}} \mathrm{TiO}_{2}$ and suggested that it comes from an ilmenite-like stacking defect in nonstoichiometric LN. Lengyel et al. [78] confirmed the initial decrease of the intensity of a band at around $740 \mathrm{~cm}^{-1}$ with $\mathrm{MgO}$ doping, but have seen this band reappear for heavily doped crystals. 


\subsection{Ferroelectric to Paraelectric Phase Transition}

The high-temperature phase of $\mathrm{LN}$, above $\mathrm{T}_{\mathrm{C}} \approx 1470 \mathrm{~K}$ for material with the congruent composition [79], is paraelectric and belongs to space group R $\overline{3} \mathrm{c}$. For LT, the transition temperature is significantly lower, $\mathrm{T}_{\mathrm{C}} \approx 878 \mathrm{~K}$ [80]. In this phase, $\mathrm{Nb}$ (or Ta) a moves along the c-axis to the center of the octahedral oxygen cages, while for Li two models were proposed in the literature [81]. In the displacive model, Li moves into a triangularly coordinated site within the oxygen layer below the former Li site [82], while in the order-disorder model, the Li atoms are randomly distributed on both sides of the oxygen plane [83,84], as depicted in Figure 16.

a)

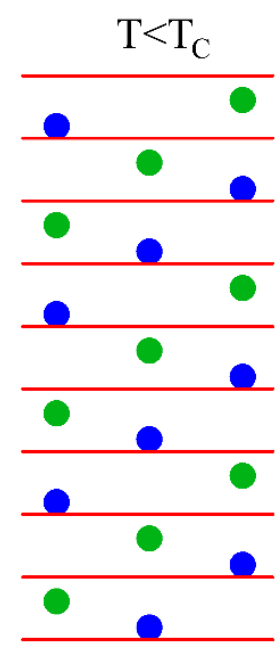

b)

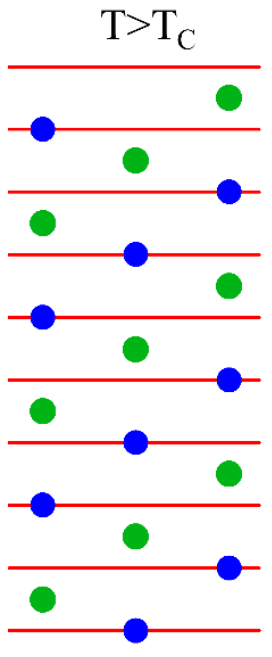

c)

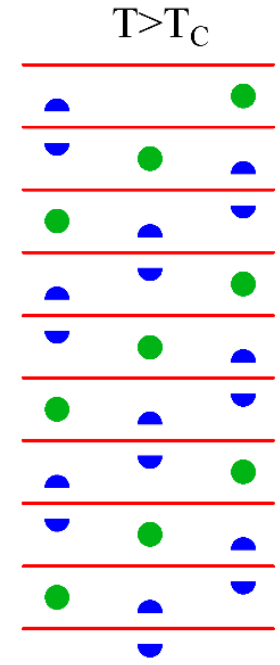

Figure 16. Projection of the $\mathrm{LiNbO}_{3}$ structure, showing two models for the phase transition: (a) $\mathrm{Li}$ and $\mathrm{Nb}$ locations in the ferroelectric phase below $\mathrm{T}_{\mathrm{C}} ;(\mathbf{b}) \mathrm{Li}$ and $\mathrm{Nb}$ locations in the paraelectric phase above $\mathrm{T}_{\mathrm{C}}$ for a displacive model; and (c) $\mathrm{Li}$ and $\mathrm{Nb}$ locations in the paraelectric phase for a disordering model, where half-circles indicate a split occupancy with a probability of $50 \%$. $\mathrm{Nb}$ is represented in green, $\mathrm{Li}$ in blue and the oxygen layers by red lines.

There is no agreement among the theoretical calculations on the phase transition. The calculations of Inbar et al. [85] suggest order-disorder features for the oxygen atoms, while the Li atoms are passive players. More recent molecular dynamics calculations of Phillpot at al. [86] and Sanna et al. [87] suggest that the phase transition presents displacive features for $\mathrm{Nb} / \mathrm{Ta}$ and order-disorder features for Li. In contrast, the theoretical calculations of Toyoura et al. [88] suggest order-disorder features for both $\mathrm{Li}$ and $\mathrm{Nb} / \mathrm{Ta}$.

There are few measurements of the temperature dependence of the nuclear quadrupole interaction at the $\mathrm{Nb} / \mathrm{Ta}$ site in LN and LT. Schempp et al. [41] reported ${ }^{181} \mathrm{Ta} \mathrm{NQR}$ measurements in polycrystalline near-stoichiometric LN in a reduced temperature range from 21 to $515 \mathrm{~K}$, where a continuous decrease of the EFG was observed. Moreover, the linewidths of the signal from near-stoichiometric samples were markedly narrower than the ones from Li-deficient material and became narrower with the increase in temperature. Figure 17 plots ${ }^{181} \mathrm{Ta}$ NQR and ${ }^{181} \mathrm{Ta}$ ME results in polycrystalline LT reported by Zhukov et al. [89] and by Löhnert et al. [90], respectively. The variation of the EFG derived from the NQR and ME measurements shows a continuous decrease with temperature in an extended temperature range which includes $T_{C}$. This variation can be essentially reproduced using the point-charge model of De Wette et al. [91], taking into account thermal lattice expansion and atom displacement [90], using data from Abrahams et al. [83]. As thermal lattice expansion alone would make the EFG increase moderately with temperature, the main contribution to the EFG comes from the displacement of the atoms. More advanced ab 
initio cluster calculations of Shelyapina et al. [92] reproduced the essential features of the EFG temperature dependence up to $\mathrm{T}_{\mathrm{C}}$.

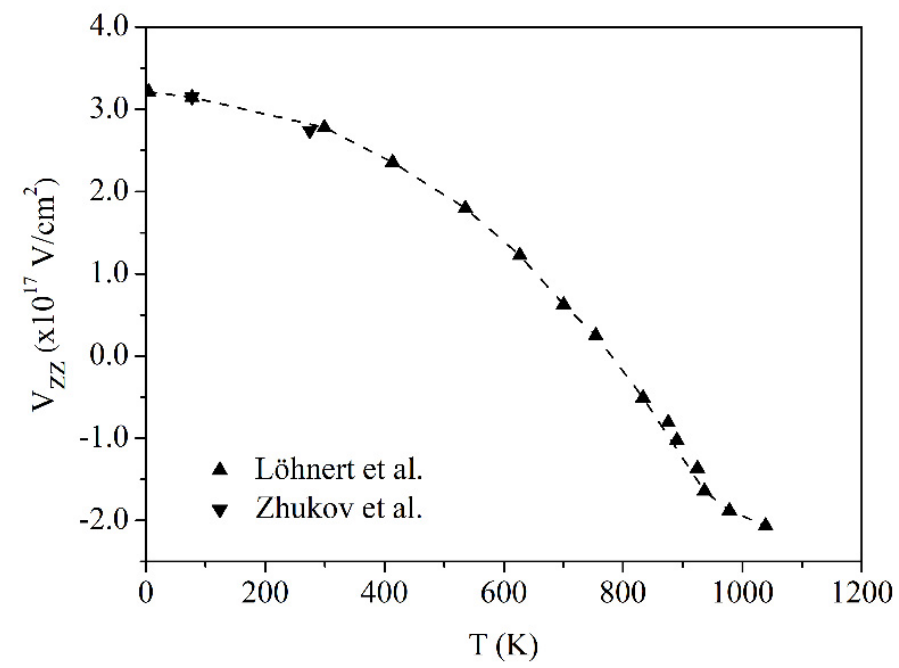

Figure 17. Temperature dependence of the nuclear quadrupole interaction at the Ta site in lithium tantalate measured with ${ }^{181} \mathrm{Ta}$ NQR and ME. Drawn using data from references [89,90]. The dashed line was drawn to guide the eye.

The temperature dependence of the nuclear quadrupole interaction at the Li site was measured using NMR, MS and PAC methods in LN and LT. ${ }^{7} \mathrm{Li}$ NMR measurements in single-crystalline $\mathrm{LN}$ were reported by Halstead [39] below $\mathrm{T}_{\mathrm{C}}$, up to $\approx 950 \mathrm{~K}$. A linear increase of the QIF was observed in this temperature range. The NMR signal had broad lines at low temperature, which became narrower with the increase in temperature, especially after $\approx 800 \mathrm{~K} .{ }^{7} \mathrm{Li}$ NMR measurements in polycrystalline LT were reported by Slotfeldt-Ellingsen et al. $[93,94]$, below and above $T_{C}$. A linear increase of the QIF was observed until close to $T_{C}$ and then a decrease. PAC measurements in polycrystalline LN and LT doped with ${ }^{181} \mathrm{Hf}$ were reported by Catchen et al. [50,95]. They observed extensive line broadening at temperatures well below $\mathrm{T}_{\mathrm{C}}$ and significantly less line broadening above $\mathrm{T}_{C}$. The anisotropy coefficient was non-zero below $\mathrm{T}_{C}$ and dropped to zero above $\mathrm{T}_{C}$. This result was not expected, because the axial symmetry at the Li site implies that $\eta$ should vanish at temperatures both below and above $\mathrm{T}_{\mathrm{C}}$. A second QIF was reported in the measurements above $T_{C}$, with a value about an order of magnitude lower than the one of $\mathrm{Hf}$ probes in Li sites, which was tentatively attributed to Hf probes in $\mathrm{Nb} / \mathrm{Ta}$ sites [95]. Moreover, in the case of a previous MS study in Fe doped LN, a second QIF was found at high temperature, but no more details were given [96]. Marques et al. [97] reported high precision PAC measurements in single-crystalline LT implanted with ${ }^{111} \mathrm{In}$. While at RT two nearby QIF were found, $v_{Q 1}=230(2) \mathrm{MHz}$ and $v_{Q 2}=242(2) \mathrm{MHz}$, with nonzero asymmetry parameters, above $\mathrm{T}_{\mathrm{C}}$ only one QIF and $\eta=0$ was found. The observation of two nearby QIF is consistent with the previous measurements of Hauer et al. [53] in congruent LN and with the extensive line broadening reported in other studies well below $\mathrm{T}_{\mathrm{C}}$. Ohkubo et al. [98] reported PAC measurements in polycrystalline LT with the ${ }^{111 \mathrm{~m}} \mathrm{Cd}$ and ${ }^{117} \mathrm{Cd}$ probes. Figure 18 shows the temperature dependence of the QIF for the measurements in LT.

The temperature dependence of the QIF doublet reported by Marques et al. [97] is shown in Figure 19. The temperature dependence of $v_{\mathrm{Q} 1}$ is close to the observed with ${ }^{7} \mathrm{Li}$ in LT [93], as expected since the ${ }^{111} \mathrm{In}$ probe atoms replace Li. The same is applicable for the ${ }^{181} \mathrm{Hf},{ }^{117} \mathrm{Cd}$ and ${ }^{111 \mathrm{~m}} \mathrm{Cd}$ probes which also replace Li. In contrast, $v_{\mathrm{Q} 2}$ that is associated to probes in Li-II sites, shows only a very weak temperature dependence. Close to and above $\mathrm{T}_{\mathrm{C}}$, the derived $v_{\mathrm{Q} 1}$ and $v_{\mathrm{Q} 2}$ values are no longer distinguishable. This 
suggests that the differences between the Li-I and Li-II sites vanish in the high-temperature paraelectric phase.
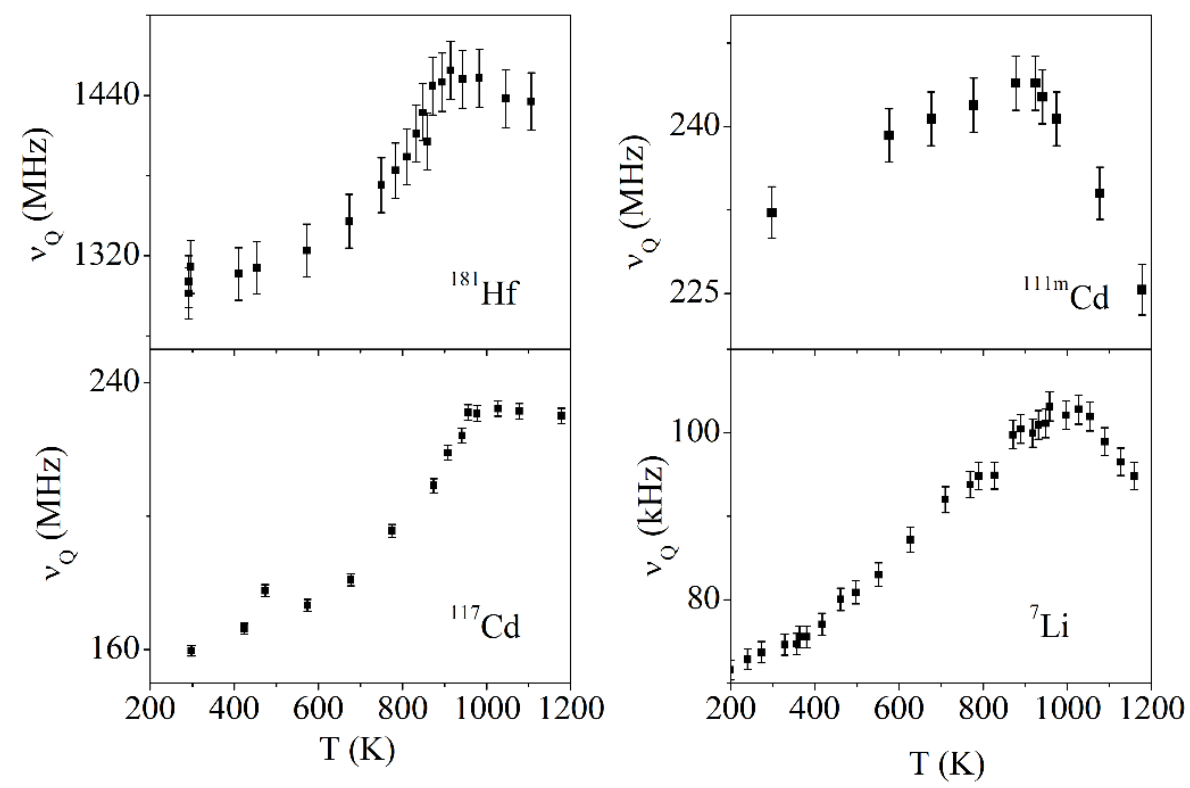

Figure 18. Temperature dependence of the nuclear quadrupole interaction at the Li site measured with the ${ }^{181} \mathrm{Hf},{ }^{117} \mathrm{Cd},{ }^{111 \mathrm{~m}} \mathrm{Cd}$ and ${ }^{7} \mathrm{Li}$ probes in lithium tantalate. Drawn using data from references $[50,93,95,98]$.

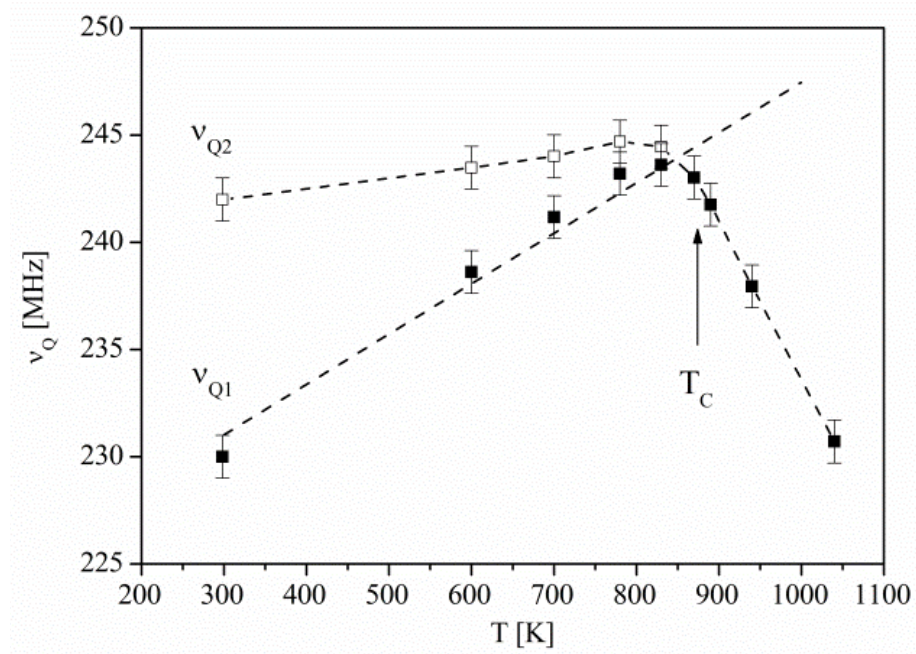

Figure 19. Temperature dependence of the quadrupole interaction frequencies measured with the ${ }^{111}$ In probe at the Li site in lithium tantalate. Redrawn from ref. [97].

Point-charge model EFG calculations reproduce the observed linear increase of $v_{\mathrm{Q} 1}$ up to $\mathrm{T}_{\mathrm{C}}$ taking into account thermal lattice expansion only [97]. If the corresponding $\mathrm{Li} / \mathrm{O}$ displacements of Abrahams et al. [83] are taken into account, then the EFG would be too large by a factor of two close to $\mathrm{T}_{\mathrm{C}}$. The main contribution to the EFG at a Li site comes from the six surrounding $\mathrm{O}$ atoms, distributed in two planes, with $\mathrm{Li}-\mathrm{O}$ distances of $2.08 \AA$ and $2.29 \AA$ at room temperature. At $940 \mathrm{~K}$ these distances are $2.05 \AA$ and $2.51 \AA$ [83], which results in a significantly increased EFG. To explain the observed decrease above $T_{C}$ it is necessary to decrease the difference between the two $\mathrm{Li}-\mathrm{O}$ distances. Inbar and Cohen [85] proposed that the driving mechanism for the phase transition in LT is a displacement of the $\mathrm{O}$ atoms towards the $\mathrm{Ta}$ atoms. Since a displacement of the $\mathrm{O}$ only along the c-axis would result in too short Ta-O distances, they further proposed that the $\mathrm{O}$ atoms move 
also in the plane perpendicular to the c-axis, toward $\mathrm{Li}$ and lead to a coupled $\mathrm{Li}-\mathrm{O}$ motion. EFG calculations using the above-mentioned point charge model show that such a $\mathrm{Li}-\mathrm{O}$ coupled movement explains qualitatively the decrease of the EFG above $T_{C}$ [97].

\subsection{Ion Implantation Induced Defects}

Ion implantation matured to a standard technique for defect engineering and doping of all kinds of materials. In the case of LN the main applications that will be discussed in their respective section are the formation of optical waveguides (Section 5.3) as well as the introduction of optical active (Section 4.3) and insoluble dopants (Section 4.5). This section is dedicated solely to investigation of basic effects of ion implantation leading to the production of intrinsic defects and their removal by annealing.

The production of defects occurs in two ways: (i) by collisions of the incoming ion with a lattice atom that cause its displacement from the lattice site, eventually initiating a collision cascade (nuclear damage); (ii) by excitation of electrons in the material which, in the case of swift heavy ions, can cause the formation of amorphization tracks on the nanometer scale (electronic damage). Since the nuclear damage is mainly occurring at the end of the ion track, it is the dominating damage producer at low energy irradiation. On the other hand, the electronic damage dominates in swift ion irradiations on the major part of the trajectory. In both cases, increasing fluence causes the defects to accumulate until full amorphization of the material is achieved. Defects cause dechanneling similar to interstitials allowing to determine their concentration and depth distribution by ion channeling.

\subsubsection{Nuclear Damage Dominated Cases}

For irradiation, already the first systematic studies on ion implantation in LN by Jetschke et al. [99] and Götz and Karge [100,101] showed a clear anisotropy in the generation of lattice defects. For irradiation with $150 \mathrm{keV} \mathrm{N}^{+}$ions at room temperature amorphization at the surface was reached with fluences of $5 \times 10^{15} \mathrm{~cm}^{-2}$ and $2 \times 10^{16} \mathrm{~cm}^{-2}$ for $\mathrm{x}$ - and $\mathrm{y}$-cut material. In contrast, $\mathrm{z}$-cut material sustained a heavily damaged but not amorphized surface layer even at a fluence of $4 \times 10^{16} \mathrm{~cm}^{-2}$. Three different stages in the damage evolution were distinguished:

(i) In the pre-damage stage (fluence $<1 \times 10^{15} \mathrm{~cm}^{-2}$ ) mainly point defects were produced of which a significant fraction was attributed to $\mathrm{Nb}$ displaced from its regular lattice site to the free octahedron. This explains the lower dechanneling along the $\langle 0001\rangle$-axis in which these displaced $\mathrm{Nb}$ is still aligned with the guiding atomic rows, while for the $\langle 11 \overline{2} 0\rangle$-axis this lattice site appears in the center of the channel enhancing the dechanneling.

(ii) The heavy damage stage $\left(1 \times 10^{15} \mathrm{~cm}^{-2}<\right.$ fluence $\left.<5 \times 10^{15} \mathrm{~cm}^{-2}\right)$ defect clusters form that cause $\langle 11 \overline{2} 0\rangle$ - and $\langle 01 \overline{1} 0\rangle$-directions to be amorphous but still maintain some alignment with the $\langle 0001\rangle$-axis.

(iii) In the final stage (fluence $>5 \times 10^{15} \mathrm{~cm}^{-2}$ ) saturation of defect formation is observed along the $\langle 11 \overline{2} 0\rangle$ - and $\langle 01 \overline{1} 0\rangle$-axis. A recent study [102] revisited the issue employing $350 \mathrm{keV} \mathrm{Ar}{ }^{+}$implantation into samples with $\mathrm{x}$ - and $\mathrm{z}$-cut as well as a sample cut in a direction equally distanced from $\langle 11 \overline{2} 0\rangle$ - and $\langle 0001\rangle$-axis by $45^{\circ}$ which allowed to study both axial directions in a single sample. Plotting the mean maximum damage concentration versus the ion fluence yielded perfect overlaps for $\langle 11 \overline{2} 0\rangle$ - and $\langle 0001\rangle$ channeling measurements for the $\mathrm{x}-\mathrm{z}$ cut sample with those of the respective standard cuts. The same work presents an additional confirmation of displaced $\mathrm{Nb}$ occupying the intrinsic vacant by angular-resolved RBS/C for a $1 \mathrm{MeV} \mathrm{I}^{+}$implanted x-cut LN.

A study on ion irradiation at low temperature $(15 \mathrm{~K})$ was performed by Gischkat et al. [103] for various ions $\left(50 \mathrm{keV} \mathrm{H}^{+}, 160 \mathrm{keV} \mathrm{Li}^{+}, 160 \mathrm{keV} \mathrm{O}^{+}, 350 \mathrm{keV} \mathrm{Ar}^{+}\right)$at fluences ranging from $5 \times 10^{11} \mathrm{~cm}^{-2}$ and $2 \times 10^{17} \mathrm{~cm}^{-2}$. The analysis by RBS/C was done in situ at the same low temperature. Nevertheless, the analyzing $\mathrm{He}^{+}$-ion beam induced an annealing effect attributed to energy deposition by electronic processes. Taking into 
account this effect, the undisturbed damage concentrations were calculated indicating an enhanced defect formation with regard to room temperature.

Bianconi et al. [104] deduced, based on own experimental $\left(\mathrm{C}^{+}, 0.5-5.0 \mathrm{MeV}, \mathrm{O}^{+}\right.$, 0.44-8.0 MeV) and literature data, a universal curve for the $\mathrm{Nb}$-defect fraction in the endof-track region as function of the energy deposited by nuclear stopping. The relation holds for all ions with $\mathrm{Z} \leq 14$ independent of the fluence.

While the $\mathrm{Nb}$-related damage is easily detected by RBS/C the other two constituents of $\mathrm{LN}$ are more difficult to access. In a work by Schmidt et al. [105] the ${ }^{7} \mathrm{Li}(\mathrm{p}, \alpha)^{4} \mathrm{He}$ reaction was employed to study the Li-related damage in $\mathrm{x}$ - and $\mathrm{z}$-cut material irradiated with $1 \mathrm{MeV} \mathrm{I}^{+}$(fluences between $2 \times 10^{13} \mathrm{~cm}^{-2}$ and $1 \times 10^{14} \mathrm{~cm}^{-2}$ ). The evolution of the Li-damage concentration with the fluence rate was found to accompany closely that for $\mathrm{Nb}$ in the z-cut material. Due to the low contribution of Li to the channeling effect in LN other crystallographic directions than along the $\langle 0001\rangle$-axis are difficult to investigate in terms of defect formation.

Götz and Karge [100] also found an enhancement of the etching rate in diluted hydrofluoric acid for room temperature implantation fluences above $5 \times 10^{14} \mathrm{~N}^{+} \mathrm{cm}^{-2}$ that increased with increasing fluence. Schrempel et al. [106] investigated the etching rates for z-cut LN implanted at $15 \mathrm{~K}$ and room temperature with $40 \mathrm{keV} \mathrm{He}^{+}$and $350 \mathrm{keV} \mathrm{Ar}^{+}$with fluences ranging from $5 \times 10^{12}$ to $5 \times 10^{16} \mathrm{~cm}^{-2}$. The larger amount of damage created by low temperature irradiation as well as the higher nuclear damage produced by the irradiation by heavier ions increase the etching rate strongly.

Jentschke and Hehl [107] studied the influence of annealing procedures in air on the implantation induced by in $\mathrm{P}^{+}(250 \mathrm{keV})$ and $\mathrm{N}^{+}(150 \mathrm{keV})$ implanted LN. For the case of a partial damaged $\left(5 \times 10^{14} \mathrm{~N}^{+} \mathrm{cm}^{-2}\right) \mathrm{x}$-cut sample, a virtually complete recovery of the lattice was achieved after annealing at $300{ }^{\circ} \mathrm{C}$ for $30 \mathrm{~min}$. On the other hand, $\mathrm{x}$ - and z-cut samples with RBS channeling spectra indicating full amorphization show only a moderate reduction of the dechanneling even for annealing temperatures up to $1100^{\circ} \mathrm{C}$. This is related to the loss of $\mathrm{Li}$ by $\mathrm{Li}_{2} \mathrm{O}$ outdiffusion from the amorphous layer during the annealing process. Random RBS spectra of these samples show a surface region with a higher yield of $\mathrm{Nb}$ than for the virgin crystal due to the formation of the Li-deficient $\mathrm{LiNb}_{3} \mathrm{O}_{8}$ compound. The loss of $\mathrm{Li}$ during annealing at high temperature can be avoided by substituting air by flowing wet oxygen resulting in high-quality recrystallization of the material. This is demonstrated in Figure 20 for Cr-implanted LN after annealing in the two different atmospheres.

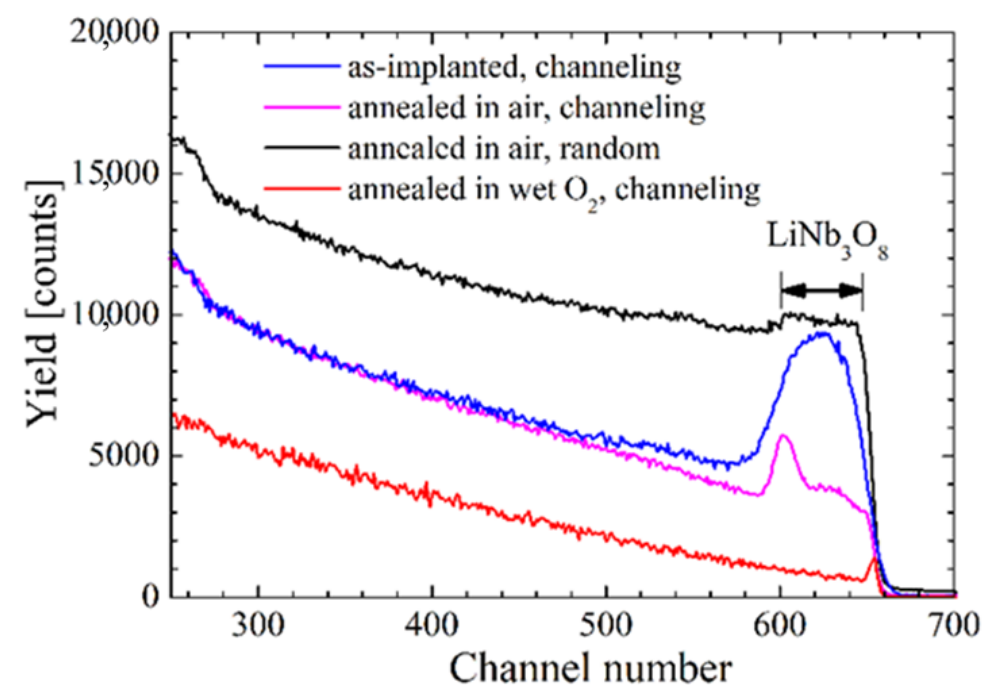

Figure 20. RBS spectra in random and channeling conditions for Cr-implanted LN in the as-implanted state and after annealing in air and wet oxygen. For the sample annealed in air the recrystallization is incomplete and shows the formation of $\mathrm{LiNb}_{3} \mathrm{O}_{8}$ at the surface. 


\subsubsection{Electronic Damage Dominated Cases}

For ions with specific energies above $0.1 \mathrm{MeV} / \mathrm{amu}$, the electronic stopping power outweighs the nuclear along most of the path. For the formation of damage consisting of amorphous tracks the electronic stopping power of the ions has to exceed a material dependent threshold value.

The effect of electronic damage is seen most perfectly separated from nuclear damage for irradiation of materials with $\mathrm{GeV}$ ions. Canut et al. [108-110] performed a series of irradiation of LN using Sn-, Gd- and U-ions with energies in the GeV range and fluences ranging between $1 \times 10^{11}$ to $1 \times 10^{12} \mathrm{~cm}^{-2}$. RBS/C investigations reveal even for the lowest fluences a significant damage in the observable depth range. The lattice disorder was found to increase with ion energy and fluence showing some saturation tendency for the latter at the maximum fluence. Plotting the damage fraction against the electronic stopping power for the different ions reveals a linear dependence.

Irradiations with lower ion energies, a few to tens of $\mathrm{MeV}$, are of interest for optoelectronic applications and have therefore experienced an immense attention in the last two decades. In the following only a selective overview on the observed features can be given. Bentini et al. [111] investigated the implantation of $5 \mathrm{MeV} \mathrm{O}^{3+}$ ions with fluences of $1 \times 10^{14} \mathrm{~cm}^{-2}$ and $6 \times 10^{14} \mathrm{~cm}^{-2}$ into $x$-cut LN. RBS/C spectra of the as-implanted samples show for all fluences a damage peak at the end-of-range $(2.7 \mu \mathrm{m})$ of the implantation, while a second peak appears at the surface region for fluences above $4 \times 10^{14} \mathrm{~cm}^{-2}$ that has to be attributed to electronic damage. Samples annealed for $2 \mathrm{~h}$ at $235^{\circ} \mathrm{C}$ in dry oxygen show a significant for the low fluence irradiation but a poor effect for higher fluences. The literature reports further similar RBS/C investigations on electronic damage for C [112], N [113], O [112-115], F [113,115,116], Si [117] and Mg [115].

Determination of the threshold electronic stopping power induced damage was the aim of several works. Rivera et al. [118] reported a value of about $6 \mathrm{keV} / \mathrm{nm}$ based on measurements for very low fluences $\left(1 \times 10^{11} \mathrm{~cm}^{-2}\right.$ to $\left.1 \times 10^{12} \mathrm{~cm}^{-2}\right)$ investigating a set of six different ion species. Ramos et al. [119] found a smaller value, $3.5 \mathrm{keV} / \mathrm{nm}$, for irradiation with $\mathrm{Cl}$ - and $\mathrm{Br}$-ions in the adjacent fluence range $\left(1 \times 10^{12} \mathrm{~cm}^{-2}\right.$ to $\left.1 \times 10^{13} \mathrm{~cm}^{-2}\right)$. An extensive study for the higher fluence range $\left(1 \times 10^{13} \mathrm{~cm}^{-2}\right.$ to $\left.1 \times 10^{15} \mathrm{~cm}^{-2}\right)$ using $\mathrm{O}-$ and Si-ions was recently presented by Wesch et al. [120]. A threshold value of $2.5 \mathrm{keV}$ was extracted using the RBS/C data, in good agreement with the $2.2 \mathrm{keV}$ reported in ref. [113] for $1 \times 10^{14} \mathrm{~cm}^{-2} \mathrm{O}$ implantation. These data evidence the reduction of the threshold value with increasing fluence. A plot of the threshold electronic stopping power versus the logarithm of the ion fluence can be fitted with a straight line as demonstrated by Agulló-Lopez et al. [121].

The theoretical modelling of the processes leading to amorphization experimentally observed in the electronic stopping power regime is a very active field, steadily generating new approaches. A detailed discussion is therefore out of the scope of this paper. In brief, the most used description is based on thermal spike model that assumes that local melting of the crystal structure occurs above the threshold value [122]. However, this cannot explain the damage production observed even below the threshold. Other effects as the exciton based mechanisms have been invoked as an explanation for this effect $[123,124]$. Finally, the cumulative character of defect generation has been invoked to explain the damage enhancement and amorphization in sub-threshold irradiation [120,125].

The defect formation by $\mathrm{Si}^{+}$ion irradiation of $\mathrm{LN}$ along crystallographic directions has been investigated by Schrempel et al. [126,127]. For the case of low ion energies $\left(<1 \mathrm{MeV}\right.$ for $\left.\mathrm{Si}^{+}\right)$it was observed that the nuclear damage maxima were shifted to higher depth for aligned irradiation with respect to those of random incidence. This effect is related to the reduced stopping power in axial direction due to the channeling effect that keeps the ion in regions with lower electron density and consequently less energy loss. Additionally, the aligned irradiation creates significantly less defects for the same fluence. For higher energies the electronic stopping passes the threshold. Surface region defect 
formation is observed and the shift of the damage maxima for channeling irradiation decreases again.

\subsection{Neutron Irradiation Induced Defects}

The interest in the behavior of LN-based acoustical devices close to the core of a nuclear fission reactor started in the 1970s [128-131]. Materials close to a reactor core are exposed to neutrons from the fission of ${ }^{235} \mathrm{U}$ and to gamma radiation [132]. While the neutrons directly released from fission have an average energy of $\approx 2 \mathrm{MeV}$ (thus being considered fast neutrons), neutron moderation in most reactors extends the spectrum down to the meV energy range (thermal neutrons). Thus, most irradiations are done with neutrons with a wide energy range, unless specific filters are interposed [133]. Besides structural characterization performed with neutron scattering, LN crystals mostly with congruent composition were irradiated with fast and/or thermal neutrons with fluences up to $10^{20} \mathrm{~cm}^{-2}[31,49,134-141]$, although with scarce details on the actual neutron spectrum in many cases. An expansion along the c-axis and a shift towards longer wavelengths of the UV absorption edge were reported by Dowell et al. [128] for neutron fluences up to $4 \times 10^{17} \mathrm{~cm}^{-2}$. Primak et al. [130] reported that irradiated LN becomes highly disordered and shows loss of piezoelectric response and optical birefringence at a fluence of $8 \times 10^{19} \mathrm{~cm}^{-2}$. This process of destruction of $\mathrm{LN}$ was found to be significantly reduced when the LN sensors were kept at $\approx 800 \mathrm{~K}$ during the irradiation [131].

The basic physics of neutron damage production is well understood [142,143]. Fast neutrons with energy up to a few $\mathrm{MeV}$ produce displacement damage mostly through elastic collisions. In contrast, thermal neutrons produce displacement damage mostly through $(\mathrm{n}, \gamma)$ reactions, due to the recoil induced by the emission of the $\gamma$ photons. In the case of $\mathrm{LN}$ one has to consider also the ${ }^{6} \mathrm{Li}(\mathrm{n}, \alpha)^{3} \mathrm{H}$ nuclear reaction, with a high cross-section for thermal neutrons [144] and whose products, $\alpha$ and ${ }^{3} \mathrm{H}$, also produce displacement damage. Although in general fast neutrons are expected to create more damage than thermal neutrons, this is not always the case [145].

Figure 21 shows the number of collisions per neutron incident on a thin slab of LN (100 $\mu \mathrm{m}$ thick) as function of energy, covering a range from $0.1 \mathrm{meV}$ to $20 \mathrm{MeV}$ in 69 groups, calculated with the MCNPX Monte Carlo code [146]. Besides the total number of collisions, the contributions coming from collisions with $\mathrm{Li}, \mathrm{O}$ and $\mathrm{Nb}$ are also shown. In the thermal neutron region, until about $1 \mathrm{eV}$, the number of collisions is essentially driven by reactions with $\mathrm{Li}$ (and within $\mathrm{Li}$, with its less abundant isotope, ${ }^{6} \mathrm{Li}$ ). After this energy, the number of collisions per incident neutron is essentially constant until about $1 \mathrm{MeV}$, when it starts to decrease.

In order to evaluate the damage caused by the above collisions, it is necessary to know the threshold energy for displacement of the atoms in LN. Seitz estimated the threshold energy for displacement of an ion or atom in a tightly bound solid, $E_{d}$, to be $25 \mathrm{eV}$ [147]. Calculations of $\mathrm{E}_{\mathrm{d}}$ values have been done using molecular dynamics for several technologically-relevant materials (see, e.g., references [148-151]), but are scarce for LN. The displacement energy values calculated by Petersen [152] are $E_{d}(\mathrm{Li})=30 \mathrm{eV}$, $E_{d}(\mathrm{Nb})=34 \mathrm{eV}$ and $E_{d}(O)=22 \mathrm{eV}$. The value of $E_{d}$ for oxygen has been estimated from irradiations with electrons as $53 \mathrm{eV}[153,154]$, which is well within the normal range for oxides [155], but significantly higher than obtained by calculation. An estimate for the value of $\mathrm{E}_{\mathrm{d}}$ for $\mathrm{Hf}$ in $\mathrm{Nb}$ and Li sites can be obtained from the PAC measurements of Marques et al. [31]. The typical neutron fluence (all energies) for the preparation of the PAC measurements was less than $5 \times 10^{16} \mathrm{~cm}^{-2}$, well below the fluence for which amorphization was observed [130]. Annealing in air at $573 \mathrm{~K}$ was enough to remove the coloration induced by the irradiation and annealing at $973 \mathrm{~K}$ was enough to remove all defects, as seen by RBS [31]. 


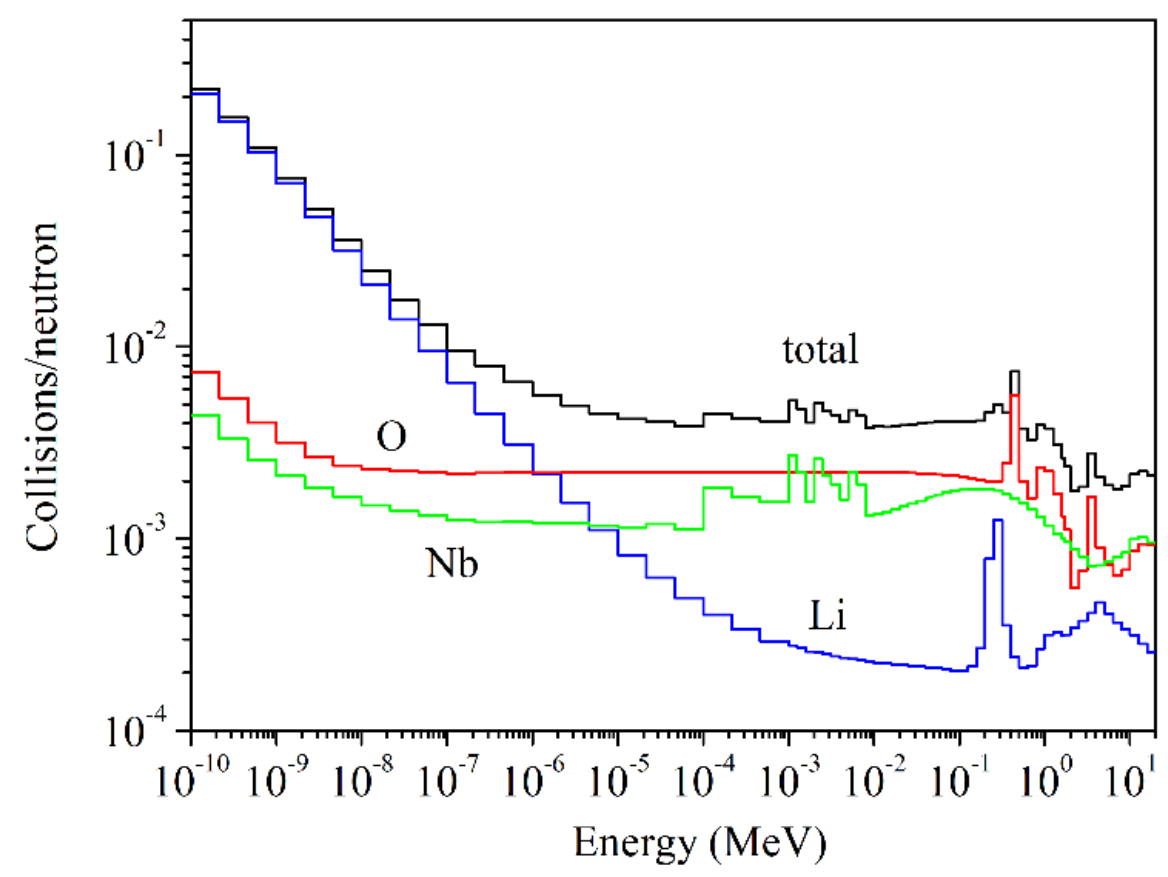

Figure 21. Number of collisions per neutron incident on a thin slab of LN (100 $\mu \mathrm{m}$ thick) as function of energy from $0.1 \mathrm{meV}$ to $20 \mathrm{MeV}$ calculated with the MCNPX Monte Carlo code.

In a congruent $\mathrm{LN}$ crystal doped with $1 \mathrm{~mol} \% \mathrm{HfO}_{2}$ the spectra before and after thermal annealing show the same characteristic QIF around $1200 \mathrm{MHz}$, associated with Hf probes in Li sites. In contrast, in a near-stoichiometric crystal doped with $1 \mathrm{~mol} \% \mathrm{HfO}_{2}$ where $\mathrm{Hf}$ is distributed between $\mathrm{Li}(45 \%)$ and $\mathrm{Nb}(55 \%)$ sites, the spectrum after irradiation shows that the fraction of $\mathrm{Hf}$ probes in $\mathrm{Nb}$ sites is strongly reduced to $18 \%$, with a full recovery only after annealing at $973 \mathrm{~K}$. However, RBS data shows no change on the lattice site of Hf after irradiation [31]. Thus the change of lattice location after irradiation can only affect the radioactive ${ }^{181} \mathrm{Hf}$ atoms produced via the $(\mathrm{n}, \gamma)$ reaction. Since these atoms are much less than $1 \mathrm{ppm}$ of the total amount of $\mathrm{Hf}$ in the crystal, no effect can be detected by RBS. It thus seems reasonable to assume that the displacement is due to the recoil induced by emission of the $\gamma$ photons from the ${ }^{180} \mathrm{Hf}(\mathrm{n}, \gamma)^{181} \mathrm{Hf}$ reaction, characterized by Alenius et al. [156]. As the maximum recoil that can be induced is $96 \mathrm{eV}$, corresponding to the emission of a $5.6 \mathrm{MeV} \gamma$ photon, only one displacement per recoil is expected.

The transfer of $\mathrm{Hf}$ form $\mathrm{Nb}$ to Li sites upon irradiation can be qualitatively explained by the existence of Li vacancies in the congruent and near-stoichiometric crystals. In this way, a recoiled ${ }^{181} \mathrm{Hf}$ from a $\mathrm{Nb}$ position finds easily a vacant $\mathrm{Li}$ site, leading to the observed change. In the case of a recoiled ${ }^{181} \mathrm{Hf}$ from a Li site, which finds another Li site, no change is seen. If the energy necessary to displace $\mathrm{Hf}$ from $\mathrm{Li}$ and $\mathrm{Nb}$ lattice sites is approximately the same and $x$ represents the fraction of ${ }^{181} \mathrm{Hf}$ recoiled from $\mathrm{Li}$ and $\mathrm{Nb}$ sites, we can write:

$$
x=1-\frac{\left[H f_{N b}\right]^{\prime}}{\left[H f_{N b}\right]^{\prime}}
$$

where $\left[\mathrm{Hf}_{\mathrm{Nb}}\right]$ and $\left[\mathrm{Hf}_{\mathrm{Nb}}\right]^{\prime}$ are, respectively, the fraction of $\mathrm{Hf}$ probes in $\mathrm{Nb}$ sites before and after irradiation. Using the $\left[\mathrm{Hf}_{\mathrm{Nb}}\right]$ and $\left[\mathrm{Hf}_{\mathrm{Nb}}\right]^{\prime}$ values and respective uncertainties reported by Marques et al. [31], we obtain $\mathrm{x}=0.37 \pm 0.07$. From the intensity of the discrete values of the $\gamma$ photons emitted by the ${ }^{180} \mathrm{Hf}(\mathrm{n}, \gamma)^{181} \mathrm{Hf}$ reaction, a recoiled fraction of $37 \%$ would correspond to the emission of photons with energy of $3979 \mathrm{keV}$ and above, imposing a minimum recoil energy of $47 \mathrm{eV}$ to $\mathrm{Hf}$. Thus, our estimate for the required energy to displace $\mathrm{Hf}$ in $\mathrm{Nb}$ and $\mathrm{Li}$ sites is $47 \pm 8 \mathrm{eV}$, in reasonable agreement with the $\mathrm{E}_{\mathrm{d}}$ value for $\mathrm{Li}$ and $\mathrm{Nb}$ sites calculated by Petersen [152]. 
Displacement of other dopants as a result of $(n, \gamma)$ reactions is possible. Table 1 compiles data on the neutron capture cross section at $0.025 \mathrm{eV}\left(1 \mathrm{~b}=100 \mathrm{fm}^{2}\right)$ [157], main activation reactions(s), respective cross section [158], maximum $\gamma$ energy released [159] and maximum recoil energy.

Table 1. Recoil resulting from neutron activation of several dopants in LN.

\begin{tabular}{|c|c|c|c|c|c|c|c|}
\hline Dopant & $\overline{\sigma_{C}}[\mathrm{~b}]$ & $\begin{array}{l}\text { Main Activation } \\
\text { Reaction(s) }\end{array}$ & $\sigma_{C}[\mathbf{b}]$ & $\begin{array}{c}\text { Relative } \\
\text { Weight [\%] }\end{array}$ & $\begin{array}{c}\text { Max } \gamma \text { Energy } \\
{[\mathrm{MeV}]}\end{array}$ & $\begin{array}{l}\text { Max Induced } \\
\text { Recoil [eV] }\end{array}$ & Importance \\
\hline Er & 159.4 & ${ }^{167} \operatorname{Er}(\mathrm{n}, \gamma)^{168} \mathrm{Er}$ & 642.3 & 92 & 7.691 & 188 & High \\
\hline $\mathrm{Fe}$ & 2.56 & ${ }^{56} \mathrm{Fe}(\mathrm{n}, \gamma){ }^{57} \mathrm{Fe}$ & 2.59 & 93 & 7.646 & 551 & Moderate \\
\hline $\mathrm{Hf}$ & 104.1 & ${ }^{177} \mathrm{Hf}(\mathrm{n}, \gamma){ }^{178} \mathrm{Hf}$ & 375.5 & 67 & 6.451 & 126 & High \\
\hline In & 193.8 & ${ }^{115} \operatorname{In}(\mathrm{n}, \gamma)^{116} \mathrm{In}$ & 201.0 & 99 & 6.561 & 199 & High \\
\hline $\mathrm{Mg}$ & 0.063 & ${ }^{24} \mathrm{Mg}(\mathrm{n}, \gamma)^{25} \mathrm{Mg}$ & 0.05 & 63 & 7.329 & 1153 & Low \\
\hline $\mathrm{Nd}$ & 50.5 & ${ }^{143} \mathrm{Nd}(\mathrm{n}, \gamma)^{144} \mathrm{Nd}$ & 325.0 & 78 & 6.502 & 158 & High \\
\hline Sc & 27.14 & ${ }^{45} \mathrm{Sc}(\mathrm{n}, \gamma)^{46} \mathrm{Sc}$ & 27.14 & 100 & 8.760 & 896 & High \\
\hline $\mathrm{Ti}$ & 6.09 & ${ }^{48} \mathrm{Ti}(\mathrm{n}, \gamma)^{49} \mathrm{Ti}$ & 7.84 & 95 & 6.760 & 501 & Moderate \\
\hline $\mathrm{Yb}$ & 34.8 & ${ }^{174} \mathrm{Yb}(\mathrm{n}, \gamma){ }^{175} \mathrm{Yb}$ & 69.4 & 63 & 5.308 & 86 & Moderate \\
\hline \multirow[t]{2}{*}{$\mathrm{Zn}$} & 1.11 & ${ }^{64} \mathrm{Zn}(\mathrm{n}, \gamma)^{65} \mathrm{Zn}$ & 0.93 & 41 & 7.864 & 511 & Moderate \\
\hline & & ${ }^{67} \mathrm{Zn}(\mathrm{n}, \gamma)^{68} \mathrm{Zn}$ & 6.8 & 28 & 9.120 & 657 & Moderate \\
\hline
\end{tabular}

For the estimation of displacement damage, Dale et al. [160] have shown that is convenient to use a quantity named Non-Ionizing Energy-Loss (NIEL) to quantify the portion of energy lost by a particle that is used for displacement damage, with the remainder of the energy being dissipated as heat. It was shown that NIEL can be used to correlate displacement damage effects in materials induced by different types of radiation [160], even if some exceptions are known [161]. For a particle with energy $\mathrm{E}_{0}$ incident on a material with a single type of atom with atomic weight $\mathrm{A}$, it is defined as:

$$
\operatorname{NIEL}\left(E_{0}\right)=\frac{N_{A}}{A} \int_{T_{\min }}^{T_{\max }}\left(\frac{d \sigma}{d T}\right)_{E_{0}} Q(T) T d T,
$$

where is $\mathrm{N}_{\mathrm{A}}$ is Avogadro's number, $\mathrm{d} \sigma / \mathrm{dT}$ is the total differential cross section (elastic and inelastic) for energy transfer to an atom of the material, $\mathrm{T}_{\min }$ and $\mathrm{T}_{\max }$ are the minimal and maximal energies that can be transferred to a lattice atom, and $Q(T)$ is a partition function which gives the fraction of $T$ that is lost to NIEL. $T_{\min }$ is usually taken as $T_{\min }=2 E_{d}$, while $T_{\max }=4 \mathrm{E}_{0} \mathrm{~A} /\left(\mathrm{A}+\mathrm{A}^{\prime}\right)^{2}$, where $\mathrm{A}^{\prime}$ is the mass of the incident particle. The partition function $\mathrm{Q}(\mathrm{T})$ has a classical formulation given by Lindhard et al. [162] and fitted by Robinson et al. [143], as well as a more recent formulation by Akkerman et al. [163] with improved handling of low energy ions. Total NIEL for LN results from the application of Equation (4) to $\mathrm{Li}, \mathrm{Nb}$ and $\mathrm{O}$, taking stoichiometry in account, as:

$\operatorname{NIEL}\left(\operatorname{LiNbO}_{3}, E_{0}\right)=\frac{A(\operatorname{Li}) N I E L\left(L i, E_{0}\right)+A(N b) N I E L\left(N b, E_{0}\right)+3 A(O) N I E L\left(O, E_{0}\right)}{A(L i)+A(N b)+3 A(O)}$,

The product of the NIEL and the particle fluence gives the displacement damage energy deposition per unit mass of material. NIEL plays the same role to the displacement damage energy deposition as the stopping power to the total ionizing dose. Figure 22 shows the values of NIEL for electrons, neutrons, protons and alphas incident in LN, with energy up to $100 \mathrm{MeV}$, calculated with the tools available at the SR-NIEL platform [164], using the Akkerman partition function. Displacement energy values of $30 \mathrm{eV}, 35 \mathrm{eV}$ and $25 \mathrm{eV}$ were used for $\mathrm{Li}, \mathrm{Nb}$ and $\mathrm{O}$, as the nearest to the values calculated by Petersen [152], due to the constraints of the calculations for neutrons. NIEL for incident neutrons has a weak dependence of the value of $E_{d}$ : a change from 20 to $50 \mathrm{eV}$ in the $E_{d}$ of the 3 species leads to a neutron NIEL average decrease of $3 \%$ in the range $10^{-4}-10^{-2} \mathrm{MeV}$ and less than $1 \%$ outside this range. Table 2 shows discrete values, for reference. The tabled values for neutrons were obtained by a simple linear interpolation between the two nearest values. It 
is worth noting that at $1 \mathrm{MeV}$ protons are about 20 times more effective than neutrons in producing displacement damage in $\mathrm{LN}$.

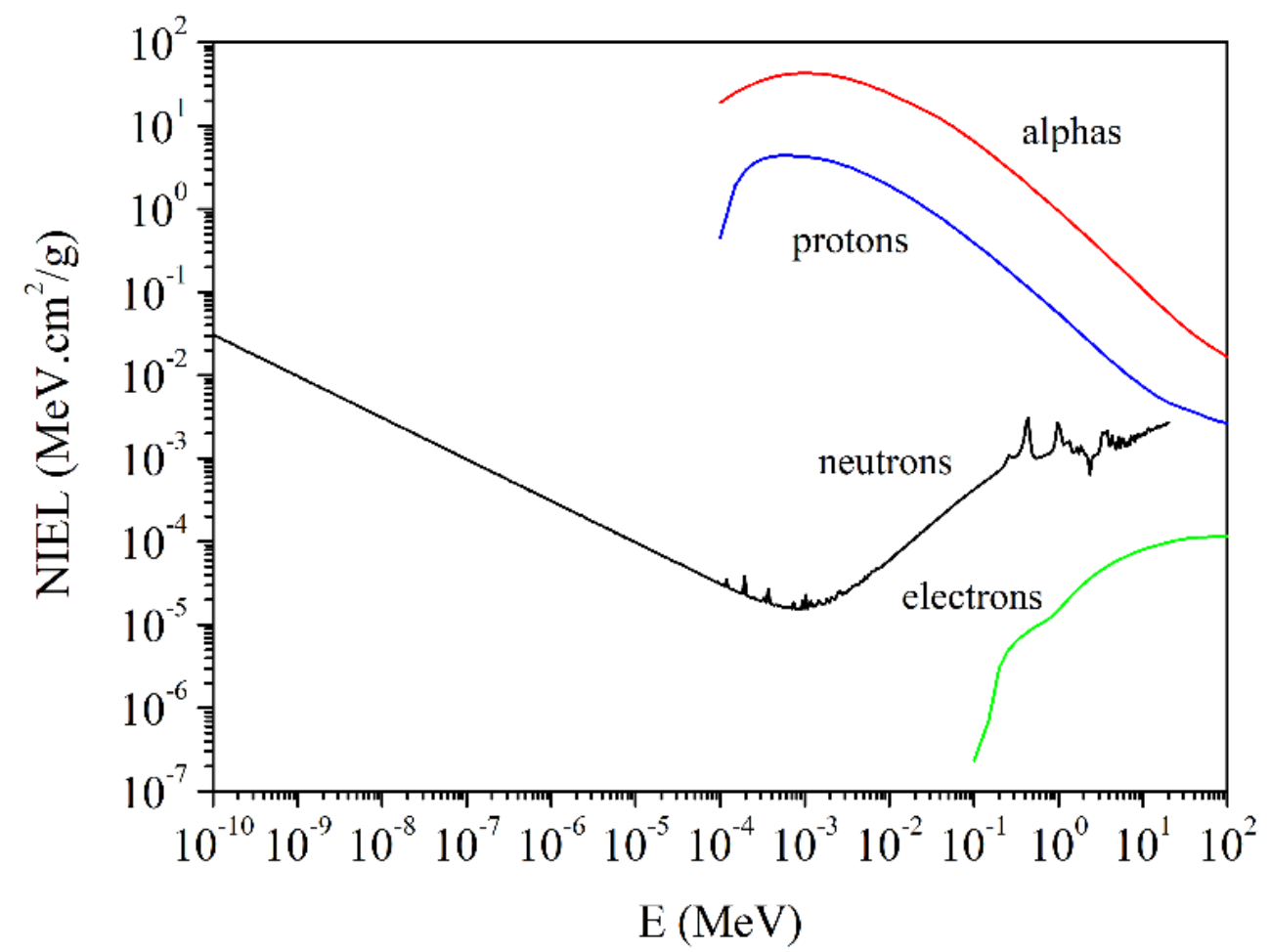

Figure 22. Non-Ionizing Energy-Loss (NIEL) for electrons, neutrons, protons and alphas incident in lithium niobate, with energy up to $100 \mathrm{MeV}$, calculated with the tools available at the SR-NIEL website (www.sr-niel.org; acessed on 31 March 2021).

Table 2. Non-Ionizing Energy-Loss (NIEL) values for electrons, neutrons, protons and alphas incident in lithium niobate, calculated with the tools available at the SR-NIEL website (www.sr-niel.org; acessed on 31 March 2021).

\begin{tabular}{ccccc}
\hline $\begin{array}{c}\text { Energy } \\
{[\mathrm{MeV}]}\end{array}$ & $\begin{array}{c}\text { NIEL } \mathbf{~}^{-} \\
{\left[\mathrm{MeV} \cdot \mathbf{c m}^{2} / \mathbf{g}\right]}\end{array}$ & $\begin{array}{c}\text { NIEL } \mathbf{n} \\
{\left[\mathbf{M e V} \cdot \mathbf{c m}^{2} / \mathbf{g}\right]}\end{array}$ & $\begin{array}{c}\text { NIEL } \mathbf{p} \\
{\left[\mathbf{M e V} \cdot \mathbf{c m}^{2} / \mathbf{g}\right]}\end{array}$ & $\begin{array}{c}\text { NIEL } \boldsymbol{\alpha} \\
{\left[\mathbf{M e V} \cdot \mathbf{c m}^{2} / \mathbf{g}\right]}\end{array}$ \\
\hline 0.001 & & $1.886 \times 10^{-5}$ & 4.255 & $4.285 \times 10^{+1}$ \\
0.01 & & $5.984 \times 10^{-5}$ & 1.914 & $2.450 \times 10^{+1}$ \\
0.1 & $2.346 \times 10^{-7}$ & $4.229 \times 10^{-4}$ & $3.932 \times 10^{-1}$ & 6.528 \\
1 & $1.506 \times 10^{-5}$ & $2.568 \times 10^{-3}$ & $5.537 \times 10^{-2}$ & $9.452 \times 10^{-1}$ \\
10 & $8.037 \times 10^{-5}$ & $1.962 \times 10^{-3}$ & $7.368 \times 10^{-3}$ & $1.090 \times 10^{-1}$ \\
\hline
\end{tabular}

\section{Extrinsic Point Defects}

This section is dedicated to the determination of lattice sites occupied by foreign atoms in LN. The influence of dopant concentration, co-doping and stoichiometry of the material are addressed. The subsections are mainly organized according to the functionality of the dopant.

\subsection{Dopants to Increase Photorefractive Damage Resistance}

Although congruent LN exhibits excellent optical, electro-optical and non-linear optical properties, the relatively low optical damage resistance hampers its application in optical devices [165]. Besides the attempt to improve the optical damage resistance by growing stoichiometric LN, the introduction of divalent $\left(\mathrm{Mg}^{2+}[166,167], \mathrm{Zn}^{2+}[168]\right)$, trivalent $\left(\mathrm{Sc}^{3+}\right.$ [169], $\mathrm{In}^{3+}$ [170]) and tetravalent $\left(\mathrm{Hf}^{4+}\right.$ [171], $\mathrm{Zr}^{4+}$ [172]) dopants has been proven to be successful. The observed minimum concentration for suppression of the optical damage (4.5 mol\% for doping with $\mathrm{MgO}, 6 \mathrm{~mol} \%$ for $\mathrm{ZnO}, 1.5 \mathrm{~mol} \%$ for $\mathrm{Sc}_{2} \mathrm{O}_{3}$ and 
$\mathrm{In}_{2} \mathrm{O}_{3}$ and $4 \mathrm{~mol} \%$ for $\mathrm{HfO}_{2}$ and $6 \mathrm{~mol} \%$ for $\mathrm{ZrO}_{2}$ ) indicate that it is important to clarify the lattice location and interaction of these dopants with intrinsic defects of $\mathrm{LN}$.

As the doping with $\mathrm{Mg}$ is by far the most technically most important way innumerous studies about the characteristics and application extensively studied and attempts were made. From the more fundamental viewpoint, the main interest is to understand the incorporation of this dopant in dependence on its concentration and to elucidate the underlying mechanisms.

Most of the theoretical approaches published so far depend largely on the model adopted to explain the non-stoichiometry of the congruent material. Zhang and Feng [173] proposed a series of overlapping concentration dependent mechanisms, based on the $\mathrm{Nb}$ vacancy model. At low concentration ( $<2.7 \mathrm{~mol} \%) \mathrm{Mg}$ substitutes $\mathrm{Nb}$ on antisites until they are consumed; for higher concentration up to the threshold $\mathrm{Mg}$ is incorporated at the $\mathrm{Li}$ site and accompanied by a trapped electron for charge compensation; above the threshold the incorporation occurs on both $\mathrm{Li}$ and $\mathrm{Mg}$ sites. These ideas were readopted by Liu et al. [174] and more recently by Abdi et al. [175]. Based on the Li-vacancy model, Iyi et al. [176] propose that $\mathrm{Mg}$ at first replaces $\mathrm{Nb}$ at Li sites up to $3 \mathrm{~mol} \% \mathrm{MgO}$ at which the removal of $\mathrm{Nb}_{\mathrm{Li}}$ is completed. In the range between 3 and $8 \mathrm{~mol} \% \mathrm{MgO}$ magnesium will only occupy regular Li sites while at higher concentration both cation sites are incorporating $\mathrm{Mg}$. The studies by Donnerberg et al. [177,178] (further refined in $[179,180]$ ) are based on the occurrence of ilmenite-type stacking faults with $\mathrm{Li}$ vacancies but are formally treated as $\mathrm{Nb}$ antisites and $\mathrm{Nb}$ vacancies. In the following, we also adopt this procedure for simplicity. According to this model, $\mathrm{Mg}$ is replacing in the two concentration ranges $<1.5 \mathrm{~mol} \%$ and 1.5 to $5.0 \mathrm{~mol} \%$ simultaneously $\mathrm{Nb}$ on antisites and Li on regular sites employing different mechanisms. The preferential substitution of $\mathrm{Nb}_{\mathrm{Li}}$ by $\mathrm{Mg}$ in the second range results in their complete removal at the threshold level. For even higher $\mathrm{Mg}$ concentrations both $\mathrm{Li}$ and $\mathrm{Nb}$ sites should be occupied.

Since a direct determination of the lattice site of magnesium in dependence of its concentration has to be regarded as essential to decide which of the proposed models is the most adequate, an extended channeling study on a set of Mg-doped crystals was performed employing $\mathrm{He}^{+}$in order to improve the attainable minimum yield and minimize bremsstrahlung background [181]. As no adequate nuclear reaction for the study of magnesium is available, PIXE/C has been applied. Due to very low energy of the characteristic $\mathrm{Mg}-\mathrm{K}$ X-rays a $\mathrm{Si}(\mathrm{Li})$-detector with an extremely thin Be window was used to limit absorption. This set of crystals, containing one undoped and six doped (0.5, 1.0, 2.0, 4.0, 6.0 and $9.0 \mathrm{~mol} \% \mathrm{MgO}$ in melt), was grown at the Siemens Research Laboratory in Munich and thoroughly characterized regarding crystal composition, lattice constants, density, temperature, piezoelectricity and various optical properties [182-187].

Angular scans crossing through the $\langle 0001\rangle$-axis showed for all concentration dips with a width and minimum yield for the Mg-PIXE between those of Nb-RBS and Li-NRA. Computer simulations with CASSIS confirmed that this is consistent with the absence of non-axial lattice sites for $\mathrm{Mg}$.

For $\mathrm{MgO}$ concentrations of 0.5 and $1.0 \mathrm{~mol} \%$ the most striking observation is the strong peak in the Mg-PIXE yield for alignment with the $\langle 11 \overline{2} 0\rangle$-axis. This indicates that $\mathrm{Mg}$ is not occupying a regular cation lattice site but some interstitial site. The fact that the Mg- PIXE scans for the other axial directions show clear dips and a similar behavior to the $\mathrm{Li}$-scans one can further exclude that $\mathrm{Mg}$ is located in the intrinsically vacant or in the $\mathrm{Nb}$-octahedron. The computer simulation with the CASSIS code allows to identify the occupied position as the center of the Li-Octahedron which yields for $\mathrm{Mg}$ an oxygen environment similar to that of magnesium oxide. The epitaxial growth of $\mathrm{LN}$ on $\mathrm{MgO}$ substrates it is known that the (111)-plane of $\mathrm{MgO}$ and (001)-plane of LN have the same oxygen framework [188] which might explain this behavior.

It is tempting to identify the observed behavior with a substitution of $\mathrm{Nb}$ in the stacking but this would require a substitution of the following type:

$$
2 \mathrm{MgO}+3 \mathrm{Li}_{2} \mathrm{O}+3 \mathrm{~V}_{\mathrm{Li}}+2 \mathrm{Nb}_{\mathrm{Li}} \rightarrow 2 \mathrm{Mg}_{\mathrm{Li}}+6 \mathrm{Li}_{\mathrm{Li}}+\mathrm{Nb}_{2} \mathrm{O}_{5}
$$


incorporating so much lithium that a near-stoichiometric crystal would be obtained. However, the measurements on the lithium fraction and Curie temperature for these samples exclude this scenario [182]. It is more likely that the $\mathrm{Mg}$ occupied sites associated to the ilmenite stacking faults ( $\mathrm{Li}$ vacancies or Li sites in the vicinity) and the movement to the center of the Li-Octahedron can be interpreted as a relaxation mechanism.

The Mg-scans along the $\langle 11 \overline{2} 0\rangle$-axis for concentrations above $2.0 \mathrm{~mol} \% \mathrm{MgO}$ in melt differ clearly from those at low concentration. For all axial directions clear minima are observed with scan curve that resemble those of Li. However, computer simulations demonstrate that $\mathrm{Mg}$ solely occupying regular Li sites would result in minimum yields that are significantly lower than the observed ones. The best fit to the experimental data was obtained assuming 2/3 of the $\mathrm{Mg}$ to occupy regular Li sites and 1/3 sites in the center of the $\mathrm{Nb}$ oxygen cage (occupation of regular $\mathrm{Nb}$ sites yielded even lower minima). Interestingly this observation holds for the whole concentration range from 2.0 to $9.0 \mathrm{~mol} \% \mathrm{MgO}$, without any change at the threshold concentration for photorefractive damage suppression. Indeed, there exists a substitution reaction for divalent dopants that would be compatible with these findings:

$$
3 \mathrm{MgO}+\mathrm{V}_{\mathrm{Li}}+\mathrm{Li}_{\mathrm{Li}}+\mathrm{Nb}_{\mathrm{Nb}} \rightarrow 2 \mathrm{Mg}_{\mathrm{Li}}+\mathrm{Mg}_{\mathrm{Nb}}+\mathrm{LiNbO}_{3},
$$

which on the other hand does not remove any antisites. A possible solution is that the reactions described by Equations (6) and (7) occur simultaneously until the threshold of 6 $\mathrm{mol} \% \mathrm{Mg}$ in the crystal is reached, causing a deviation in the $\mathrm{Mg}_{\mathrm{Li}} / \mathrm{Mg}_{\mathrm{Nb}}$ ratio that is too small to be detectable by the PIXE/C measurements.

A further study on this set of crystals focused on the influence of the $\mathrm{Mg}$ incorporation on the Li-NRA channeling minimum yield [189] providing further insight on the lattice modifications. The minimum yield for an atomic string in channeling directions depends strongly on repelling force of its continuum potential. The replacement of $\operatorname{Li}(Z=3)$ by atoms with higher atomic number $\mathrm{Nb}(Z=41)$ or $\mathrm{Mg}(\mathrm{Z}=12)$ increases the continuum potential of the Li-string and therefore reduces the minimum yield. Figure 23 shows the dependence of the Li-NRA minimum yield in various axial directions in dependence of the $\mathrm{MgO}$-concentration. The main observation is that the minimum yield increases steeply for all but the $\langle 0001\rangle$-axis (in which all cations are aligned with each other) strongly for $\mathrm{MgO}$ melt concentrations up to $1 \mathrm{~mol} \%$. This indicates an increase in the disturbance of the lattice due to the interstitial location of magnesium rather than changes of the continuum potential due to removal of excess $\mathrm{Nb}$. In the investigated axial directions ilmenite-like and regular $\mathrm{Li}$ site occupying $\mathrm{Nb}$ are located very close and do not produce distinguishable effects. For further increasing $\mathrm{Mg}$ concentrations the $\langle 11 \overline{2} 0\rangle$ - and $\langle 0 \overline{4} 41\rangle$ axis no systematic alteration of the minimum yield is observed since the Li atomic strings are in close neighborhood to the-in terms of channeling-dominating Nb-rows. In addition, for both axial directions $\chi_{\min }$ does not decrease anymore to the value of the congruent case. On the other hand, $\mathrm{Li}$ is isolated in the $\langle 11 \overline{2} 0\rangle$-axis within the channel and the incorporation of the $\mathrm{Mg}$ reinforces the repelling force of the Li strings. This leads to a steady decrease of the Li-NRA minimum yields for this axial direction reaching at $9 \mathrm{~mol} \%$ $\mathrm{MgO}$ a value below that of the congruent material.

In addition, one NMR study on ${ }^{25} \mathrm{Mg}$ (nuclear spin 5/2+) has been reported by Feng et al. [190] for $\mathrm{LN}$ doped with $\mathrm{MgO}$ with concentration ranging from 1.0 to $6.0 \mathrm{~mol} \%$. The NMR spectra for ${ }^{25} \mathrm{Mg}$ show clear differences for the various concentration but surprisingly no new line, that would indicate change in the lattice site, appears for concentrations above the threshold. Yatsenko et al. [191] used an indirect approach to obtain information on the incorporation of $\mathrm{Mg}$ using ${ }^{7} \mathrm{Li}$ - and ${ }^{93} \mathrm{Nb}-\mathrm{NMR}$ in samples doped with 2 to $7 \mathrm{~mol} \%$. They conclude that the amount of vacancies is steadily increasing up to the threshold at which on the other hand no more $\mathrm{Nb}$-antisites are present. $\mathrm{Mg}$ is supposed to occupy Li sites forming next-neighbor $\mathrm{Mg}_{\mathrm{Li}}-\mathrm{V}_{\mathrm{Li}}$ complexes. 


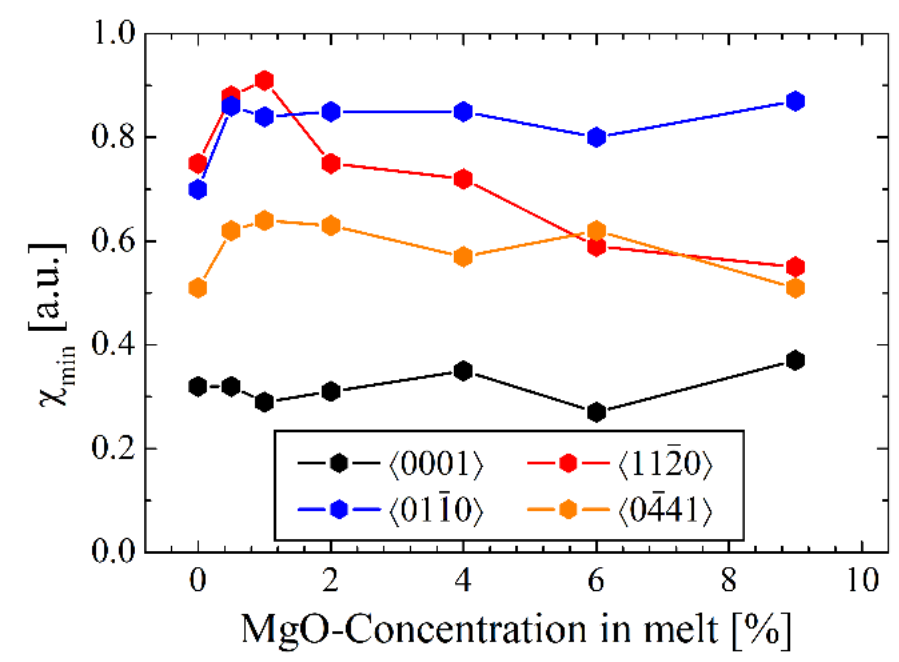

Figure 23. The dependence of the Li-NRA minimum yield on the MgO doping concentration for various axial directions. Redrawn from Kling et al. [189].

Although less popular as dopant for photorefractive suppression in LN, Hf is highly interesting for studies on the basic incorporation mechanism of dopants since it can be accessed simultaneously by RBS/C and PAC. The advantage use of the combination of these two nuclear techniques in investigating has already been demonstrated in the case of intrinsic defects.

Hf-doped crystals LN were grown with $1.0 \mathrm{~mol} \%$ [49,192] and $6.0 \mathrm{~mol} \%$ [138] of $\mathrm{HfO}_{2}$ in congruent melt. For comparison, samples of near-stoichiometric material, to which $4.6 \mathrm{wt} \% \mathrm{~K}_{2} \mathrm{O}$ was added, were doped with 0.2 and $1.0 \mathrm{~mol} \%[138,193] \mathrm{HfO}_{2}$.

RBS enabled to determine the actual concentrations of the melt grown samples and derive the corresponding distribution coefficients (Table 3). Channeling measurements for various axial direction proved that in the $1.0 \mathrm{~mol} \%$ congruent crystal Hf occupies exclusively the Li site $[49,192]$. For the samples doped with $6.0 \mathrm{~mol} \%$ RBS measurements revealed that the Hf distribution in the samples is inhomogeneous $(3.5-5.1 \mathrm{~mol} \%)$ and the distribution coefficient lower than one [138]. Further, the higher minimum yield (10\%) at $\langle 02 \overline{2} 1\rangle$-axis for $\mathrm{Nb}$ and $\mathrm{Hf}$ in comparison to the $1.0 \mathrm{~mol} \%$ sample $(2.5 \%)$ indicates an inferior crystal quality. Both findings indicate that the maximum solubility of $\mathrm{Hf}$ in LN has been exceeded in the sample. However, the quality of angular scans was still sufficient to obtain meaningful results for the incorporated Hf-fraction: the best fit was obtained assuming $55 \%$ of the Hf to occupy regular or slightly shifted $(0.1 \AA$ towards the octahedron center) $\mathrm{Nb}$ lattice sites and $45 \%$ to occupy regular $\mathrm{Li}$ sites. This ratio is not compatible with a charge compensation mechanism suggested in theoretical studies for which $25 \%$ of the $\mathrm{Hf}$ has to reside on $\mathrm{Li}$ sites and $75 \%$ on $\mathrm{Nb}$ sites.

Table 3. Incorporation of Hf into crystals grown from congruent and stoichiometric melts.

\begin{tabular}{cccc}
\hline Melt Type & $\begin{array}{c}\text { Concentration } \\
\text { in Melt (mol\%) }\end{array}$ & $\begin{array}{c}\text { Concentration } \\
\text { in Crystal (mol } \%)\end{array}$ & $\begin{array}{c}\text { Distribution } \\
\text { Coefficient }\end{array}$ \\
\hline congruent & 1.0 & 1.3 & 1.3 \\
congruent & 6.0 & $3.5-5.1$ & $0.58-0.85$ \\
stoichiometric & 0.2 & 0.6 & 3.0 \\
stoichiometric & 1.0 & 1.7 & 1.7 \\
\hline
\end{tabular}

Besides the already known frequencies for $\mathrm{Hf}$ in Li sites, the Fourier analyses of the PAC spectra obtained in the crystal doped with $6 \mathrm{~mol} \% \mathrm{HfO}_{2}$ and in the near-stoichiometric crystals has shown another peak at a frequency about 3.5 times smaller. The relative intensity agreed with the fraction for $\mathrm{Hf}$ in $\mathrm{Nb}$ sites determined by RBS and the EFG scaled with the ${ }^{93} \mathrm{Nb} \mathrm{NMR}$ measurements previously reported by Peterson et al. [44]. It can thus 
be safely assigned to $\mathrm{Hf}$ probes occupying $\mathrm{Nb}$ sites at room temperature. A frequency doublet for probes in $\mathrm{Nb}$ sites, $v_{\mathrm{Q} 1}=353 \mathrm{MHz}$ and $v_{\mathrm{Q} 2}=494 \mathrm{MHz}$, was necessary for a good fit of the PAC spectra [193]. However, the best fits for the $6 \mathrm{~mol} \%$ congruent and $0.2 \mathrm{~mol} \%$ near stoichiometric crystals, for which the fraction of probes in $\mathrm{Nb}$ sites was close to $50 \%$, were obtained without a fraction of probes in Li II sites. This suggests that the defect associated Li II site has disappeared or is of too small importance to make an effect.

The influence of stoichiometry on the incorporation of Hf into LN was studied by RBS/C on samples grown from stoichiometric melt $[138,193]$. The sample with higher Hf concentration (1.0 mol\%) shows clearly a mixture of $\mathrm{Li}$ - and $\mathrm{Nb}$-lattice sites occupied by Hf. Computer simulations with FLUX yield a best fit for $66 \% \mathrm{Nb}$ sites and $34 \%$ Li sites, i.e., roughly a 2:1 ratio. This deviates from the 3:1 ratio expected in the case of charge compensation during the incorporation of $\mathrm{Hf}$ into LN. From angular scans of $0.2 \mathrm{~mol} \%$ $\mathrm{HfO}_{2}$ sample, which can be regarded closer to a stoichiometric case, a fraction of more than $85 \%$ of Hf is located on the Li site. It can be concluded that Hf, despite being a tetravalent ion, shows a strong preference to incorporation on Li sites.

In order to demonstrate the influence of co-doping in $\mathrm{LN}$ on the incorporation mechanisms in LN, the case of Hf-Mg will be discussed in detail. A set of single crystals of congruent $\mathrm{LN}$ doped with $1 \mathrm{~mol} \%$ of $\mathrm{HfO}_{2}$ in melt and $\mathrm{MgO}$ concentrations ranging between 2.0 and $4.0 \mathrm{~mol} \%$ in steps of $0.5 \mathrm{~mol} \%$ as well as one with $6.0 \mathrm{~mol} \%$ have been studied by RBS/C and PAC [194-197]. The evaluation of the first set of co-doped samples showed that the fraction of $\mathrm{Hf}$ located on Li sites decreases constantly with increasing $\mathrm{MgO}$ concentration from about $90 \%$ at $2.0 \mathrm{~mol} \% \mathrm{MgO}$ to about $20 \%$ at $4.0 \mathrm{~mol} \%$ and changes to full occupation of $\mathrm{Nb}$ sites at $6.0 \mathrm{~mol} \%$. This reveals that the tendency of $\mathrm{Mg}$ to occupy $\mathrm{Li}$ sites is stronger than that of $\mathrm{Hf}$ but falls short on being a charge compensation effect. Unfortunately, only for the case of $6 \mathrm{~mol} \% \mathrm{MgO}$ data on the lattice site occupation by $\mathrm{Mg}$ are available from an additional study [198]. In this case the mixed occupation of regular $\mathrm{Li}$ and $\mathrm{Nb}$-octahedron sites as in the single $\mathrm{Mg}$-doped case has been confirmed indicating that $\mathrm{Mg}$ may keep its incorporation mechanisms despite co-doping.

PAC measurements were performed in the same crystals after irradiation with neutrons and annealing. The spectrum obtained in the $6 \mathrm{~mol} \%$ co-doped crystal could only be fitted considering a doublet $v_{Q 1}=327(10) \mathrm{MHz}$ and $v_{Q 2}=398(10) \mathrm{MHz}$ for probes in $\mathrm{Nb}$ sites. This frequency doublet is slightly different from the one observed for Hf probes in $\mathrm{Nb}$ sites of near-stoichiometric crystals, although no shift was observed for probes in $\mathrm{Li}$ sites, $v_{Q 1}=1154(12) \mathrm{MHz}$ and $v_{\mathrm{Q} 2}=1213(12) \mathrm{MHz}$. Figure 24 shows the dependence of the fractions of $\mathrm{Hf}$ on the different $\mathrm{Li}$ and $\mathrm{Nb}$ sites on the $\mathrm{MgO}$ concentration. The fraction of $\mathrm{Hf}$ occupying the $\mathrm{Nb}$ antisite (Li-II site) is constant up to $2.5 \mathrm{~mol} \% \mathrm{MgO}$ in the crystal. In this concentration range, $\mathrm{Mg}$ is exclusively located at the center of the Li octahedron. It therefore appears that $\mathrm{Mg}$ substitutes in $\mathrm{Li}_{\mathrm{Li}}$ or vacant $\mathrm{Li}$ sites, decreasing the number of Li sites available for Hf. Further, full suppression of Hf on the Li-II occurs between 4 and $6 \mathrm{~mol} \%$, the region in which the suppression of the photorefractive damage is completed.

For indium only one PIXE/C study for co-doping with $6 \mathrm{~mol} \% \mathrm{MgO}$ in melt is available [199]. The results indicate that In mainly substitutes $\mathrm{Li}$ in its regular lattice site but a fraction occupying regular $\mathrm{Nb}$ sites cannot be ruled completely. 


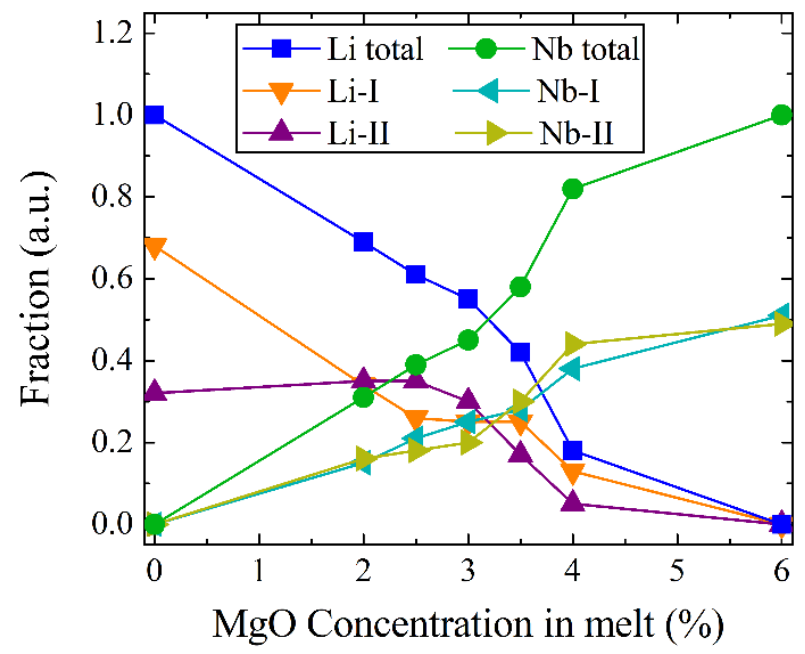

Figure 24. Dependence of the fractions of $\mathrm{Hf}$ on the different $\mathrm{Li}$ and $\mathrm{Nb}$ sites on the $\mathrm{MgO}$ concentration as determined by PAC.

\subsection{Dopants to Enhance Photorefractive Damage}

Despite the photorefractive effect being undesired for most optical applications it has an interesting application in the field of holographic recording of data [200]. Therefore also dopants that increase this effect have been the target of intense research. So far Fe has been identified as the single dopant with the most promising properties but other single dopants as $\mathrm{Mn}, \mathrm{Co}, \mathrm{Cu}, \mathrm{Ni}, \mathrm{Cr}, \mathrm{Mo}, \mathrm{Ru}, \mathrm{Rh}, \mathrm{Ce}$ and $\mathrm{Tb}$ [201-203] were investigated. Moreover, combinations of dopants, e.g., $\mathrm{LiNbO}_{3}: \mathrm{Fe}, \mathrm{Mn}[204]$ or $\mathrm{LiNbO}_{3}: \mathrm{Zr}, \mathrm{Cu}, \mathrm{Ce}$ [205] were investigated intensively.

In contrast to the suppressing dopants the incorporation of photorefractive elements has gotten rather little attention by nuclear methods. Studies exist on the technically most important dopant, iron, on cobalt and on titanium. The latter enhances the photorefractive effect only very slightly but is of importance for optical waveguide applications.

It is generally presumed that the charge state of iron $\left(\mathrm{Fe}^{2+}\right.$ or $\left.\mathrm{Fe}^{3+}\right)$ is of importance for the photorefractive efficiency. Various teams studied this topic applying Mössbauer Spectroscopy with ${ }^{57} \mathrm{Co}$ as radiation source. The first study by Vayashko et al. [206] used lithium deficient LN heavily Fe-doped (2.4 to $5.1 \mathrm{~mol} \%$ ) crystals and detected both charge states in the material. They also reported that the fraction of $\mathrm{Fe}^{2+}$ increases with increasing Li-deficiency. Further studies with diffusion-doped [43] ( 0.5 to $1.0 \mathrm{~mol} \%$ of Fe enriched to $86 \%$ in $\left.{ }^{57} \mathrm{Fe}\right)$ and melt-doped $[207,208]\left(0.22 \mathrm{~mol} \% \mathrm{Fe}_{2} \mathrm{O}_{3}\right.$ enriched to $90.7 \%$ in $\left.{ }^{57} \mathrm{Fe}\right)$ by and confirmed that a major fraction $(90 \%)$ of the iron is present as $\mathrm{Fe}^{3+}$ in the virgin material. Annealing under reducing atmosphere (in Ar at $1000{ }^{\circ} \mathrm{C}$ for $140 \mathrm{~h}$ or under vacuum at $635^{\circ} \mathrm{C}$ for $24 \mathrm{~h}$ ), changes the charge state of the majority of the dopant to $\mathrm{Fe}^{2+}$. The measurements also indicate that the Fe dopant is located on an axial site [209].

Additional Mössbauer studies addressed the electron trapping in congruent, nearstoichiometric, Mg-doped and Fe-doped LN [210,211]. It was found that the electron trapping effect by $\mathrm{Nb}$-antisite outweighs that attributed to $\mathrm{Fe}^{3+}$ despite the larger cross section of the latter. For crystals doped with $\mathrm{Mg}$ up to threshold concentration the trapping is strongly reduced. Due to Li-loss during ${ }^{57} \mathrm{Co}$ diffusion at high temperature no quantitative results could be obtained for the near-stoichiometric material.

A first study on the lattice location of Fe was performed by Rebouta et al. [212] using samples of congruent $\mathrm{LN}$ doped in melt with $0.5 \mathrm{~mol} \% \mathrm{Fe}_{2} \mathrm{O}_{3}$. Due to the growth method, Fe was mainly incorporated as $\mathrm{Fe}^{2+}$ (as was confirmed by optical absorption spectrometry) rather than in the form of $\mathrm{Fe}^{3+}$ preferred in applications using the photorefractive effect However, previous studies suggest that the lattice location should not be affected by this [213]. PIXE/C with protons was used to determine the lattice location. Although the 
use of protons produces less pronounced dips and peaks in the angular scans the results definitely show that Fe is located in the Li site.

Zaltron et al. [214] presented a PIXE/C study on Fe-diffused samples. The material was produced by coating the LN substrate with a metallic Fe film and performing a diffusion treatment for $5 \mathrm{~h}$ at $1000{ }^{\circ} \mathrm{C}$ in oxygen atmosphere. Since the resulting samples contained $\mathrm{Fe}^{3+}$, an additional treatment under reducing atmosphere $\left(96 \% \mathrm{Ar}+4 \% \mathrm{H}_{2}\right)$ for different times at $500{ }^{\circ} \mathrm{C}$ was performed in order to obtain up to $100 \% \mathrm{Fe}^{2+}$. The depth profiles of Fe before and after reduction were measured by SIMS revealing a distribution extending up $\mu \mathrm{m}$ into the bulk with a maximum concentration of about $0.9 \mathrm{~mol} \% \mathrm{Fe}$ at the surface. The distribution remained unaltered after reduction. Angular scans measured for the as-diffused $\left(1 \% \mathrm{Fe}^{2+}\right)$ and two reduced $\left(20 \%\right.$ and $\left.100 \% \mathrm{Fe}^{2+}\right)$ samples show fully overlapping Fe-PIXE curves. Despite the poor crystalline quality of the samples (Nb-RBS minimum yield of $\approx 45 \%$ in the $\langle 02 \overline{2} 1\rangle$-axis) the data indicate that $\mathrm{Fe}$ is located on the $\mathrm{Li}$ site. This confirms also the assumption that the lattice site does not depend iron being incorporated in the divalent or trivalent state.

The lattice site of Co in LN was studied by Szilagy et al. [215] in melt-doped $(0.2 \mathrm{~mol} \%$ $\mathrm{CoO}$ ) congruent material. In this case, a $\mathrm{He}^{+}$ion beam was used to obtain PIXE/C scans for $\mathrm{Co}-$ and $\mathrm{Nb}$-PIXE with pronounced dips for five major axial directions. The simultaneous recording of $\mathrm{Nb}$-RBS axial scans allowed to demonstrate the high quality of the crystals grown $\left(\chi_{\min } \approx 2 \%\right)$. Comparison of the experimental results with simulations using CASSIS demonstrated that $\mathrm{Co}$ is located exclusively on the regular Li site.

In contrast to its homologues $\mathrm{Zr}$ and $\mathrm{Hf}$, Ti does not suppress the photorefractive effect. It is therefore of interest if its behavior is linked to some different incorporation mechanism. A first study was made by Buchal et al. [216] with a sample implanted with Ti at a fluence of $2.5 \times 10^{17} \mathrm{~cm}^{-2}$ and $360 \mathrm{keV}$ energy and subjected to a heat treatment at $1000{ }^{\circ} \mathrm{C}$. This caused an almost complete recovery of the crystal structure and a diffusion of Ti in the bulk material. The maximum concentration of Ti in the samples was reported to $12 \mathrm{~mol} \%$. The PIXE/C measurements for Ti-K characteristic X-ray showed an almost perfect overlap with that of $\mathrm{Nb}$ leading to the conclusion that Ti occupies the $\mathrm{Nb}$ lattice site. Kollewe et al. [217] studied two different cases: melt-doped material with $3 \mathrm{~mol} \% \mathrm{Ti}$ and Ti-indiffused waveguides with a peak concentration of about $9 \mathrm{~mol} \%$. PIXE/C scans were recorded for various axial directions. For measurements along the $\langle 0001\rangle$-axis both samples evidence the absence of off-axis lattice sites while for the other axial directions clear differences are visible. While for the melt-doped crystal an almost complete overlap of the Ti-PIXE scan with those of the Li-NRA is found, the indiffused sample shows a behavior that resembles mainly the Nb-PIXE signal. Finally, Hauer et al. [218] reported a combined PIXE/C and PAC study for LN doped in melt with $1 \mathrm{~mol} \%$ of Ti. The angular PIXE/C scans for various axial directions confirm clearly that Ti occupies only Li sites at this concentration level and that no off-axis sites are occupied. The PAC measurements show a single QIF, $v_{Q}=15.4(2) \mathrm{MHz}$, which scales up very well with the results obtained with other probes occupying Li sites [34]. These findings led to the conclusion that $\mathrm{Ti}$ occupies solely Li-sites for lower concentrations while for higher concentrations a mixture of $\mathrm{Li}$ - and $\mathrm{Nb}$-sites has to be assumed. Ti and Hf have obviously similar tendencies in the occupation of lattice sites although with opposite influence on the photorefractive index.

\subsection{Optically Active Dopants}

The excellent linear and non-linear properties turn LN into a highly desirable host material for optically active ions. Coherent stimulated emission from the rare earths $\mathrm{Nd}$, Tm and Ho was observed in this material already in 1969 [219]. The interest on the laser applications of rare earths and $\mathrm{Cr}$ has led to innumerous studies on their optical properties in the last decades. Since these are strongly dependent on the dopant's crystallographic environment the determination of its lattice site is of outmost interest. Although some pertinent information can be obtained by spectroscopic methods the direct determination of the lattice location by ion beam methods is indispensable. The study of rare earths in LN 
by RBS/C is fostered by their larger mass in comparison to $\mathrm{Nb}$ as the heaviest component of the host material while chromium has to be investigated using PIXE/C.

For optical communications applications $\mathrm{Er}^{3+}$ has attracted interest in a wide range of laser host materials due to its IR emission at about $1.5 \mu \mathrm{m}$ coinciding with a minimum in the absorption in optical fibers. Erbium has been incorporated into LN by melt-doping, indiffusion and ion-implantation. RBS/C studies have been reported only for melt-doped $\mathrm{LN}$. The first investigation used two crystals co-doped with $0.5 \mathrm{~mol} \% \mathrm{Er}_{2} \mathrm{O}_{3}$ and 5.8 and $8.0 \mathrm{~mol} \% \mathrm{MgO}$ in melt $(0.79 \mathrm{~mol} \% \mathrm{Er}, 4.8$ and $7.5 \mathrm{~mol} \% \mathrm{Mg}$ in crystal), respectively [220,221]. Angular scans for axial directions show an exclusive occupation of the regular Li lattice site. For a second study, a series of singly-doped crystals with concentrations of $0.5,1,2,3,4$ and $5 \mathrm{~mol} \%$ in a congruent melt was grown and investigated [222]. The comparison of the experimental angular scans with simulations using the modified FLUX program confirmed that the main fraction Er is located in the Li-Octahedron but appears to be shifted form the regular site by $0.2 \AA$ towards the closest oxygen layer. The Er concentration of these sites increases at first with increasing total $\mathrm{Er}$ concentration but reaches a saturation value at about $2.5 \mathrm{~mol} \%$. The high minimum yields for Er in axial directions point out that an additional fraction of Er occupies non-axial sites but cannot be identified with the known tetrahedral site in LN. The authors claim that these sites off the c-axis cannot be seen as a new crystalline structure but are rather amorphous precipitates or defect clusters.

Another important rare earth in optical communication application is praseodymium. Crystals doped with 0.2 and $0.5 \mathrm{~mol} \% \mathrm{Pr}^{3+}$ in melt were studied by RBS/C [223-225]. The comparison of experimental scans and simulations with the FLUX code shows that as in the case of erbium Pr is located in the Li oxygen-cage but with a larger shift $(0.45 \AA)$ towards the closest oxygen layer. On the other hand, site selective spectroscopy performed on the same samples suggests that more than one site for $\mathrm{Pr}^{3+}$ exists. This discrepancy can be easily understood taking into account the defect structure of the congruent material that causes (due to vacancies and stacking faults) different local surroundings for the $\mathrm{Pr}^{3+}$ ion.

Also the lattice site of the probably most popular laser active ion, $\mathrm{Nd}$, has been investigated using RBS/C. The history of the investigation of this impurity highlights the importance of computer simulations for the interpretation of lattice location measurements in complex non-cubic crystal structures like LN. The first studies of the $\mathrm{Nd}^{3+}$ lattice sites for a $1 \mathrm{~mol} \% \mathrm{Nd}^{3+}$ in melt $(0.33 \mathrm{~mol} \%$ in the crystal) where first interpreted based on assumptions adopted from the study of simpler crystal lattice and pointed out a mixed occupation of Li- and Nb-sites [192]. Another study even claimed the occupation of three different axial lattice sites within the Li-Octahedron [226,227]. A new interpretation of the experimental results using the FLUX code revealed that $\mathrm{Nd}^{3+}$ is actually located in the Li-Octahedron displaced by $0.4 \AA$ towards the closest oxygen layer [23].

In order to complete the overview on the lanthanides it has to be mentioned that three other rare earths were also found to occupy positions shifted from the Li site towards the closest oxygen plane: $\mathrm{Eu}(0.4 \AA)[23,192,228]$, Ho $(0.38 \AA)[223,224]$ and $\mathrm{Yb}(0.3 \AA)[223,224]$. Plotting the five known displacement values against the ionic radius as suggested by Lorenzo et al. $[223,224]$, shows an apparent linear dependence, depicted in Figure 25. The measured position of the main fraction of Er [222] $(0.2 \AA)$ has been added to the Lorenzo's data.

For $\mathrm{Nd}, \mathrm{Gd}, \mathrm{Er}, \mathrm{Tm}$, and $\mathrm{Lu}$ ( $1 \mathrm{~mol} \%$ in melt) RBS/C studies on samples co-doped with $\mathrm{Mg}(6 \mathrm{~mol} \%)$ have been performed [199,221]. For Nd, Gd and Tm the angular scans show only a partial occupation of the Li octahedron. In contrast to the singly-doped crystals, remarkably large fractions of randomly incorporated ions (almost complete for $\mathrm{Nd}, 70 \%$ for $\mathrm{Gd}, 20 \%$ for Tm) are observed. Rare earths with low or no random fractions are Er and Lu. Interestingly, also the distribution coefficient of $\mathrm{Nd}$ in the $\mathrm{MgO}$ co-doped crystal, $\mathrm{k}=0.03$, is an order of magnitude lower than in the singly-doped material [192]. This indicates that the incorporation of lanthanides with large ionic radius into the LN lattice is strongly hampered by $\mathrm{Mg}$. The lattice location study for $\mathrm{Mg}$ on the $\mathrm{LiNbO}_{3}: \mathrm{Lu}, \mathrm{Mg}$ sample by Kling et al. [198] demonstrates that, in contrast to Hf-co-doping, the distribution of $\mathrm{Mg}$ in the 
lattice is identical to the singly $6 \mathrm{~mol} \% \mathrm{MgO}$-doped crystal. In the competition for the occupation of sites in the Li-Octahedron the divalent $\mathrm{Mg}$ may be favored with regard to the trivalent lanthanides since it requires less charge compensation by formation of additional Li vacancies.

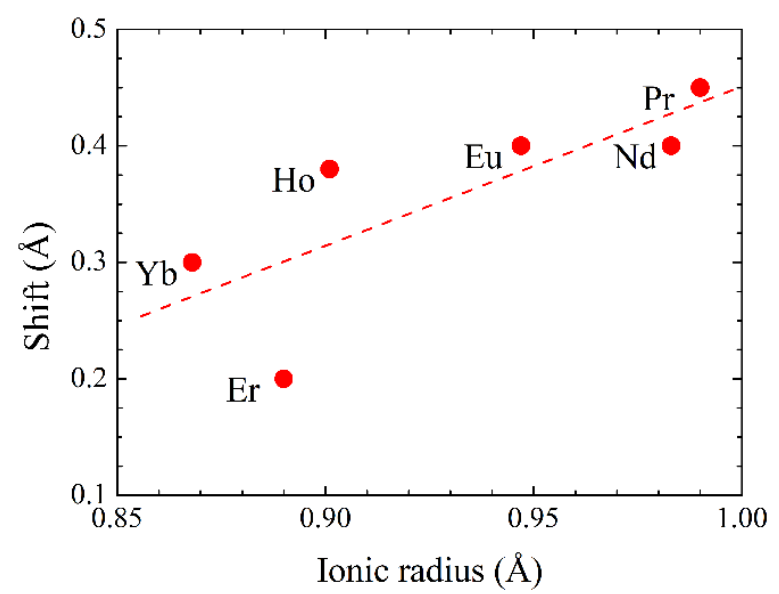

Figure 25. Dependence of the shift of the rare earth lattice sites with respect to the regular Li-site on the ionic radius.

Trivalent chromium has been already used in the very first laser as optically active ion. The potential application as a compact tunable laser initiated an intense research on the properties of Cr-doped LN. The introduction of chromium in LN with chromium can be achieved by melt doping [229,230], ion implantation [231] and diffusion [232]. Since chromium as a transition metal shows the tendency to increase the photorefractive effect the co-doping with $\mathrm{Mg}$ at high concentration is desired. However, the co-doping alters the absorption (Cr-doped LN is green, $\mathrm{Cr}-\mathrm{Mg}$-co-doped pink) and luminescence properties. Optical [233], ESR [234] and EXAFS [235] studies suggest that these effects are related to changes in the lattice site occupied by the $\mathrm{Cr}$-only Li-sites for singly-doped material, $\mathrm{Li}$ and $\mathrm{Nb}$-sites for $\mathrm{Mg}$-co-doped.

The lattice location of $\mathrm{Cr}$ was studied by PIXE/C in a congruent sample doped with $0.1 \mathrm{~mol} \% \mathrm{Cr}$ and one with $6 \mathrm{~mol} \% \mathrm{Mg}$ and $0.1 \mathrm{~mol} \% \mathrm{Cr}$ in melt [236]. The very low $\mathrm{Cr}$ dopant concentration turned to out to be extremely challenging for the experiment and a copper monolayer had to be deposited on the samples to suppress low energy X-ray emission due to charging effects by the ion beam. Nevertheless, it was possible to determine the lattice location by comparing the angular scans obtained with computer simulations using CASSIS. Surprisingly, it was found that already the singly doped crystal contains about $40 \%$ of the Cr on niobium sites and $60 \%$ on Li sites. This implies that chromium, in contrast to all other trivalent dopants studied so far, shows a tendency for charge compensation $\mathrm{Cr}_{\mathrm{Li}}^{3+}-\mathrm{Cr}_{\mathrm{Nb}}^{3+}$ replacing $\left.\mathrm{Li}^{1+}-\mathrm{Nb}^{5+}\right)$. The results align well with those of the ESR study by Jaque et al. [234] suggesting that in singly-doped material mainly $\mathrm{Cr}_{\mathrm{Li}}^{3+}-\mathrm{Cr}_{\mathrm{Nb}}^{3+}$ occur with some $\mathrm{Cr}^{3+}$ on Li-sites. For the case of the co-doped material the fraction of $\mathrm{Cr}$ located on Li sites is reduced to about $20 \%$ while $80 \%$ occupy the $\mathrm{Nb}$ octahedron although shifted about $0.1 \AA$ towards the center of the octahedron.

Waveguide lasers require only a thin near-surface with the optically active ion, instead of bulk-doping. Ion implantation is an advantageous tool to dope a material with a controllable concentration and depth distribution. In order to verify the applicability of this method y-cut LN samples were implanted with $100 \mathrm{keV} \mathrm{Cr}$ to fluences of $1 \times 10^{16}$ and $5 \times 10^{16} \mathrm{~cm}^{-2}$, respectively [115]. This resulted in a peak concentration of $2.2 \mathrm{~mol} \% \mathrm{Cr}$ for the latter fluence with a projected range of about $55 \mathrm{~nm}$. In order to remove the implantation induced lattice damage annealing was performed under wet oxygen atmosphere for various temperatures and times. The success of the annealing process was verified by RBS/C showing that for $1000{ }^{\circ} \mathrm{C}$ and $4 \mathrm{~h}$ the almost completely amorphized 
surface layer was reconstructed and the RBS/C spectra hardly distinguishable from those for virgin material. In order to verify the incorporation of chromium in the crystal lattice angular scans were taken with PIXE/C. An almost perfect overlap with the results for the melt-doped case demonstrate the successful incorporation of $\mathrm{Cr}$ into the LN crystal.

\subsection{Pentavalent and Hexavalent Dopants}

Dopants in the pentavalent state are of interest since they can replace $\mathrm{Nb}$ without need of charge compensation. However, none of the elements in the pnictogen group incorporates into the LN lattice. An alternative are the homologues of $\mathrm{Nb}, \mathrm{V}$ and Ta. The latter is known to be able to form mixed crystals covering the full stoichiometry range [237].

Since Ta has about double the atomic mass of $\mathrm{Nb}$ it was easy to study this impurity by RBS/C. The results of congruent crystal doped with $1 \mathrm{~mol} \%$ of Ta showed that the angular scans for $\mathrm{Nb}$ and Ta fully overlap for all investigated axial and planar direction evidencing that Ta fully replaces $\mathrm{Nb}$ on its lattice site [228].

Similar to the case of pnictogens, also no doping of LN with chalcogenides could be achieved. Nevertheless, three elements that readily form hexavalent oxides-Mo [238], W [239-241] and U [242] have been successfully incorporated into LN. The lattice location of latter two was subject to studies by RBS/C.

Tungsten doping was performed in three different ways: ion implantation, doping in melt and diffusion. In the first case a fluence of $1 \times 10^{14} \mathrm{~cm}^{-2}$ of ${ }^{186} \mathrm{~W}$ was implanted into $x$-cut congruent $\mathrm{LN}$ resulting in maximum $\mathrm{W}$ concentration of $1.25 \mathrm{~mol} \%$ peaking at about $50 \mathrm{~nm}$ depth [239]. In order to remove the implantation induced damage the sample was subjected to a two-step annealing process $\left(600{ }^{\circ} \mathrm{C}\right.$ for $1 \mathrm{~h}, 800{ }^{\circ} \mathrm{C}$ for $\left.4 \mathrm{~h}\right)$ in a wet flowing oxygen atmosphere. The angular scans of the recrystallized material showed a complete overlap of the $\mathrm{Nb}$ - and $\mathrm{W}$ signals for all crystallographic directions proving the complete incorporation of tungsten on the niobium site. In a second study, LN crystals were grown from melt doped with 1 and $2.5 \mathrm{~mol}_{\%} \mathrm{WO}_{3}$ [240]. The concentration in the grown samples were determined by RBS to be 0.2 and $0.5 \mathrm{~mol} \%$, respectively, fixing the distribution coefficient of tungsten to 0.2 . The RBS/C measurements confirmed the results of the ion implantation work on $\mathrm{W}$ replacing solely $\mathrm{Nb}$. In the third approach a $\mathrm{y}$-cut LN crystal was placed on a bed of metallic tungsten and kept at $1000{ }^{\circ} \mathrm{C}$ for $2.5 \mathrm{~h}$ under vacuum which yielded an extremely W-rich (about $35 \mathrm{~mol} \%$ ) layer at the surface [241]. A subsequent annealing treatment at $1000{ }^{\circ} \mathrm{C}$ for $2 \mathrm{~h}$ reduced the $\mathrm{W}$ concentration to $0.75 \mathrm{~mol} \%$ and improved the crystal quality sufficiently to perform RBS/C scans. As in the previous two cases, the exclusive occupation of $\mathrm{Nb}$ sites by $\mathrm{W}$ was observed.

For the investigation of the lattice site of uranium a crystal grown from a congruent melt doped with uranylacetate-dihydrate ( 0.5 at.\% U equivalent to roughly $2.5 \mathrm{~mol} \%$ ) was used, in which uranium should be incorporated in the hexavalent state. The samples obtained contained about $0.18 \mathrm{~mol} \% \mathrm{U}$ (distribution coefficient $\approx 0.07$ ) as determined by RBS. Optical absorption spectroscopy confirmed that uranium had been incorporated as $\mathrm{U}^{6+}$ [242]. As in the case of W the angular scans for U-RBS and W-RBS overlapped fully confirming also for uranium the occupation of the $\mathrm{Nb}$ lattice site [240]. Calvo et al. [242] observed that a heat treatment under vacuum, i.e., reducing conditions for LN, turns the U-doped crystals from orange to red. Optical absorption studies revealed the existence of trivalent (and eventually tetravalent) uranium after this treatment. In order to check if this alteration of the valence state has any influence on the lattice site of uranium RBS/C with a sample reduced for $16 \mathrm{~h}$ at $1000{ }^{\circ} \mathrm{C}$ under high vacuum were performed. The angular scans, shown in Figure 26 for various crystallographic directions, show that part of the $\mathrm{U}$ has been pushed out of the $\mathrm{Nb}$ site but is still on an axial position [243]. Employing simulations using CASSIS suggest that about $20 \%$ of the $U$ is now on Li sites while the remainder still occupies the $\mathrm{Nb}$ site. These findings corroborate the assumption that the cation lattice site occupied by ad dopant is mainly governed by its valence state. 


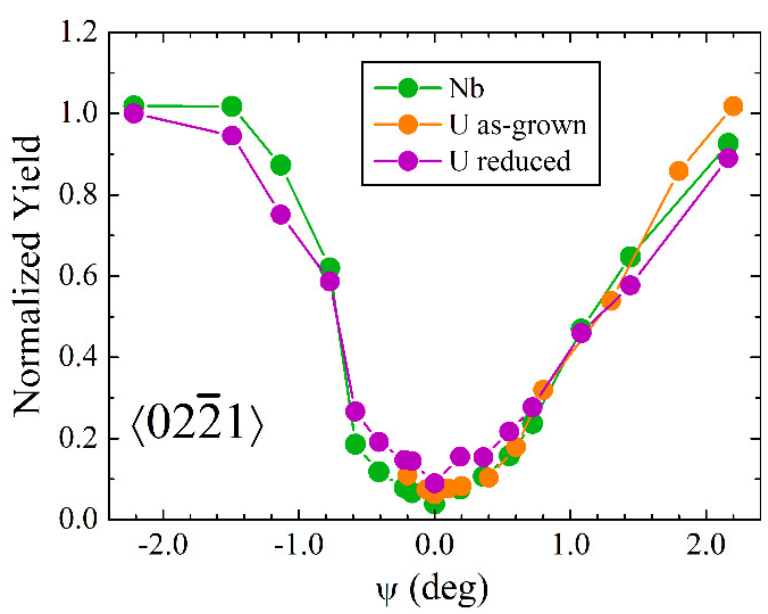

Figure 26. Angular RBS/C scans for the $\langle 02 \overline{2} 1\rangle$-axis for $\mathrm{Nb}$ and $\mathrm{U}$ in the as-grown and reduced sample. In the reduced case the narrowing of the uranium-dip near the axial direction is due to the partial occupancy of Li-sites by U.

\subsection{Noble Metals}

The introduction of noble metals into glass in order to change its color is a method applied since Roman times [244]. The coloration is due the formation of noble metal nanoparticles for which the existence of surface plasmon resonances causes strong optical absorption peaks. The associated non-linear optical properties raised the interest on formation of such nanoparticles in modern optical materials. LN can incorporate noble metals as $\mathrm{Cu}$ and $\mathrm{Au}$ only at very low concentrations in melt-doped crystals causing the absence of surface plasmon related effects. Since the first successful formation of $\mathrm{Cu}$ nanoparticles and the observation of their typical optical absorption behavior by Saito et al. [245] in 1987, this method has been applied for the production of Cu [246], Ag [247], $\mathrm{Au}$ [248] and mixed [249] nanoparticles. The influence of ion energy (20 keV-3 MeV), fluence $\left(4 \times 10^{13}-2 \times 10^{17} \mathrm{~cm}^{-2}\right)$, implantation temperature (room temperature-700 K), post-implantation treatment (annealing at various temperatures and atmospheres) on the optical properties has been studied in detail [178-181]. RBS and RBS/C was employed in several studies to investigate the distribution of the implanted species, the implantationinduced damage and its removal by annealing as well as some structural characteristics of the implanted elements.

The best investigated case is that of Au. Due its high mass it can be easily detected by RBS and the implantation-related peak in the spectrum is well separated from niobium. Shi et al. [250] demonstrated that an implantation at $1 \mathrm{MeV}$ with a fluence of $4 \times 10^{13} \mathrm{Au}^{+} \mathrm{cm}^{-2}$ only partially damages the implanted layer while for $5 \times 10^{14} \mathrm{Au}^{+} \mathrm{cm}^{-2}$ already full amorphization is achieved. Taking RBS/C spectra they were able to calculate damage depth profiles with nanometric resolution. A comparison with the popular TRIM code [251] for damage profile computation revealed that the experimentally determined damage reaches far deeper into the crystal than computed slowing down recovery of the crystal lattice during annealing. The study by Takahira et al. [252] was the first one to investigate the recrystallization of an Au-implanted $\left(550 \mathrm{keV}, 1 \times 10^{16}\right.$ to $\left.1 \times 10^{17} \mathrm{~cm}^{-2}\right) \mathrm{LN}$ crystals in detail. They showed that annealing at $600{ }^{\circ} \mathrm{C}$ for $1 \mathrm{~h}$ in air efficiently removes a large part of the damage for the sample implanted with $3.7 \times 10^{16} \mathrm{Au}^{+} \mathrm{cm}^{-2}$ —corresponding to a peak concentration of 7 at. \%. It is noteworthy that the Au implantation profile is not affected by the heat treatment.

Dev et al. [253] performed RBS/C measurements for the $\langle 0001\rangle$-axis of LN implanted with $1 \times 10^{15} \mathrm{~cm}^{-2} \mathrm{Au}(1.43 \mathrm{MeV})$ and annealed at $450{ }^{\circ} \mathrm{C}$ in flowing oxygen atmosphere for $40 \mathrm{~min}$. The curves for the $\mathrm{Nb}$ - and Au-RBS overlap mostly but show a distinct kink at about $0.5^{\circ}$ from the axial direction, ruling out a formation of nanoclusters due to a low Au concentration $(0.5 \mathrm{~mol} \%)$. This indicates that a major part of the $\mathrm{Au}$ is in axial lattice 
site but in contrast to the claims of the authors, not necessarily the $\mathrm{Nb}$-site. Due to its high atomic mass the Au-RBS scan would also overlap for $\mathrm{Li}$-, free octahedron or other aligned sites. The kink-related fraction is definitely related to a fraction on a non-axial site, possibly the tetrahedral site (although this would have to be verified by additional studies).

For a higher fluence $\left(1 \times 10^{16} \mathrm{Au}^{+} \mathrm{cm}^{-2}, 800 \mathrm{keV}\right.$, implanted at room temperature) Kling et al. [254] investigated the recrystallization of the sample after subsequent annealing at $600{ }^{\circ} \mathrm{C}(2 \mathrm{~h})$ and $800{ }^{\circ} \mathrm{C}(1 \mathrm{~h})$ in flowing wet oxygen. RBS/C measurements showed that even at $800^{\circ} \mathrm{C}$ only a partial recovery of the crystal lattice was achieved. Further, it was found that the yield for Au-RBS is reduced for the $\langle 01 \overline{1} 0\rangle$-axial direction. Since optical absorption demonstrated the formation of Au-nanoparticles in the sample an incorporation into the LN lattice was ruled out leaving only the hypothesis that the Au-cluster are aligned the with the LN lattice. Complementary studies by TEM of this sample revealed that gold did not form spherical nanoparticles as deduced from various optical investigations but thin flakes parallel to the surface with lateral dimension of up to $200 \mathrm{~nm}$. An electron diffraction measurement confirmed that these flakes are highly coherent with the LN lattice.

In another study by the same authors, the interaction between $\mathrm{Au}$ - and He-implants was in the focus of the interest [255]. All samples were implanted with $20 \mathrm{keV} \mathrm{He}^{+}$to a fluence of $1 \times 10^{16} \mathrm{~cm}^{-2}$. Au $\mathrm{u}^{+}$-implantations with $50 \mathrm{keV}\left(5 \times 10^{15} \mathrm{~cm}^{-2}\right)$ were used to obtain two well-separated profiles while others using $800 \mathrm{keV} \mathrm{Au}^{+}\left(1 \times 10^{16} \mathrm{~cm}^{-2}\right)$ achieved an overlap with the profile of He. In RBS/C spectra for the samples with separate profiles the two damage-related peaks for $\mathrm{He}$ and $\mathrm{Au}$ appear separately even after annealing at $270{ }^{\circ} \mathrm{C}$. Annealing at $600{ }^{\circ} \mathrm{C}$ causes the Au to migrate towards the bulk and broadens the profile while at $800{ }^{\circ} \mathrm{C}$ a movement of the gold towards the surface is observed. This mobility of Au contrast clearly with the static Au profiles observed for single implantation at the same temperature discussed above. Most likely the diffusion of $\mathrm{Au}$ at $600{ }^{\circ} \mathrm{C}$ is facilitated by the presence of $\mathrm{He}$ in the material but not showing a real gettering effect as in Si [256]. As in the previous case, diffusion towards the surface and an alignment of the Au-nanoparticles was found for the samples with overlapping profiles. TEM observations revealed again the existence of Au-flakes but with drastically reduced lateral sizes $(<100 \mathrm{~nm})$ compared to singly-implanted LN opening a path for the control of nanoparticle properties by co-implantation of noble gases.

For the case of Ag-implantation, Milz et al. [257] studied the influence of implantation and annealing temperatures on the damage production and removal. X-cut LN was implanted with $380 \mathrm{keV} \mathrm{Ag}^{+}$to a high fluence $\left(1 \times 10^{17} \mathrm{~cm}^{-2}\right)$ at liquid nitrogen $\left(-196^{\circ} \mathrm{C}\right)$ temperature, room temperature and $700 \mathrm{~K}\left(423^{\circ} \mathrm{C}\right)$. RBS/C spectra show that in the first two cases the implanted surface layer was completely amorphized while in the hightemperature case the layer was heavily damaged and thinner retaining some crystallinity. Rapid thermal annealing at temperatures ranging from $300-900{ }^{\circ} \mathrm{C}$ was employed for recrystallization. In the sample implanted at room temperature an increasing reduction of the amorphized layer with increasing temperature was observed but only at $900{ }^{\circ} \mathrm{C}$ a partial recovery of the crystal lattice at the surface was observed.

The interaction of Ag and O implants was the topic of a study by Williams et al. [258]. Z-cut samples were implanted with $\mathrm{Ag}$ and $\mathrm{O}$ at energies of 160 and $35 \mathrm{keV}$ and fluences of $4 \times 10^{16} \mathrm{~cm}^{-2}$ and $8 \times 10^{16} \mathrm{~cm}^{-2}$, respectively at RT and $500^{\circ} \mathrm{C}$. Both implantation sequences were used and additionally a singly $\mathrm{Ag}^{+}$implanted samples $\left(1.5 \mathrm{MeV}, 2 \times 10^{16} \mathrm{~cm}^{-2}\right.$ and $1.7 \times 10^{17} \mathrm{~cm}^{-2}$, same temperatures) were produced. The implanted material was annealed for $1 \mathrm{~h}$ at $500{ }^{\circ} \mathrm{C}$ in air. From RBS/C spectra recorded for the Ag-implanted sample it was concluded that in case of high-temperature implantation is located closer to the surface than in that for room temperature. On the other hand, during the annealing the Ag moves towards the bulk in the high-temperature sample while it approaches the surface in the RT-sample. Co-implanted material shows some difference between the two implantation sequences when the high-temperature procedure is applied. For Ag- then O-implantation the Ag-profile stays practically unaltered with most of the Ag remaining at the surface. 
For the opposite sequence, a significant Ag-diffusion towards the bulk was observed that seems to stabilize the Ag-nanoparticles formed.

The incorporation of $\mathrm{Pt}$ into $\mathrm{LN}$ was achieved by $50 \mathrm{keV} \mathrm{Pt}^{+}$ion implantation at room temperature at a fluence of $5 \times 10^{15} \mathrm{~cm}^{-2}$ [259]. A maximum concentration of about $1.5 \mathrm{~mol} \%$ of $\mathrm{Pt}$ was attained. The samples were annealed under flowing wet oxygen atmosphere at $600{ }^{\circ} \mathrm{C}$ and $800{ }^{\circ} \mathrm{C}$ for $1-6 \mathrm{~h}$ in steps of one hour or at $1000{ }^{\circ} \mathrm{C}$ for 60,90 and $120 \mathrm{~min}$. Further, an incremental annealing was done at $300^{\circ} \mathrm{C}, 400{ }^{\circ} \mathrm{C}, 450{ }^{\circ} \mathrm{C}, 500{ }^{\circ} \mathrm{C}$, $600{ }^{\circ} \mathrm{C}$ and $700{ }^{\circ} \mathrm{C}$ for $30 \mathrm{~min}$ followed by one at $1000{ }^{\circ} \mathrm{C}$ for up to $5 \mathrm{~h}$. Studying the Pt-RBS yield in the surface region $(0-10 \mathrm{~nm})$ showed no effect for $600^{\circ} \mathrm{C}$, a slight diffusion towards the bulk after $6 \mathrm{~h}$ at $800{ }^{\circ} \mathrm{C}$ and a very rapid one at $1000{ }^{\circ} \mathrm{C}$ leaving the surface region virtually without Pt. RBS/C spectra showed no alignment effect for Pt except for the sample that underwent incremental annealing. A minimum yield of $53 \%$ is observed for alignment with $\langle 01 \overline{1} 0\rangle$-axis while for all other crystallographic directions random behavior is found. It can be concluded that $\mathrm{Pt}$ forms precipitates that are preferentially aligned with the $\langle 01 \overline{1} 0\rangle$-axis of $\mathrm{LN}$ as in the case of Au.

Iridium implanted into LN $\left(130 \mathrm{keV}, 5 \times 10^{16} \mathrm{~cm}^{-2}\right)$ with a high peak concentration has been studied by Kling et al. [260] The samples were annealed under flowing wet oxygen at $500{ }^{\circ} \mathrm{C}, 800{ }^{\circ} \mathrm{C}$ and $1000{ }^{\circ} \mathrm{C}$ for $30 \mathrm{~min}$. In contrast to $\mathrm{Pt}$, significant diffusion towards the bulk was found by RBS already at $500{ }^{\circ} \mathrm{C}$. After heat treatment at $1000^{\circ} \mathrm{C}$ a practically uniform concentration of $0.015 \mathrm{~mol} \%$, i.e., about two orders of magnitude lower than in the as-implanted material, is reached. RBS/C scans show an alignment effect with the LN for all investigated axial directions with a width comparable to that of Nb-RBS. However, the high minimum yields (40-80\%) do not allow attributing positively an occupation of the $\mathrm{Nb}$-site by Ir.

\section{Optical Waveguides}

Photonic applications using optical materials like LN receive a constantly increasing interest. A key part in any photonic device is an optical waveguide. It consists of a thin surface layer (in the order of the wavelength of the light guided) with a refractive index larger than the underlying substrate. Total reflection at the interfaces with the bulk and the air confines the light propagation to the waveguide. Many different approaches for the fabrication of waveguides in LN and other optical materials have been developed in last decades. For a comprehensive review see Bazzan and Sada [261].

\subsection{Indiffusion}

The formation of LN waveguides by in-diffusion of Ti from a thin metallic layer deposited on the surface was reported for the first time by Kaminow and Carruthers [262] in 1973 and became with time the most common method. It combines a good guiding behavior with the preservation of the electro-optic properties. The downside is that $\mathrm{Ti}$, in contrast to its homologues $\mathrm{Zr}$ and $\mathrm{Hf}$, it does not suppress the photo-refractive effect.

For applications, it is of important to determine the depth profile of the in-diffused $\mathrm{Ti}$ that controls the refractive index profile of the optical waveguide. The method of choice is in this case the SIMS. The first Ti-profile measurement was performed in 1979 by Burns et al. [263]. The samples were prepared from x-cut LN coated with $17.5 \mathrm{~nm}$ of Ti and diffusing at $900-1100{ }^{\circ} \mathrm{C}$ for $6 \mathrm{~h}$ in Ar atmosphere. SIMS concentration profiles for Ti and $\mathrm{Li}$ ions for a sample treated at $1000{ }^{\circ} \mathrm{C}$ show pronounced peaks with half-width of 200-300 nm near the sample surface. A clear correlation between decreasing Ti- and increasing Li-concentration with depth is observed. These results suggest that the diffusion treatment time was too short for a sufficient redistribution of the Ti. Arizmendi et al. $[264,265]$ investigated in detail this first phase of the diffusion process combining ion beam analysis, $\mathrm{X}$-ray diffraction and electron microscopy techniques for samples indiffused in $\mathrm{Ar}$ and $\mathrm{O}_{2}$ atmospheres between 500 and $950{ }^{\circ} \mathrm{C}$. RBS/C measurements for samples annealed at $500{ }^{\circ} \mathrm{C}$ showed the formation of an amorphous $\mathrm{TiO}_{2}$-layer on the substrate and a lack of oxygen in the LN surface. For the technically more important case 
of $950{ }^{\circ} \mathrm{C}$ (30 min, dry oxygen) a $\mathrm{Ti}_{\mathrm{x}} \mathrm{Nb}_{1-\mathrm{x}} \mathrm{O}_{2}$ compound with $\mathrm{x}=0.65$ in the surface region is inferred from the RBS results in accordance with x-ray diffraction. Angular scans for several axial directions revealed that this new compound is aligned along the c-axis of the LN substrate but not with other axial directions. The authors argue that the compound formed in this step constitutes the actual source for the further in-diffusion of Ti.

Based on these observations for technical applications the diffusion treatment at high temperature and for extended time periods (up to $16 \mathrm{~h}$ ) has been adopted. Several groups reported SIMS studies on the Ti-diffusion process. Bremer et al. [266] reported a Gaussian profile peaking at the surface for Ti after indiffusion for $16 \mathrm{~h}$ under wet $\mathrm{Ar}$ atmosphere. A vast investigation of the main determining factors that govern Ti-diffusion (Ti-film thickness, diffusion temperature) has been presented by Caccavale et al. $[267,268]$. With the help of SIMS measurements on samples annealed at $900-1000{ }^{\circ} \mathrm{C}$ they could confirm that only for the highest temperature a complete indiffusion of Ti takes place while for lower temperatures an enhanced Ti-concentration near the surface is found. Further, they were able to detect a significant anisotropy in the diffusion process leading to a diffusion coefficient twice as high for z-cut material than for x-cut. Caccavale et al. [269] have given an impressive example of the lateral resolution of the SIMS technique by studying the lateral diffusion of Ti in waveguides. It was possible to determine the lateral Ti-profiles of two waveguides separated only by a few $\mu \mathrm{m}$. For near-stoichiometric LN produced by the vapor transport equilibration Zhang et al. [270] observed a diffusion profile that can rather be described by an error-function than by a Gaussian as in the congruent material.

To overcome the photorefractive effect in Ti-diffused waveguides diffusion into $\mathrm{Mg}$ doped material or $\mathrm{Mg}$ co-diffusion can be applied. The first SIMS study by Bremer et al. [271] used already Ti-diffused waveguides as described above [266]. $\mathrm{MgO}$ was deposited as Mg-source on the waveguide and indiffused at $950{ }^{\circ} \mathrm{C}$ in order to avoid further Ti-diffusion and taking into account the more rapid diffusion of $\mathrm{Mg}$. A single $\mathrm{Mg}$ diffusion treatment leads to a Gaussian distribution of the $\mathrm{Mg}$ peaking at the surface with some reduction of the Li content at the waveguide surface. Repetition of the Mg-indiffusion causes a drastic $(20 \%)$ loss of $\mathrm{Li}$ in the surface region accompanied by high Mg-peak in this region. The authors interpreted this as hint to the substitution of $\mathrm{Li}$ by $\mathrm{Mg}$ during doping. Caccavale et al. [272] concluded that the Ti-profile suffers only minor additional diffusion by $\mathrm{Mg}$ co-diffusion but that on the other hand $\mathrm{Mg}$-diffusion is clearly enhanced in comparison to an undoped crystal [273].

A comparative study on the Ti diffusion in undoped and Mg-melt-doped congruent and near-stoichiometric LN was presented by Kumar et al. [274]. Samples were indiffused at $1080^{\circ} \mathrm{C}$ for $23 \mathrm{~h}$ in dry air atmosphere. The values of the Ti-diffusion constant determined using SIMS profiles show that Ti-diffusion is slowed down in MgO-doped material for near-stoichiometric $(1 \mathrm{~mol} \% \mathrm{MgO})$ and congruent material $(5 \mathrm{~mol} \% \mathrm{MgO})$ with respect to their undoped counterparts.

An important alternative is the indiffusion of $\mathrm{Zn}$ from vapor phase into LN, reported for the first time by Herreros and Lifante [275]. Nevado et al. [276,277] produced samples indiffused at $550{ }^{\circ} \mathrm{C}$ and $700{ }^{\circ} \mathrm{C}$ with a diffusion times of $2 \mathrm{~h}$ and $8 \mathrm{~h}$, respectively. The samples were subsequently annealed for $4 \mathrm{~h}$ at the $700^{\circ} \mathrm{C}$ or $800^{\circ} \mathrm{C}$, respectively, to form the actual waveguide. As-diffused and annealed samples were investigated by SIMS and RBS. In both cases the as-diffused samples showed Zn-rich surface layers followed by a zone with decreasing $\mathrm{Zn}$ concentration. After the annealing $\mathrm{Zn}$ diffused from the Zn-rich superficial layer several $\mu \mathrm{m}$ deep into the bulk forming the actual waveguide. A further quantitative analysis was performed using HIERD [278]. This high depth-resolution quantitative technique allowed to confirm that in the as-diffused case the top layer consists of $\mathrm{LN}$ and $\mathrm{ZnNb}_{2} \mathrm{O}_{6}$ phases, i.e., a partial substitution of $\mathrm{Li}$ by $\mathrm{Zn}$ occurs. On the other hand, in the annealed sample a homogenous mixture of $\mathrm{ZnO}$ and $\mathrm{LN}$ was found on top and a $\mathrm{Zn}$-diffusion profile for the remainder of the waveguide.

For completeness, it should be mentioned, that also other elements, Sc [279] and $\mathrm{Zr}$ [280], which are candidates for waveguide formation were studied with regard to their 
diffusion properties using SIMS. Further, several studies focused on the co-diffusion of two elements: $\mathrm{Zn} / \mathrm{Ni}$ [281], Zr/Ti [282,283], Sc/Ti [283] as well as for waveguide laser applications, the important $\mathrm{Er} / \mathrm{Ti}[283,284]$.

\subsection{Proton-Exchange}

A simple alternative to metal-diffusion based waveguide production is the protonexchange (PE) technique reported in 1981 by Jackel and Rice [285], trailed by the production of the first optical waveguide in the following year [286]. Proton exchange is achieved by placing the $\mathrm{LN}$ crystal in a liquid source (most commonly melted benzoic acid) that acts as hydrogen source at elevated temperature. For a review see Cabrera et al. [287]. Unfortunately, the as-exchanged layer suffers from lattice stress and damage, as found in early RBS/C studies [288,289], which degrades the optical properties. Therefore, a subsequent annealing procedure at about $300{ }^{\circ} \mathrm{C}$ in air is employed in order to obtain a high-quality waveguide. Figure 27 shows the effect for LN proton-exchanged using benzoic acid.

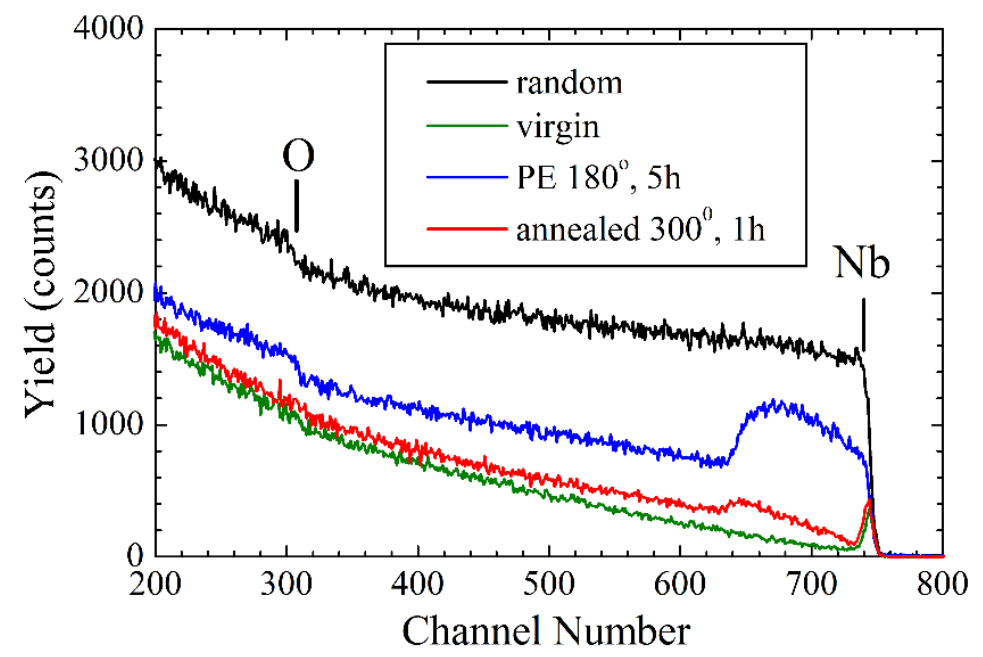

Figure 27. RBS spectra for the virgin LN (random and $\langle 01 \overline{1} 0\rangle$-axis) and after proton-exchange in benzoic acid ( $\langle 01 \overline{1} 0\rangle$-axis, as-exchanged and annealed). The clearly visible surface damage layer has a thickness of $270 \mathrm{~nm}$.

Studies of the as-exchanged layer thickness are performed by analyzing the damage profile in axially aligned directions by RBS. Changing process temperatures and times as well as the cut of the substrate allowed to determine their influence on the exchange-depth and the hydrogen diffusion coefficient. Results were reported for benzoic acid in the low $\left(110-220^{\circ} \mathrm{C}\right)$ [290] and high temperature range $\left(200-300^{\circ} \mathrm{C}\right)$ [291,292]. In accordance with the expectations, the exchange depth was found to be proportional to the square root of the exchange time while the diffusion constant follows an Arrhenius law [290] Analogue findings were reported for samples treated with sulfuric [293] and pyrophosphoric acid [294]. The comparison of channeling spectra taken before and after annealing shows a strong but incomplete recovery of the LN crystal structure [291,292,294,295].

$\mathrm{Nb}$-disorder profiles extracted from the RBS/C spectra show differences between $\mathrm{x}$ - and z-cut LN [292]. The as-exchanged z-cut material shows a low damage (up to $25 \%$ of the $\mathrm{Nb}$-atoms displaced) increasing from surface to bulk with an abrupt end. On the other hand, for x-cut material the damage was found to be constant at a high level $(80 \%)$. After annealing the damage profiles extended for both cases deeper into the bulk and interestingly, showed a smaller degree of recovery for the z-cut substrate. Olivares et al. [291] measured RBS/C spectra and angular scans for Nb-RBS along several axes in as-exchanged waveguides demonstrating high-temperature treatment leads to a superior crystal quality. Moreover, virtually no differences between samples prepared under slightly 
different conditions (addition of lithium benzoate, annealing atmosphere) were observed. The authors also performed ERD angular scans for the lattice location of hydrogen at several planar directions [291,296] — due to the need of large ion beam incidence angles $\left(\theta>70^{\circ}\right)$ for this technique no appropriate axial directions were available. A comparison of the experimental results with computer simulations based on a theoretical model proposed by Kóvacs et al. [297] (shift of $\mathrm{H}$ in c-direction by $0.1 \AA$, in y-direction $\approx 1 \AA$ ) revealed a good agreement. Although somewhat ambiguous, these results support clearly support the formation of $\mathrm{O}-\mathrm{H}$ suggested by theory.

As in the case of Ti-diffusion the actual elemental profiles within the waveguide are of outmost interest for establishing a correspondence with refractive index profile. Suitable nuclear depth profiling techniques employed in proton-exchanged LN for hydrogen are ERD, NRA and SIMS, for lithium NRA and SIMS and for oxygen SIMS.

Canali et al. [289] measured the $\mathrm{H}$ and $\mathrm{Li}$ depth profiles of as-exchanged layers using nuclear reactions. In the case of hydrogen profiling was done with the ${ }^{15} \mathrm{~N}(\mathrm{p}, \alpha \gamma){ }^{12} \mathrm{C}$ reaction that allows due to its resonant character a very high depth resolution; Li-profiles were taking using the non-resonant ${ }^{7} \mathrm{Li}(\mathrm{p}, \alpha)^{4} \mathrm{He}$ reaction that allows only moderate depth resolution. The hydrogen profiles overlap with the damage depth observed in the RBS/C. The Li-NRA spectra reveal a 70\% reduction of lithium in the treated layer corroborating that indeed an exchange reaction between $\mathrm{Li}$ and $\mathrm{H}$ takes place. Additional SIMS studies by the authors confirmed these results. Hsu et al. [295] verified the depletion in as-exchanged layers and demonstrated that after annealing a partial recovery of the Li concentrations occurs although a thin surface layer stays poor in lithium. Resonant NRA depth profiling by Ito and Kawamoto [298] revealed a reduction of the H-concentration in the surface after annealing and further diffusion into the bulk out of the depth region accessible by this method.

Rottschalk et al. [299] employed ERD for the $\mathrm{H}$ depth profiling of PE waveguides (benzoic acid, $180^{\circ} \mathrm{C}, 5 \mathrm{~h}$ or $250{ }^{\circ} \mathrm{C}, 1 \mathrm{~min}$ ) in as exchanged state and after annealing at various temperatures. Despite the extremely short treatment time, it was clearly visible that higher temperature yielded a higher hydrogen surface concentration. As expected, the hydrogen diffuses more rapidly with increasing annealing temperature reducing its concentration at the surface. The work of Hagner and Bachmann [300] investigated the $\mathrm{H}$-concentration in the as-exchanged waveguide in dependence of the amount of lithium benzoate admixture to the benzoic acid used in the process. The ERD spectra showed a reduction of the hydrogen incorporation into the layer with otherwise identical conditions.

Hydrogen profiles in PE-LN layers (benzoic acid, $185^{\circ} \mathrm{C}, 70 \mathrm{~min}$ ) annealed at $400{ }^{\circ} \mathrm{C}$ for 6-180 min were obtained by Casey et al. [301] and Zavada et al. [302] using SIMS. The measured $\mathrm{H}$ concentration profiles had to be fit using two Gaussian diffusion profiles which suggest the existence of two different types of hydrogen diffusion with distinct diffusion coefficients. The authors suggest that the fast component is related to interstitial diffusion while the slower represents substitution of lithium by hydrogen. De Souza et al. [303,304] confirmed and quantified the fractions of these two different species of hydrogen with NMR measurements for several exchange conditions. In a second study [305] the authors succeeded to separate the signal origination from the "static" hydrogen and compared the results with calculations for four defect models. The best agreement was found for $\mathrm{H}$ occupying a position within an oxygen plane along a side of an oxygen triangle equidistant from two oxygen atoms.

Yamamoto and Taniuchi [306] as well as Cheng et al. [307] reported SIMS-based hydrogen profiles for the alternative pyrophosphoric acid exchange method and show that the profiles obtained are very similar to those of samples using the common benzoic acid.

\subsection{Ion Implantation}

Among the waveguide fabrication techniques ion implantation is the one that can be applied to largest variety of materials. For comprehensive reviews see Chen et al. [308] and Peña-Rodriguez et al. [309]. As discussed in Section 3.3 defects are produced by 
electronic and nuclear interactions. In many cases, these defects cause an alteration of the refractive index forming an optical waveguide. The first successful waveguide formation using ion implantation was reported by Destefanis et al. [310]. For waveguides based on nuclear damage induced defects the quality of the waveguides is improved by an annealing procedure to remove electronic damage in the light guiding layer but leaving the buried damage layer intact. In the meantime, waveguide formation based on electronic damage production gained importance with many ions reported to be useful: $\mathrm{B}, \mathrm{C}, \mathrm{N}, \mathrm{O}, \mathrm{F}, \mathrm{Si}, \mathrm{P}, \mathrm{Ti}$, $\mathrm{Cu}, \mathrm{Ni}$, and $\mathrm{Ag}$.

Barfoot et al. [311] studied the damage built-up during implantation with $1 \mathrm{MeV}$ $\mathrm{He}^{+}\left(2.0 \times 10^{15}\right.$ and $\left.2.4 \times 10^{16} \mathrm{~cm}^{-2}\right)$ and annealing induced recovery by in-situ RBS/C. Varying the implantation temperature between 40 and $140{ }^{\circ} \mathrm{C}$ resulted in a decrease of the $\mathrm{Nb}$-lattice disorder with increasing temperature. In all cases a saturation of the damage was observed at about $1 \times 10^{16} \mathrm{He}^{+} \mathrm{cm}^{-2}$ coinciding with the value found for optimal waveguide performance. Further, the best annealing temperature was determined to be about $180^{\circ} \mathrm{C}$. Williams et al. [312] investigated similar waveguides (implanted with $1.7 \mathrm{MeV} \mathrm{He}{ }^{+}, 1.5 \times 10^{15}$ and $2.0 \times 10^{16} \mathrm{~cm}^{-2}$, RT; annealed at $175^{\circ} \mathrm{C}$ and $400{ }^{\circ} \mathrm{C}$ ) by NRA using the ${ }^{7} \mathrm{Li}(\mathrm{p}, \alpha)^{4} \mathrm{He}$ reaction. A comparison indicated among the NRA/C spectra indicated a lithium movement towards the nuclear damage region during annealing. The authors suggest that this effect is responsible for the increase in the extraordinary index in the surface region.

Low-energy $\mathrm{He}^{+}$-implantation $\left(50 \mathrm{keV}, 2.0 \times 10^{15}\right.$ and $\left.2.4 \times 10^{16} \mathrm{~cm}^{-2}\right)$ performed at temperatures of $-80{ }^{\circ} \mathrm{C},-30{ }^{\circ} \mathrm{C}, 25{ }^{\circ} \mathrm{C}$ and $80^{\circ} \mathrm{C}$ has been studied by Al-Chalabi et al. [313] employing RBS/C and HIERD. The damage in the sample implanted at $-80^{\circ} \mathrm{C}$ appeared strongly enhanced while no difference between those implanted at $-30^{\circ} \mathrm{C}$ and $80^{\circ} \mathrm{C}$ was detected. Li- and H-profiles obtained from the HIERD data indicate a loss of lithium in the implanted layer that is compensated by the incorporation of hydrogen. The lithium concentration reduction was found to increase with increasing fluence and implantation temperature.

Kling et al. [314] studied the annealing temperature dependence of the lattice damage in y-cut LN using RBS/C. Samples were implanted at room temperature with $20 \mathrm{keV} \mathrm{He}^{+}$ to a fluence of $1 \times 10^{16} \mathrm{~cm}^{-2}$ or with $25 \mathrm{keV} \mathrm{Li}^{+}\left(1 \times 10^{16} \mathrm{~cm}^{-2}\right)$ - that yield the same damage profile-in order to check for the chemical influence of the implant. Annealing was performed under wet oxygen atmosphere for $10 \mathrm{~min}$ at five different temperatures (150-350 $\left.{ }^{\circ} \mathrm{C}\right)$. At first, an increase of the damage during the heat treatment was observed with increasing temperature reaching a maximum at $270{ }^{\circ} \mathrm{C}$ with an apparent activation energy of $0.14 \mathrm{eV}$, as depicted in Figure 28. For Li-implanted samples an almost complete recovery of the lattice has been observed at this temperature indicating that He-implantation induces fundamentally different damage structures. A further increase of temperature induced a decrease in the number of defects with a much larger activation energy of $1.3 \mathrm{eV}$. This two-phase behavior resembles closely that observed for He-implantation in silicon [315]. An additional TEM study on the same samples annealed at $270{ }^{\circ} \mathrm{C}$ revealed the existence of platelet voids in the depth region at which the He ions were stopped. This region forms naturally a layer of low refractive index.

The annealing behavior of LN implanted with $800 \mathrm{keV} \mathrm{He}^{+}$ions at very low temperature $\left(-173^{\circ} \mathrm{C}\right)$ to fluences of $5 \times 10^{15}$ and $1 \times 10^{16} \mathrm{~cm}^{-2}$ was the topic of a study of Gischkat et al. [316]. RBS/C measurements were performed at implantation temperature, at room temperature and after heat treatments at $250{ }^{\circ} \mathrm{C}$ and $300{ }^{\circ} \mathrm{C}$ in air. An apparently higher defect concentration observed in $\mathrm{x}$-cut samples with respect to $\mathrm{z}$-cut material was observed. As discussed in the Section 3.3 this anisotropy is due to the dislocation of $\mathrm{Nb}$ to the free octahedron site during implantation leading to different defect geometries in terms of channeling for the two directions. The dechanneling effect due to defects was observed to decrease with heat treatment for the low-fluence case and to increase for the high-fluence case. In the latter case, the enhancement was attributed to the formation of dislocation loops. 
a)

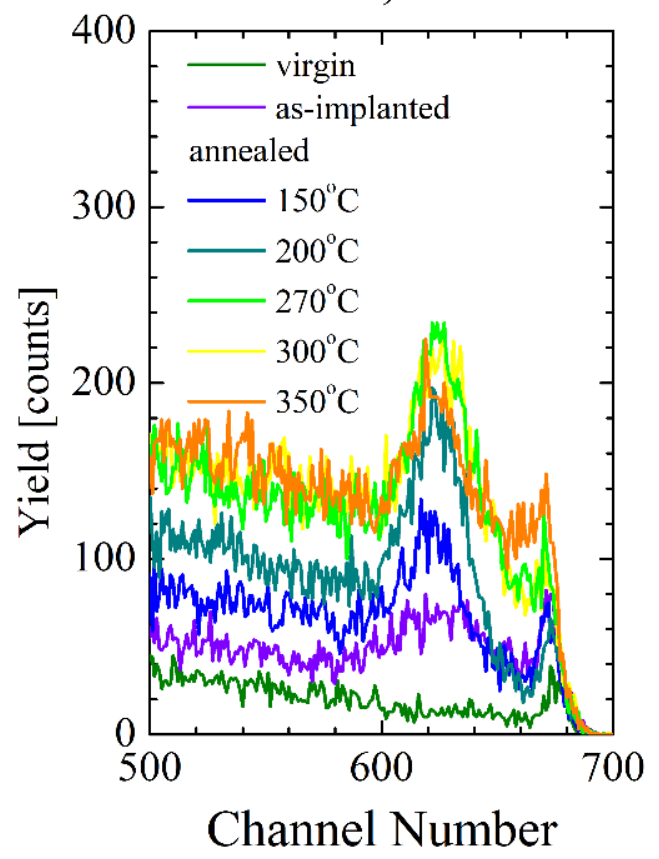

b)

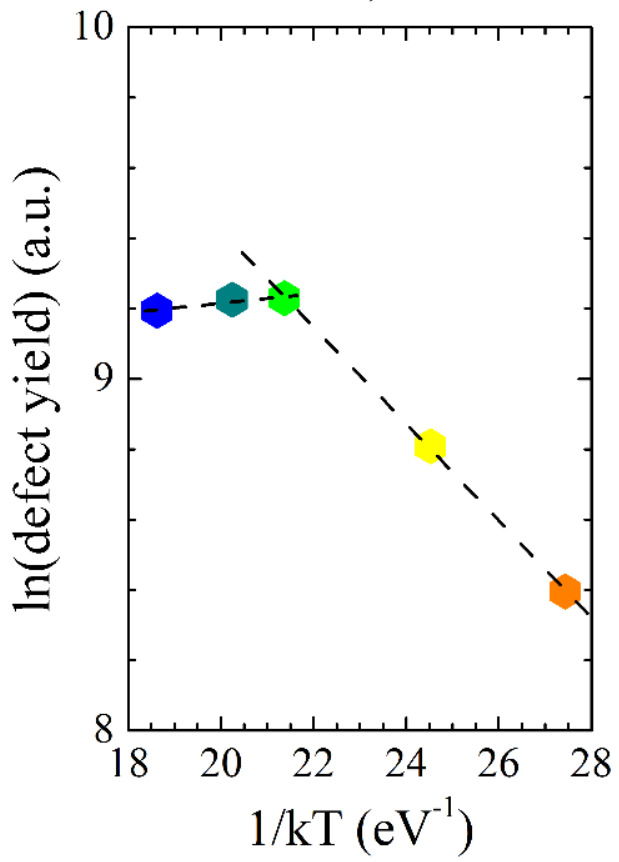

Figure 28. (a) Channeling spectra of virgin, He-implanted and annealed LN in the defect area. (b) Arrhenius plot for the determination of the apparent activation energies.

Besides helium, the implantation of nitrogen has already been explored in 1980s with view to its applications in optical waveguides $[99,100]$. Damage profiles for samples implanted with $200 \mathrm{keV} \mathrm{N}{ }^{+}$with fluences between $5 \times 10^{14}$ and $2 \times 10^{16} \mathrm{~cm}^{-2}$ were determined by RBS/C and correlated with the refractive index of the material. The formation of optically isotropic waveguide by amorphization due to electronic damage formation of a surface layer by implantation of high-energy ( $5 \mathrm{MeV}$ and $7.5 \mathrm{MeV}) \mathrm{Si}^{+}$ions has been studied by Olivares et al. [117,317]. From RBS/C spectra for samples implanted with fluences ranging from $5 \times 10^{13}$ to $1 \times 10^{15} \mathrm{~cm}^{-2}$ the authors determined threshold values for the amorphization and the associated electronic stopping power. Similar studies have also been performed for $\mathrm{H}$ [318], $\mathrm{O}$ [111,319-321] and $\mathrm{F}$ [116].

Optical waveguides can also be formed by high-fluence implantation of Ti with subsequent annealing/diffusion treatment. Bremer et al. [322] implanted y-cut LN with $200 \mathrm{keV}$ Ti to fluences of $2.5 \times 10^{17} \mathrm{~cm}^{-2}$ and $4 \times 10^{17} \mathrm{~cm}^{-2}$ at liquid nitrogen temperature, room temperature and $350{ }^{\circ} \mathrm{C}$. The samples underwent subsequent heat treatment at $1000{ }^{\circ} \mathrm{C}$ under wet oxygen atmosphere for 2 to $8 \mathrm{~h}$. RBS/C studies demonstrated a good crystal lattice recovery was achieved in all cases for long annealing times but that a higher implantation temperature favors the recrystallization process. Optical waveguide properties were observed for all samples.

A technique related to implantation is ion beam mixing. A LN sample plated with a $40 \mathrm{~nm}$ metallic Ti layer has been irradiated with $3 \mathrm{MeV} \mathrm{Ti}^{+}$ions at a fluence of $1 \times 10^{16} \mathrm{~cm}^{-2}$ by Bremer et al. [266]. After removal of excess Ti from the surface the sample was annealed at $1000{ }^{\circ} \mathrm{C}$ under wet oxygen atmosphere to achieve recrystallization. The SIMS profile measurement showed a Ti profile with a steady slope reaching deep into the bulk material which differs strongly from the Gaussian profiles found in indiffused waveguides.

\subsection{Combination of Techniques}

The combination of the proton-exchange and the implantation technique produces interesting results. For samples subjected first to a $\mathrm{He}^{+}$implantation $\left(200 \mathrm{keV}, 3 \times 10^{16} \mathrm{~cm}^{-2}\right)$ and then undergoing a proton exchange treatment the hydrogen indiffusion is strongly enhanced [323]. It appears that the damage introduced by ion implantation process facilitates 
the incorporation of the hydrogen. For the inverse treatment sequence, it was observed that a proton-exchanged sample subsequently implanted with $6 \mathrm{MeV} \mathrm{O}^{+}$at a fluence of $6 \times 10^{14} \mathrm{~cm}^{-2}$ is fully amorphized while PE-only and implantation-only samples show only minor damage [324]. Obviously, the proton-exchange process leads to a more fragile lattice increasing the susceptibility to lattice disorder.

\subsection{Interaction with Optical Active Dopants}

For optical waveguide lasers the absence of interferences between the waveguide formation process and the optically active dopants is mandatory. Therefore lattice site location and crystal structure studies for several rare earths in bulk and processed waveguide materials have been performed. Herreros et al. [325,326] compared the lattice sites for $\mathrm{LiNbO}_{3}: \mathrm{Tm}, \mathrm{Mg}$ and $\mathrm{LiNbO}_{3}: \mathrm{Er}, \mathrm{Mg}$ in as-grown and ion-implanted (2.6 and $2.0 \mathrm{MeV}$ $\mathrm{He}^{+}$, respectively, $2 \times 10^{16} \mathrm{~cm}^{-2}$; annealing: $250{ }^{\circ} \mathrm{C}, 30 \mathrm{~min}$, air) samples. Angular scans for an axial direction demonstrated that the lattice sites of Tm and Er stay unaltered after waveguide fabrication. The same authors also studied the structural differences in waveguides fabricated by proton-exchange (benzoic acid, $300{ }^{\circ} \mathrm{C}, 20 \mathrm{~h}$ ) and by $\mathrm{He}^{+}$implantation $\left(2 \mathrm{MeV}, 2 \times 10^{16} \mathrm{~cm}^{-2}\right)$ in $\mathrm{LiNbO}_{3}: \mathrm{Nd}, \mathrm{Mg}$ using RBS/C. Again, the results show that ion-implanted waveguides essentially maintain their properties while proton-exchanged present a larger deterioration [327]. Cajzl et al. [328] reported on the influence of the three waveguide fabrication methods (Ti-diffusion, proton-exchange and ion implantation) on the lattice site of erbium. Angular RBS scans confirm that none of the methods has any measurable influence on the position of the Er. These results indicate that rare-earth ions are successfully incorporated of into LN waveguides.

\section{Conclusions}

The relevance of nuclear techniques in the investigation of defect structures in modern materials has been demonstrated for the case of LN, presently one of the most important optoelectronic materials. It has been shown that the techniques originally developed for a simple crystal system can be successfully transferred to complex cases.

In the case of the intrinsic defect structure of congruent LN the combination of Ion Beam Analysis and Perturbed Angular Correlation studies delivered evidence for an additional lattice site in the Li-Octahedron. The features of this site observed by nuclear techniques support the interpretation that the excess $\mathrm{Nb}$ is incorporated through ilmenitetype stacking faults dispersed in the crystal lattice.

Channeling measurements are found to be the method of choice for the characterization of ion implantation induced damage and its recovery laying the basis for the theoretical interpretation of damage formation in oxides.

The determination of lattice sites for a large number of elements, including the role of co-doping furnishes pertinent information for future engineering of LN by introduction of foreign atoms. It was demonstrated that the main factor determining the occupation of a Lior a $\mathrm{Nb}$-octahedron by a dopant is the valence state. Divalent, trivalent and tetravalent ions occupy-with the single exception of $\mathrm{Cr}$, the Li-Octahedron, pentavalent and hexavalent the $\mathrm{Nb}$.

Depth profiling and defect characterization in optical waveguides by ion beam methods is essential for the development of opto-electronic devices.

Author Contributions: Conceptualization, writing, review and editing: A.K., J.G.M. All authors have read and agreed to the published version of the manuscript.

Funding: This research was partially funded by Fundação para a Ciência e Tecnologia, Portugal, through project UIDB/04349/2020 of Centro de Ciências e Tecnologias Nucleares.

Institutional Review Board Statement: Not applicable.

Informed Consent Statement: Not applicable.

Data Availability Statement: Not applicable. 


\begin{abstract}
Acknowledgments: The authors gratefully acknowledge José Carvalho Soares (University of Lisbon, Portugal) and Fernando Agulló-López (Universidad Autónoma de Madrid, Spain) for their guidance and support. Juan Antonio Sanz-García, Maria Dolores Serrano and Ernesto Diéguez (Universidad Autónoma de Madrid, Spain) and Barbara Christa Grabmaier (Siemens AG, Germany), Ágnes Péter and Katalin Polgár (Hungarian Academy of Sciences, Hungary) are gratefully acknowledged for the many high-quality lithium niobate crystals supplied over the years. Reiner Vianden (HelmholtzInstitut für Strahlen- und Kernphysik, University of Bonn, Germany) is gratefully acknowledged for the local support to perform PAC measurements. Pier Giorgio Rancoita (Istituto Nazionale di Fisica Nucleare, Milano-Bicocca, Italy) is gratefully acknowledged for granting access to the SR-NIEL web platform.
\end{abstract}

Conflicts of Interest: The authors declare no conflict of interest.

\title{
References
}

1. Kong, Y.; Bo, F.; Wang, W.; Zheng, D.; Liu, H.; Zhang, G.; Rupp, R.; Xu, J. Recent progress in lithium niobate: Optical damage, defect simulation, and on-chip devices. Adv. Mater. 2020, 32, 1806452. [CrossRef]

2. Volk, T.; Wöhlecke, M. Lithium Niobate: Defects, Photorefraction and Ferroelectric Switching; Springer: Berlin, Germany, 2008.

3. Shur, V.Y.; Akhmatkhanov, A.R.; Baturin, I.S. Micro- and nano-domain engineering in lithium niobate. Appl. Phys. Rev. 2015, 2, 040604. [CrossRef]

4. Arizmendi, L. Photonic applications of lithium niobate crystals. Phys. Stat. Sol. 2004, 201, 253-283. [CrossRef]

5. Alford, T.L.; Feldman, L.C.; Mayer, J.W. Fundamentals of Nanoscale Film Analysis; Springer Science and Business Media Inc.: Berlin/Heidelberg, Germany, 2007; ISBN 978-0-387-29260-1.

6. Nastasi, M.; Mayer, J.W.; Wang, Y. (Eds.) Ion Beam Analysis-Fundamentals and Applications; CRC Press: Boca Raton, FL, USA; Taylor \& Francis Group: Boca Raton, FL, USA, 2014; ISBN 978-1-4398-4639-1.

7. Nastasi, M.; Wang, Y. (Eds.) Handbook of Modern Ion Beam Materials Analysis, 2nd ed.; Cambridge University Press: Cambridge, UK, 2010; Volume 2, ISBN 9781605112176.

8. Verma, H.R. Atomic and Nuclear Analytical Methods; Springer: Berlin, Germany, 2007; ISBN 3-540-30277-8.

9. Chu, W.-K.; Mayer, J.W.; Nicolet, M.A. Backscattering Spectrometry; Elsevier Inc.: Amsterdam, The Netherlands, 1978; ISBN 978-0-12-173850-1.

10. Amsel, G.; Lanford, W.A. Nuclear Reaction Techniques in Materials Analysis. Ann. Rev. Nucl. Part. Sci. 1984, 34, 435-460. [CrossRef]

11. Johansson, S.A.E.; Campbell, J.L. (Eds.) Particle-Induced X-Ray Emission Spectrometry (PIXE); Wiley \& Sons: Hoboken, NJ, USA, 1995; ISBN 978-0-471-58944-0.

12. Gemmell, D.S. Channeling and Related Effects in the Motion of Charged Particles through Crystals. Rev. Mod. Phys. 1974, 46, 129-235. [CrossRef]

13. Morgan, D.V. Channeling: Theory, Observation and Applications; Wiley \& Sons: Hoboken, NJ, USA, 1973; ISBN 978-0471615101.

14. Van der Heide, P. Secondary Ion Mass Spectrometry: An Introduction to Principles and Practices; Wiley \& Sons: Hoboken, NJ, USA, 2014; ISBN 978-1-118-48048-9.

15. Lanford, W.A. Analysis for Hydrogen by Nuclear Reaction and Energy Recoil Detection. Nucl. Instr. Meth. B 1992, 66, 65-82. [CrossRef]

16. Bik, W.M.A.; Habraken, F.H.P.M. Elastic Recoil Detection. Rep. Prog. Phys. 1983, 56, 859-902. [CrossRef]

17. Geiger, H.; Marsden, E. On a diffuse reflection of the $\alpha$-particles. Proc. R. Soc. Lond. A 1909, 82, 495-500. [CrossRef]

18. Doolittle, L. Algorithms for the rapid simulation of Rutherford backscattering spectra. Nucl. Instr. Meth. B 1985, 9, 344-351. [CrossRef]

19. Barradas, N.P.; Jeynes, C.; Webb, R.P. Simulated annealing analysis of Rutherford backscattering data. Appl. Phys. Lett. 1997, 71, 291-293. [CrossRef]

20. Swanson, M. The Study of Lattice Defects by Channeling. Rep. Prog. Phys. 1982, 45, 47-93. [CrossRef]

21. Gärtner, K. Modified master equation approach of axial dechanneling in perfect compound crystals. Nucl. Instr. Meth. B 2005, 227, 522-530. [CrossRef]

22. Smulders, P.J.M.; Boerma, D.O. Computer Simulation of Channeling in Single Crystals. Nucl. Instr. Meth. B 1987, 29, 471-489. [CrossRef]

23. Rebouta, L.; Smulders, P.J.M.; Boerma, D.O.; Agulló-López, F.; da Silva, M.F.; Soares, J.C. Ion-Beam Channeling Yields of Host and Impurity Atoms in $\mathrm{LiNbO}_{3}$ : Computer Simulation. Phys. Rev. B 1993, 48, 3600-3610. [CrossRef]

24. Kling, A. CASSIS-A New Monte-Carlo Computer Program for Channeling Simulation of RBS, NRA and PIXE. Nucl. Instr. Meth. B 1995, 102, 141-144. [CrossRef]

25. Kling, A.; Soares, J.C.; da Silva, M.F. Computer Simulation of Channeling Spectra with the CASSIS Program. Rad. Eff. Def. Solids 1997, 141, 53-61. [CrossRef]

26. Kling, A.; Soares, J.C.; da Silva, M.F. Simulation of Channeling in Crystals with Defects Using the CASSIS Code. Nucl. Instr. Meth. $B$ 1999, 153, 457-460. [CrossRef] 
27. Kling, A. The refurbished CASSIS code for channeling simulations. Nucl. Instr. Meth. B 2012, 273, 88-90. [CrossRef]

28. Soares, J.C. Microscopic characterization of materials by ion beam and hyperfine interaction analysis. Nucl. Instr. Meth. B 1992, 64, 215-220. [CrossRef]

29. Marques, J.G.; Correia, J.G.; Melo, A.A.; da Silva, M.F.; Soares, J.C. A four-detector spectrometer for $\mathrm{e}^{-}-\gamma$ PAC on-line with the ISOLDE-CERN isotope separator. Nucl. Instr. Meth. B 1995, 99, 645-648. [CrossRef]

30. Fernandes, A.C.; Santos, J.P.; Marques, J.G.; Kling, A.; Ramos, A.R.; Barradas, N.P. Validation of the Monte Carlo model supporting core conversion of the Portuguese Research Reactor (RPI) for neutron fluence rate determinations. Ann. Nucl. Ener. 2010, 37, 1139-1145. [CrossRef]

31. Marques, J.G.; Kling, A.; de Jesus, C.M.; Soares, J.C.; da Silva, M.F.; Diéguez, E.; Agulló-López, F. Annealing recovery of neutron irradiated $\mathrm{LiNbO}_{3}: \mathrm{Hf}$ single crystals. Nucl. Instr. Meth. B 1998, 141, 326-331. [CrossRef]

32. Schatz, G.; Weidinger, A. Nuclear Condensed Matter Physics; John Wiley and Sons: Chichester, UK, 1996 ; ISBN 0471954799.

33. Schwarz, K.; Blaha, P. Electronic structure of solids and surfaces with WIEN2k. In Practical Aspects of Computational Chemistry I; Leszczynski, J., Shukla, M., Eds.; Springer: Berlin, Germany, 2012; pp. 191-207.

34. Marques, J.G.; Lorenz, K. Lattice location of $\mathrm{Hf}$ and its interaction with other impurities in $\mathrm{LiNbO}_{3}$ : A review. Opt. Eng. 2014, 53, 060901. [CrossRef]

35. Reisman, A.; Holtzberg, F. Heterogeneous Equilibria in the Systems $\mathrm{Li}_{2} \mathrm{O}-, \mathrm{Ag}_{2} \mathrm{O}-\mathrm{Nb}_{2} \mathrm{O}_{5}$ and Oxide-Models. J. Am. Chem. Soc. 1958, 80, 6503-6507. [CrossRef]

36. Peterson, G.E.; Bridenbaugh, P.M.; Green, P. NMR study of ferroelectric $\mathrm{LiNbO}_{3}$ and $\mathrm{LiTaO}_{3}$ I. J. Chem. Phys. 1967, 46, 4009-4014. [CrossRef]

37. Peterson, G.E.; Bridenbaugh, P.M. NMR study of ferroelectric $\mathrm{LiNbO}_{3}$ and $\mathrm{LiTaO}_{3}$ II. J. Chem. Phys. 1968, 48, 3402-3406. [CrossRef]

38. Peterson, G.E.; Carruthers, J.R. ${ }^{93} \mathrm{Nb}$ NMR as a sensitive and accurate probe of stoichiometry in $\mathrm{LiNbO}_{3}$ crystals. J. Sol. State Chem. 1969, 1, 98-99. [CrossRef]

39. Halstead, T.K. Temperature dependence of the Li NMR spectrum and atomic motion in LiNbO3. J. Chem. Phys. 1970, 53, 3427-3435. [CrossRef]

40. Blümel, J.; Born, E.; Metzger, T. Solid state NMR study supporting the lithium vacancy defect model in congruent lithium niobate. J. Phys. Chem. Sol. 1994, 55, 589-593. [CrossRef]

41. Burns, G. Nuclear quadrupole resonance of Li in ferroelectric compounds. Phys. Rev. 1962, 127, 1193-1197. [CrossRef]

42. Schempp, E.; Peterson, G.E.; Carruthers, J.R. ${ }^{93} \mathrm{Nb}$ nuclear quadrupole resonance investigation of LiNbO 3 . J. Chem. Phys. 1970, 53, 306-311. [CrossRef]

43. Keune, W.; Date, S.K.; Dézsi, I.; Gonser, U. Mössbauer-effect study of $\mathrm{Co}^{57}$ and $\mathrm{Fe}^{57}$ impurities in ferroelectric LiNbO 3 . J. Appl. Phys. 1975, 46, 3914-3924. [CrossRef]

44. Peterson, G.E.; Carnevale, A. ${ }^{93} \mathrm{Nb}$ NMR linewidths in nonstoichiometric lithium niobate. J. Chem. Phys. 1972, 56, $4848-4851$. [CrossRef]

45. Douglass, D.C.; Peterson, G.E.; McBrierty, V.J. Reexamination of the local electric field gradients in LiNbO 3 . Phys. Rev. B 1989, 40, 10694-10703. [CrossRef] [PubMed]

46. Yatsenko, A.Y.; Ivanova, E.N.; Sergeev, N.A. NMR Study of Defects in Congruent $\mathrm{LiNbO}_{3}$. 1. “Unoverlapping” Defects. Phys. B 1997, 240, 254-262. [CrossRef]

47. Yatsenko, A.Y.; Ivanova-Maksimova, H.M.; Sergeev, N.A. NMR Study of Intrinsic Defects in Congruent LiNbO 3 . 2. "Overlapping” Defects. Physica B 1998, 254, 256-259. [CrossRef]

48. Yatsenko, A.; Maksimova, H.; Sergeev, N.A. NMR Study of Intrinsic Defects in Congruent Lithium Niobate. Cryst. Res. Technol. 1999, 34, 709-713. [CrossRef]

49. Rebouta, L.; Da Silva, M.F.; Soares, J.C.; Sanz-Garcia, J.A.; Diéguez, E.; Agulló-López, F. Combined RBS/Channeling and PAC studies of hafnium doped $\mathrm{LiNbO}_{3}$. Nucl. Instr. Meth. B 1990, 45, 495-498. [CrossRef]

50. Catchen, G.L.; Spaar, D.M. Order-disorder effects in the phase transitions of $\mathrm{LiNbO}_{3}$ and $\mathrm{LiTaO}_{3}$ measured by perturbed-angularcorrelation spectroscopy. Phys. Rev. B 1991, 44, 12137-12145. [CrossRef] [PubMed]

51. Davis, J.; Tinet, D.; Fripiat, J.J.; Amarilla, J.M.; Casal, B.; Ruis-Hitzky, E. ${ }^{51} \mathrm{~V}$ and ${ }^{93} \mathrm{Nb}$ high resolution $\mathrm{NMR}$ study of $\mathrm{NbVO}_{5} . J$. Mat. Res. 1991, 6, 393-400. [CrossRef]

52. Lapina, O.B.; Khabibulin, D.F.; Romanenko, K.V.; Gan, Z.; Zue, M.G.; Krasil'nikov, V.N.; Federov, V.E. ${ }^{93} \mathrm{Nb}$ NMR chemical shift scale for niobia systems. Sol. State Nucl. Magn. Resonance 2005, 28, 204-224. [CrossRef]

53. Hauer, B.; Vianden, R.; Marques, J.G.; Barradas, N.P.; Correia, J.G.; Melo, A.A.; Soares, J.C.; Agulló-López, F.; Diéguez, E. Electric-field gradients at the ${ }^{111} \mathrm{In}$ and ${ }^{111 \mathrm{~m}} \mathrm{Cd}$ in undoped and Mg-doped LiNbO 3 . Phys. Rev. B 1995, 51, 6208-6214. [CrossRef]

54. Forker, M. The problematic of the derivation of the electric field gradient asymmetry parameter from TDPAC measurements or Mössbauer spectroscopy in imperfect crystal lattices. Nucl. Instr. Meth. 1973, 106, 121-126. [CrossRef]

55. Kitamura, K.; Yamamoto, J.K.; Iyi, N.; Kimura, S.; Hayashi, T. Stoichiometric $\mathrm{LiNbO}_{3}$ single crystal growth by double crucible Czochralski method using automatic powder supply system. J. Cryst. Growth 1992, 116, 327-332. [CrossRef]

56. Bordui, P.F.; Norwood, R.G.; Jundt, D.H.; Fejer, M.M. Preparation and characterization of off-congruent lithium niobate crystals. J. Appl. Phys. 1992, 71, 875-879. [CrossRef]

57. Polgár, K.; Péter, Á.; Kovács, L.; Corradi, G.; Szaller, Z. Growth of stoichiometric $\mathrm{LiNbO}_{3}$ single crystals by top seeded solution growth method. J. Cryst. Growth 1997, 177, 211-216. [CrossRef] 
58. Serrano, M.D.; Bermúdez, V.; Arizmendi, L.; Diéguez, E. Determination of the Li/Nb ratio in $\mathrm{LiNbO}_{3}$ crystals grown by Czochralski method with $\mathrm{K}_{2} \mathrm{O}$ added to the melt. J. Cryst. Growth 2000, 210, 670-676. [CrossRef]

59. Földvári, I.; Polgár, K.; Voszka, R.; Balasanyan, R.N. A simple method to determine the real composition of LiNbO 3 crystals. Cryst. Res. Tech. 1984, 19, 1659-1661. [CrossRef]

60. Kling, A.; Marques, J.G.; Correia, J.G.; Da Silva, M.F.; Diéguez, E.; Agulló-López, F.; Soares, J.C. Study of structural differences between stoichiometric and congruent lithium niobate. Nucl. Instr. Meth. B 1996, 113, 293-295. [CrossRef]

61. Kling, A.; Rebouta, L.; Marques, J.G.; Correia, J.G.; Da Silva, M.F.; Diéguez, E.; Agulló-López, F.; Soares, J.C. Ion beam channeling and hyperfine interaction analysis for the characterization of stoichiometry and anti-site population in $\mathrm{LiNbO}_{3}$. Nucl. Instr. Meth. B 1996, 118, 622-625. [CrossRef]

62. Gärtner, K.; Hehl, K.; Schlotzhauer, G. Axial dechanneling: II. Point defects. Nucl. Instr. Meth. B 1984, 4, 55-62. [CrossRef]

63. Marques, J.G.; Kling, A.; Soares, J.C.; Da Silva, M.F.; Vianden, R.; Polgár, K.; Diéguez, E.; Agulló-López, F. Structural defects in congruent and near-stoichiometric $\mathrm{LiNbO}_{3}$. Rad. Eff. Def. Solids 1999, 150, 233-236. [CrossRef]

64. Nassau, K.; Lines, M.E. Stacking-fault model for stoichiometry deviations in $\mathrm{LiNbO}_{3}$ and $\mathrm{LiTaO}_{3}$ and the effect on the Curie temperature. J. Appl. Phys. 1970, 41, 533-537. [CrossRef]

65. Smyth, D.M. Defects and transport in $\mathrm{LiNbO}_{3}$. Ferroelectrics 1983, 50, 93-102. [CrossRef]

66. Smyth, D.M. Defect Chemistry of $\mathrm{LiNbO}_{3}$. In Proceedings of the Sixth IEEE International Symposium on Applications of Ferroelectrics, Bethlehem, PA, USA, 8-11 June 1986; Wood, V.E., Ed.; IEEE: Piscataway, NJ, USA, 1986; pp. 115-117. [CrossRef]

67. Donnerberg, H.; Tomlinson, S.M.; Catlow, C.R.A.; Schirmer, O.F. Computer simulation studies of intrinsic defects in LiNbO 3 crystals. Phys. Rev. B 1989, 40,11909-11916. [CrossRef]

68. Molière, G. Theorie der Streuung schneller geladener Teilchen I. Einzelstreuung am abgeschirmten Coulomb-Feld. Z. Natur. A 1947, 2, 133-145. [CrossRef]

69. Navrotsky, A. Energetics and crystal chemical systematics among ilmenite, lithium niobate, and perovskite structures. Chem. Mat. 1998, 10, 2787-2793. [CrossRef]

70. Yusa, H.; Akaogi, M.; Sata, N.; Kojitani, H.; Yamamoto, R.; Ohishi, Y. High-pressure transformations of ilmenite to perovskite, and lithium niobate to perovskite in zinc germanate. Phys. Chem. Min. 2006, 33, 217-226. [CrossRef]

71. Kumada, N.; Ozawa, N.; Muto, F. LiNbO 3 with ilmenite-type structure prepared via ion-exchange reaction. J. Sol. St. Chem. 1985, 57, 267-268. [CrossRef]

72. Kumada, N.; Kinomura, N.; Muto, F. Crystal-structures of ilmenite type $\mathrm{LiNbO}_{3}$ and $\mathrm{NaNbO}_{3}$. J. Ceram. Soc. Japan 1990, 98, 384-388. [CrossRef]

73. Mehta, A.; Navrotsky, A.; Kumada, N.; Kinomura, N. Structural transitions in $\mathrm{LiNbO}_{3}$ and $\mathrm{NaNbO}_{3}$. J. Solid State Chem. 1993, 102, 213-225. [CrossRef]

74. Wiegel, M.; Blasse, G.; Navrotsky, A.; Mehta, A.; Kumada, N.; Kinomura, N. Luminescence of the ilmenite phase of LiNbO 3 . J. Sol. St. Chem. 1994, 109, 413-415. [CrossRef]

75. Corradi, G.; Kovács, L.; Zaritskii, I.M. Optical absorption edge and some shallow donor levels in $\mathrm{LiNbO}_{3}$ systems. Rad. Eff. Def. Sol. 1999, 150, 211-219. [CrossRef]

76. Baran, E.J.; Botto, I.L.; Muto, F.; Kumada, N.; Kinomura, N. Vibrational spectra of the ilmenite modifications of LiNbO 3 and $\mathrm{NaNbO}_{3}$. J. Mat. Sci. Lett. 1986, 5, 671-672. [CrossRef]

77. Kong, Y.; Xu, J.; Chen, X.; Zhang, C.; Zhang, W.; Zhang, G. Ilmenite-like stacking defect in nonstoichiometric lithium niobate crystals investigated by Raman scattering spectra. J. Appl. Phys. 2000, 87, 4410-4414. [CrossRef]

78. Lengyel, K.; Kovács, L.; Péter, Á.; Polgár, K.; Corradi, G. The effect of stoichiometry and Mg doping on the Raman spectra of $\mathrm{LiNbO}_{3}: \mathrm{Mg}$ crystals. Appl. Phys. B 2007, 87, 317-322. [CrossRef]

79. Abrahams, S.C.; Marsh, P. Defect structure dependence on composition in lithium niobate. Acta Crystal. 1986, 42, 61-68. [CrossRef]

80. Glass, A.M. Dielectric, thermal, and pyroelectric properties of ferroelectric $\mathrm{LiTaO}_{3}$. Phys. Rev. 1968, 172, 564-571. [CrossRef]

81. Birnie, D.P. Model for the ferroelectric transition in nonstoichiometric lithium niobate and lithium tantalate. J. Amer. Ceram. Soc. 1991, 74, 988-993. [CrossRef]

82. Johnston, W.D.; Kaminow, I.P. Temperature dependence of Raman and Rayleigh scattering in $\mathrm{LiNbO}_{3}$ and $\mathrm{LiTaO}_{3}$. Phys. Rev. 1968, 168, 1045-1054. [CrossRef]

83. Abrahams, S.C.; Buehler, E.; Hamilton, W.C.; Laplaca, S.J. Ferroelectric lithium tantalate-III. Temperature dependence of the structure in the ferroelectric phase and the paraelectric phase at 940 K. J. Phys. Chem. Sol. 1973, 34, 521-532. [CrossRef]

84. Boysen, H.; Altdorfer, F. A neutron powder investigation of the high-temperature structure and phase transition in $\mathrm{LiNbO}_{3}$. Acta Crystal. B 1994, 50, 405-414. [CrossRef]

85. Inbar, I.; Cohen, R.E. Comparison of the electronic structures and energetics of ferroelectric $\mathrm{LiNbO}_{3}$ and $\mathrm{LiTaO}_{3}$. Phys. Rev. B 1996, 53, 1193-1204. [CrossRef]

86. Phillpot, S.R.; Gopalan, V. Coupled displacive and order-disorder dynamics in $\mathrm{LiNbO}_{3}$ by molecular-dynamics simulation. Appl. Phys. Lett. 2004, 84, 1916-1918. [CrossRef]

87. Sanna, S.; Schmidt, W.G. Ferroelectric phase transition in $\mathrm{LiNbO}_{3}$ : Insights from molecular dynamics. IEEE Trans. Ultrason. Ferroel. Freq. Control 2012, 59, 1925-1928. [CrossRef]

88. Toyoura, K.; Ohta, M.; Nakamura, A.; Matsunaga, K. First-principles study on phase transition and ferroelectricity in lithium niobate and tantalate. J. Appl. Phys. 2015, 118, 064103. [CrossRef] 
89. Zhukov, A.P.; Soboleva, L.V.; Belyaev, L.M.; Volkov, A.F. Niobium-93, Lanthanum-139, and Tantalum-181 pure NQR in rare earth orthoniobates and lithium tantalate. Ferroelectrics 1978, 21, 601-604. [CrossRef]

90. Löhnert, M.; Kaindl, G.; Wortmann, G.; Salomon, D. Temperature-induced changes of the electronic structure of ferroelectric $\mathrm{LiTaO}_{3}$. Phys. Rev. Lett. 1981, 47, 194-197. [CrossRef]

91. De Wette, F.W.; Schacher, G.E. Electric field gradients in point-ion and uniform-background lattices II. Physical Review 1965, 137, A92-A94. [CrossRef]

92. Shelyapina, M.G.; Kasperovich, V.S.; Shchegolev, B.F.; Charnaya, E.V. Cluster calculations of electric-field-gradients at the Ta Site for the ferroelectric $\mathrm{LiTaO}_{3}$ crystal. Ferroelectrics 2003, 282, 1-7. [CrossRef]

93. Slotfeldt-Ellingsen, D. NMR study of the temperature dependence of the 7Li quadrupole coupling constant above and below the Curie temperature in ferroelectric $\mathrm{LiTaO}_{3}$. In Proceedings of the 17th Congress Ampere; Hovi, V., Ed.; North Holland Publishing Company: Amsterdam, The Netherlands, 1972; pp. 350-352.

94. Slotfeldt-Ellingsen, D.; Pedersen, B. The structural phase transition in $\mathrm{LiTaO}_{3}$ studied by pulsed ${ }^{7} \mathrm{Li}-\mathrm{NMR}$. Phys. Stat. Sol. 1974, 24, 191-195. [CrossRef]

95. Catchen, G.L.; Adams, J.M.; Rearick, T.M. High-temperature partitioning of ${ }^{181} \mathrm{Hf}$-probe impurities between Li and group-V sites in $\mathrm{LiNbO}_{3}$ and $\mathrm{LiTaO}_{3}$. Phys. Rev. B 1992, 46, 2743-2749. [CrossRef]

96. Tomov, T.; Engelmann, H.; Dézsi, I.; Gonser, U. Investigation of the ferroelectric phase transition in $\mathrm{LiNbO}_{3}$ :Fe by $\mathrm{Mössbauer}$ spectroscopy. Solid State Commun. 1989, 69, 41-44. [CrossRef]

97. Marques, J.G.; Kling, A.; De Jesus, C.M.; Soares, J.C.; Friedsam, P.; Freitag, K.; Vianden, R. Electric field gradients in the ferroelectric and paraelectric phases of $\mathrm{LiTaO}_{3}$. Hyperfine Interact. 1999, 120-121, 485-489. [CrossRef]

98. Ohkubo, Y.; Murakami, Y.; Saito, T.; Yokohama, A.; Uerhara, S.; Kawase, Y. Mechanism of the ferroelectric phase transitions in $\mathrm{LiNbO}_{3}$ and $\mathrm{LiTaO}_{3}$. Phys. Rev. B 2002, 65, 052107. [CrossRef]

99. Jetschke, S.; Karge, H.; Hehl, K. Anisotropic Effects in N+-Implanted LiNbO . Phys. Stat. Sol. 1983, 77, 207-214. [CrossRef]

100. Götz, G.; Karge, H. Ion Implantation into $\mathrm{LiNbO}_{3}$. Nucl. Instr. Meth. 1983, 209/210, 1079-1088. [CrossRef]

101. Götz, G. Radiation Effects in Optoelectronic Materials. Rad. Eff. 1986, 98, 189-209. [CrossRef]

102. Wendler, E.; Becker, G.; Rensberg, J.; Schmidt, E.; Wolf, S.; Wesch, W. Direction-Dependent RBS Channelling Studies in Ion Implanted $\mathrm{LiNbO}_{3}$. Nucl. Instr. Meth. B 2016, 379, 195-199. [CrossRef]

103. Gischkat, T.; Schrempel, F.; Wesch, W. Ion-beam induced effects at $15 \mathrm{~K}$ in $\mathrm{LiNbO}_{3}$. Nucl. Instr. Meth. B 2008, $266,2906-2909$. [CrossRef]

104. Bianconi, M.; Argiolas, N.; Bazzan, M.; Bentini, G.G.; Cerutti, A. Quantification of Nuclear Damage in High Energy Ion Implanted Lithium Niobate. Nucl. Instr. Meth. B 2007, 257, 597-600. [CrossRef]

105. Schmidt, E.; Ritter, K.; Gärtner, K.; Wendler, E. Investigation of Li/Nb-Sublattices in Ion Implanted $\mathrm{LiNbO}_{3}$ by $\mathrm{RBS}_{\text {and }} \mathrm{NRA}$ in Channelling Configuration. Nucl. Instr. Meth. B 2017, 409, 126-132. [CrossRef]

106. Schrempel, F.; Gischkat, T.; Hartung, H.; Kley, E.-B.; Wesch, W. Ion Beam Enhanced Etching of $\mathrm{LiNbO}_{3}$. Nucl. Instr. Meth. B 2006, 250, 164-168. [CrossRef]

107. Jetschke, S.; Hehl, K. Diffusion and Recrystallization Processes during Annealing of $\mathrm{N}^{+}$- and $\mathrm{P}^{+}$-Implanted LiNbO 3 . Phys. Stat. Sol. 1985, 88, 193-205. [CrossRef]

108. Canut, B.; Brenier, R.; Meftah, A.; Moretti, P.; Ould Salem, S.; Ramos, S.M.M.; Thevenard, P.; Toulemonde, M. Damage Induced in $\mathrm{LiNbO}_{3}$ Single Crystals by GeV Gadolinium Ions. Nucl. Instr. Meth. B 1994, 91, 312-316. [CrossRef]

109. Canut, B.; Brenier, R.; Meftah, A.; Moretti, P.; Salem, S.O.; Pitaval, M.; Ramos, S.M.M.; Thevenard, P.; Toulemonde, M. Latent track formation in $\mathrm{LiNbO}_{3}$ single crystals irradiated by $\mathrm{GeV}$ uranium ions. Rad. Eff. Def. Sol. 1995, 136, 307-310. [CrossRef]

110. Canut, B.; Ramos, S.M.M.; Brenier, R.; Thevenard, P.; Loubet, J.L.; Toulemonde, M. Surface Modifications of LiNbO 3 Single Crystals Induced by Swift Heavy Ions. Nucl. Instr. Meth. B 1996, 107, 194-198. [CrossRef]

111. Bentini, G.G.; Bianconi, M.; Chiarini, M.; Correra, L.; Sada, C.; Mazzoldi, P.; Argiolas, N.; Bazzan, M.; Guzzi, R. Effect of Low

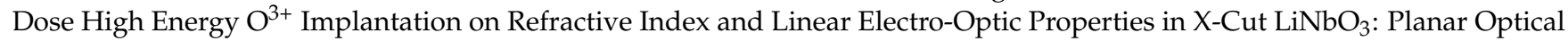
Waveguide Formation and Characterization. J. Appl. Phys. 2002, 92, 6477-6483. [CrossRef]

112. Bentini, G.G.; Bianconi, M.; Cerutti, A.; Chiarini, M.; Pennestrì, G.; Sada, C.; Argiolas, N.; Bazzan, M.; Mazzoldi, P.; Guzzi, R. Structural and Compositional Characterization of $\mathrm{X}-\mathrm{Cut} \mathrm{LiNbO}_{3}$ Crystals Implanted with High Energy Oxygen and Carbon Ions. Nucl. Instr. Meth. B 2005, 240, 174-177. [CrossRef]

113. Bentini, G.G.; Bianconi, M.; Correra, L.; Chiarini, M.; Mazzoldi, P.; Sada, C.; Argiolas, N.; Bazzan, M.; Guzzi, R. Damage Effects Produced in the Nearsurface Region of $\mathrm{X}$-cut $\mathrm{LiNbO}_{3}$ by Low Dose, High Energy Implantation of Nitrogen, Oxygen, and Fluorine Ions. J. Appl. Phys. 2004, 96, 242-247. [CrossRef]

114. Bianconi, M.; Argiolas, N.; Bazzan, M.; Bentini, G.G.; Chiarini, M.; Cerutti, A.; Mazzoldi, P.; Pennestrì, G.; Sada, C. On the Dynamics of the Damage Growth in 5 MeV Oxygen-Implanted Lithium Niobate. Appl. Phys. Lett. 2005, 87, 072901. [CrossRef]

115. Olivares, J.; García-Navarro, A.; García, G.; Agulló-López, F.; Agulló-Rueda, F.; García-Cabañes, A.; Carrascosa, M. Buried Amorphous Layers by Electronic Excitation in Ion-Beam Irradiated Lithium Niobate: Structure and Kinetics. J. Appl. Phys. 2007, 101, 033512. [CrossRef]

116. Olivares, J.; García, G.; García-Navarro, A.; Agulló-López, F.; Caballero, O.; García-Cabanes, A. Generation of High-Confinement Step-Like Optical Waveguides in $\mathrm{LiNbO}_{3}$ by Swift Heavy Ion-Beam Irradiation. Appl. Phys. Lett. 2005, 86, 183501. [CrossRef] 
117. Olivares, J.; García, G.; Agulló-López, F.; Agulló-Rueda, F.; Kling, A.; Soares, J.C. Generation of Amorphous Surface Layers in $\mathrm{LiNbO}_{3}$ by Ion Beam-Irradiation: Thresholding and Boundary Propagation. Appl. Phys. A 2005, 81, 1465-1469. [CrossRef]

118. Rivera, A.; Olivares, J.; Crespillo, M.L.; García, G.; Bianconi, M.; Agulló-López, F. Assessment of Swift-Ion Damage by RBS/C: Determination of the Amorphization Threshold. Nucl. Instr. Meth. B 2009, 267, 1460-1463. [CrossRef]

119. Ramos, S.M.M.; Canut, B.; Ambri, M.; Bonardi, N.; Pitaval, M.; Bernas, H.; Chaumont, J. Defect creation in $\mathrm{LiNbO}_{3}$ irradiated by medium masses ions in the electronic stopping power regime. Rad. Eff. Def. Sol. 1998, 143, 299-309. [CrossRef]

120. Wesch, W.; Rensberg, J.; Schmidt, M.; Wendler, E. Damage evolution in $\mathrm{LiNbO}_{3}$ due to Electronic Energy Deposition below the Threshold for Direct Amorphous Track Formation. J. Appl. Phys. 2019, 126, 125105. [CrossRef]

121. Agulló-López, F.; García, G.; Olivares, J. Lattice Preamorphization by Ion Irradiation: Fluence Dependence of the Electronic Stopping Power Threshold for Amorphization. J. Appl. Phys. 2005, 97, 093514. [CrossRef]

122. Toulemonde, M.; Dufour, C.; Meftah, A.; Paumier, E. Transient thermal processes in heavy ion irradiation of crystalline inorganic insulators. Nucl. Instr. Meth. B 2000, 166-167, 903-912. [CrossRef]

123. Agulló-López, F.; Climent-Font, A.; Muñoz-Martín, A.; Olivares, J.; Zucchiatti, A. Ion beam modification of dielectric materials in the electronic excitation regime: Cumulative and exciton models. Progr. Mat. Sci. 2016, 76, 1-58. [CrossRef]

124. Agulló-López, F.; Mendez, A.; García, G.; Olivares, J.; Cabrera, J.M. Synergy between thermal spike and exciton decay mechanisms for ion damage and amorphization by electronic excitation. Phys. Rev. B 2006, 74, 174109. [CrossRef]

125. García, G.; Rivera, A.; Crespillo, M.L.; Gordillo, N.; Olivares, J.; Agulló-López, F. Amorphization Kinetics under Swift Heavy Ion Irradiation: A Cumulative Overlapping-Track Approach. Nucl. Instr. Meth. B 2011, 269, 492-497. [CrossRef]

126. Schrempel, F.; Steinbach, T.; Gischkat, T.; Wesch, W. Channeling irradiation of $\mathrm{LiNbO}_{3}$. Nucl. Instr. Meth. B 2008, $266,2958-2961$. [CrossRef]

127. Steinbach, T.; Schrempel, F.; Gischkat, T.; Wesch, W. Influence of ion energy and ion species on ion channeling in $\mathrm{LiNbO}_{3}$. Phys. Rev. B 2008, 78, 184106. [CrossRef]

128. Dowell, M.B.; Lefkowitz, I.; Taylor, G.W. Radiation damage in lithium niobate. Proc. 2nd Int. Meeting on Ferroelectricity, Kyoto, 1969. J. Phys. Soc. Japan 1970, 28, 442-444.

129. Berg, N.; Speulstra, J. The operation of acoustic surface wave delay lines in a nuclear environment. IEEE Trans. Nucl. Sci. 1973, 20, 137-143. [CrossRef]

130. Primak, W.; Anderson, T.T. Metamictization of lithium niobate by thermal neutrons. Nucl. Technol. 1976, 28, 235-248. [CrossRef]

131. Primak, W.; Gavin, A.P.; Anderson, T.T.; Monahan, E. Stability of lithium niobate on irradiation at elevated reactors temperature. Nucl. Technol. 1977, 36, 79-84. [CrossRef]

132. Marques, J.G. Evolution of nuclear fission reactors: Third generation and beyond. Energy Convers. Manag. 2010, 51, 1774-1780. [CrossRef]

133. Giuliani, F.; Oliveira, C.; Collar, J.I.; Girard, T.A.; Morlat, T.; Limagne, D.; Marques, J.G.; Ramos, A.R.; Waysand, G. Response of SIMPLE SDDs to monochromatic neutron irradiations. Nucl. Instr. Meth. A 2004, 526, 348-358. [CrossRef]

134. González, R.; Chen, Y.; Abraham, M.M. Transmutation-induced tritium in $\mathrm{LiNbO}_{3}$ single crystals. Phys. Rev. B 1988, 37, 6433-6435. [CrossRef]

135. González, R.; Ballesteros, C.; Chen, Y.; Abraham, M.M. Diffusion of tritons, deuterons, and protons in $\mathrm{LiNbO}_{3}$ crystals. Phys. Rev. B 1989, 39, 11085-11092. [CrossRef] [PubMed]

136. Verma, R.; Arunachalam, J.; Gangadharan, S.; Vyas, J.C.; Kothiyal, G.P.; Gupta, M.K. Trace characterisation of lithium niobate by neutron activation analysis. Fresenius J. Anal. Chem. 1992, 344, 261-264. [CrossRef]

137. Brannon, P.J. Transient radiation-induced absorption at $1061 \mathrm{~nm}$ in $\mathrm{LiNbO}_{3}$ and $\mathrm{MgO}: \mathrm{LiNbO}_{3}$. IEEE Trans. Nucl. Sci. 1994, 41, 642-647. [CrossRef]

138. Marques, J.G.; Kling, A.; Soares, J.C.; Rebouta, L.; Da Silva, M.F.; Diéguez, E.; Agulló-López, F. Lattice site location of Hf in $\mathrm{LiNbO}_{3}$ : Influence of dopant concentration and crystal stoichiometry. Nucl. Instr. Meth. B 1998, 136-138, 431-435. [CrossRef]

139. Orlova, A.N.; Ped'ko, B.B.; Filinova, A.V.; Franko, N.Y.; Prokhorova, A.Y. Influence of gamma and gamma-neutron irradiation on the optical properties of $\mathrm{LiNbO}_{3}$ single crystals. Phys. Sol. State 2006, 48, 544-547. [CrossRef]

140. Mandula, G.; Rupp, R.A.; Balaskó, M. Erasure of elementary holograms in $\mathrm{LiNbO}_{3}$ :Fe by neutron irradiation. In Proceedings of the Holography 2005: International Conference on Holography, Optical Recording and Processing of Information; SPIE-International Society for Optics and Photonics: Bellingham, WA, USA, 2006; Volume 6252, p. 62520N. [CrossRef]

141. Sha, G.; Harlow, C.; Chernatynskiy, A.; Daw, J.; Khafizov, M. In-situ measurement of irradiation behavior in $\mathrm{LiNbO}_{3}$. Nucl. Instr. Meth. B 2020, 472, 46-52. [CrossRef]

142. Coltman, R.R.; Klabunde, C.E.; McDonald, D.L.; Redman, J.K. Reactor damage in pure metals. J. Appl. Phys. 1962, 33, 3509-3522. [CrossRef]

143. Robinson, M.T. Basic physics of radiation damage production. J. Nucl. Mat. 1994, 216, 1-28. [CrossRef]

144. Pritychenko, B.; Mughabghab, S.F. Neutron thermal cross sections, Westcott factors, resonance integrals, Maxwellian averaged cross sections and astrophysical reaction rates calculated from the ENDF/B-VII.1, JEFF-3.1.2, JENDL-4.0, ROSFOND-2010, CENDL-3.1 and EAF-2010 evaluated data libraries. Nucl. Data Sheets 2012, 113, 3120-3144. [CrossRef]

145. Lorenz, K.; Marques, J.G.; Franco, N.; Alves, E.; Peres, M.; Correia, M.R.; Monteiro, T. Defect studies on fast and thermal neutron irradiated GaN. Nucl. Instr. Meth. B 2008, 266, 2780-2783. [CrossRef]

146. Pelowitz, D.B. MCNPX User's Manual Version 2.7, LA-CP-11-00438; Los Alamos National Laboratory: Los Alamos, NM, USA, 2011. 
147. Seitz, F. On the disordering of solids by action of fast massive particles. Discuss. Faraday Soc. 1949, 5, 271-282. [CrossRef]

148. Nord, J.; Nordlund, K.; Keinonen, J. Molecular dynamics study of damage accumulation in GaN during ion beam irradiation. Phys. Rev. B 2003, 68, 184104. [CrossRef]

149. Tsuchihira, H.; Oda, T.; Tanaka, S. Molecular-dynamics simulation of threshold displacement energies in lithium aluminate. Nucl. Instr. Meth. B 2011, 269, 1707-1711. [CrossRef]

150. Lucas, G.; Pizzagalli, L. Ab initio molecular dynamics calculations of threshold displacement energies in silicon carbide. Phys. Rev. B 2005, 72, 161202. [CrossRef]

151. Liu, B.; Xiao, H.Y.; Zhang, Y.; Aidhy, D.S.; Weber, W.J. Ab initio molecular dynamics simulations of threshold displacement energies in $\mathrm{SrTiO}_{3}$. J. Phys. Cond. Matt. 2013, 25, 485003. [CrossRef]

152. Petersen, B.A. Low Energy Recoil Simulations in $\mathrm{MgO}, \mathrm{LiNbO}_{3}$, and $\mathrm{LiTaO}_{3}$ Using $\mathrm{Ab}$ Initio Molecular Dynamics. PhD Thesis, University of Tennessee, Knoxville, TN, USA, 2017.

153. Hogdson, E.R.; Agulló-López, F. Oxygen vacancy centres induced by electron irradiation in $\mathrm{LiNbO}_{3}$. Solid State Commun. 1987, 64, 965-968. [CrossRef]

154. Hogdson, E.R.; Agulló-López, F. Displacement damage in $\mathrm{LiNbO}_{3}$. Nucl. Instr. Meth. B 1988, 32, 42-44. [CrossRef]

155. Popov, A.I.; Kotomin, E.A.; Maier, J. Basic properties of the F-type centers in halides, oxides and perovskites. Nucl. Instr. Meth. B 2010, 268, 3084-3089. [CrossRef]

156. Alenius, G.; Arnell, S.E.; Schale, C.; Wallander, E. Low spin states in ${ }^{181} \mathrm{Hf}$ from the thermal neutron capture reaction. Phys. Scrip. 1971, 3, 105-110. [CrossRef]

157. Sears, V.F. Neutron scattering lengths and cross sections. Neutron News 1992, 3, 26-37. [CrossRef]

158. Nakagawa, T.; Shibata, K.; Kawasaki, H. Curves and Tables of Neutron Cross Sections in JENDL-3.3. JAERI-Data/Code 2002-020; Japan Atomic Energy Research Institute: Tokaimura, Japan, 2002.

159. Molnar, G. (Ed.) Handbook of Prompt Gamma Activation Analysis; Springer: Berlin, Germany, 2003; ISBN 978-1402013041.

160. Dale, C.J.; Marshall, P.W.; Summers, G.P.; Wolicki, E.A.; Burke, E.A. Displacement damage equivalent to dose in silicon devices. Appl. Phys. Lett. 1989, 54, 451-453. [CrossRef]

161. Angelescu, T.; Vasilescu, A. Comparative radiation hardness results obtained from various neutron sources and the NIEL problem. Nucl. Instr. Meth. A 1996, 374, 85-90. [CrossRef]

162. Lindhard, J.; Nielsen, V.; Scharff, M.; Thonsen, P.V. Integral equations governing radiation effects (Notes on atomic collisions III). Matematisk-Fysiske Meddelelser 1963, 33, 1-42.

163. Akkerman, A.; Barak, J. New partition factor calculations for evaluating the damage of low energy ions in silicon. IEEE Trans. Nucl. Sci. 2006, 53, 3667-3674. [CrossRef]

164. Boschini, M.J.; Rancoita, P.G.; Tacconi, M. SR-NIEL Calculator: Screened Relativistic (SR) Treatment for Calculating the Displacement Damage and Nuclear Stopping Powers for Electrons, Protons, Light-and Heavy- Ions in Materials (version 6.9.0); INFN sez Bicocca: Milan, Italy, 2020; Volume 10. Available online: http:/ /www.sr-niel.org/ (accessed on 31 March 2021).

165. Ashkin, A.; Boyd, G.D.; Dziedzic, J.M.; Smith, R.G.; Ballman, A.A.; Levinstein, J.J.; Nassau, K. Optically-Induced Refractive Index Inhomogenities in $\mathrm{LiNbO}_{3}$ and $\mathrm{LiTaO}_{3}$. Appl. Phys. Lett. 1966, 9, 72-74. [CrossRef]

166. Zhong, G.G.; Jian, J.; Wu, Z.-K. Proceedings of the 11th International Quantum Electronics Conference; Cat. No. 80 CH 1561-0; IEEE: New York, NY, USA, 1980; p. 631.

167. Bryan, D.A.; Gerson, R.; Tomaschke, H.E. Increased Optical Damage Resistance in Lithium Niobate. Appl. Phys. Lett. 1984, 44, 847-849. [CrossRef]

168. Volk, T.R.; Pryalkin, V.I.; Rubinina, N.M. Optical-Damage-Resistant $\mathrm{LiNbO}_{3}: Z n$ Crystal. Opt. Lett. 1990, 15, 996-998. [CrossRef]

169. Yamamoto, J.K.; Kitamura, K.; Iyi, N.; Kimura, S.; Furukawa, Y.; Sato, M. Increased Optical Damage Resistance in $\mathrm{Sc}_{2} \mathrm{O}_{3}$-Doped $\mathrm{LiNbO}_{3}$. Appl. Phys. Lett. 1992, 61, 2156-2158. [CrossRef]

170. Volk, T.R.; Rubinina, N.M. A New Optical Damage Resistant Impurity in Lithium Niobate Crystals: Indium. Ferroelectrics Lett. 1992, 14, 37-43. [CrossRef]

171. Kokanyan, E.P.; Razzari, L.; Cristiani, I.; Degiorgio, V.; Gruber, J.B. Reduced Photorefraction in Hafnium-Doped Single-Domain and Periodically Poled Lithium Niobate Crystals. Appl. Phys. Lett. 2004, 84, 1880-1882. [CrossRef]

172. Sun, L.; Guo, F.; Lv, Q.; Yu, H.; Li, H.; Cai, W.; Xu, Y.; Zhao, L. Increased Optical Damage Resistance of Zr:LiNbO 3 Crystals. Cryst. Res. Technol. 2007, 42, 1117-1122. [CrossRef]

173. Zhang, Q.; Feng, X. Defect Structures and Densities of Mg-Doped Lithium Niobate. Phys. Stat. Sol. 1990, 121, 429-435. [CrossRef]

174. Liu, J.; Zhang, W.; Zhang, G. Defect Chemistry Analysis of the Defect Structure in Mg-Doped LiNbO ${ }_{3}$ Crystals. Phys. Stat. Sol. 1996, 156, 285-291. [CrossRef]

175. Abdi, F.; Aillerie, M.; Bourson, P.; Fontana, M.D. Defect structure in Mg-doped $\mathrm{LiNbO}_{3}$ : Revisited study. J. Appl. Phys. 2009, 106, 033519. [CrossRef]

176. Iyi, N.; Kitamura, K.; Yajima, Y.; Kimura, S.; Furukawa, Y.; Sato, M. Defect Structure Model of MgO-Doped LiNbO 3 . J. Solid State Chem. 1995, 118, 148-152. [CrossRef]

177. Donnerberg, H.J.; Tomlinson, S.M.; Catlow, C.R.A. Defects in $\mathrm{LiNbO}_{3}$, II. Computer Simulation. J. Phys. Chem. Solids 1991, 52, 201-210. [CrossRef]

178. Donnerberg, H.J.; Tomlinson, S.M.; Catlow, C.R.A.; Schirmer, O.F. Computer-Simulation Studies of Extrinsic Defects in LiNbO 3 Crystals. Phys. Rev. B 1991, 44, 4877-4883. [CrossRef] 
179. Donnerberg, H. Comments on the Defect Chemistry of Magnesium-Doped Lithium Niobate (LiNbO 3 ). J. Solid State Chem. 1996, 123, 208-214. [CrossRef]

180. Wöhlecke, M.; Volk, T.; Donnerberg, H. On the Role of Intrinsic Clusters in Damage-Resistant LiNbO 3 . Ferroelectr. Lett. Sect. 1997, 22, 53-58. [CrossRef]

181. Kling, A.; Kollewe, D.; Grabmaier, B.C. Lattice site Investigations for $\mathrm{Mg}$ in $\mathrm{LiNbO}_{3}$ by Combined RBS-PIXE-NRA-Channeling Experiments. Nucl. Instr. Meth. B 1992, 64, 232-236. [CrossRef]

182. Grabmaier, B.C.; Otto, F. Growth and Investigation of MgO-doped $\mathrm{LiNbO}_{3}$. J. Cryst. Growth 1986, 79, 682-688. [CrossRef]

183. Grabmaier, B.C.; Otto, F. Growth of $\mathrm{LiNbO}_{3}$ Single Crystals for Optical Applications. Proc. SPIE 1986, 651, 2-6. [CrossRef]

184. Sommerfeldt, R.; Holtmann, L.; Krätzig, E.; Grabmaier, B.C. Influence of Mg Doping and Composition on the Light-Induced Charge Transport in $\mathrm{LiNbO}_{3}$. Phys. Stat. Sol. 1988, 106, 89-98. [CrossRef]

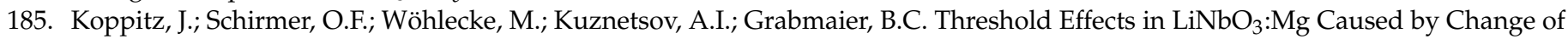
Electron-Lattice Coupling. Ferroelectrics 1989, 92, 233-241. [CrossRef]

186. Grabmaier, B.C.; Wersing, W.; Koestler, W. Properties of Undoped and $\mathrm{MgO}$-Doped $\mathrm{LiNbO}_{3}$; Correlation to the Defect Structure. J. Cryst. Growth 1991, 110, 339-347. [CrossRef]

187. Schmidt, N.; Betzler, K.; Grabmaier, B.C. Composition dependence of the second harmonic phase-matching temperature in $\mathrm{LiNbO}_{3}$. Appl. Phys. Lett. 1991, 58, 34-35. [CrossRef]

188. Nunomura, K.; Ishitani, A.; Matsubara, T.; Hayashi, I. Second Harmonic Generation in a Sputtered $\mathrm{LiNbO}_{3}$ Film on $\mathrm{MgO} \mathrm{J}$. Crystal Growth 1978, 45, 355-360. [CrossRef]

189. Kling, A.; Kollewe, D.; Grabmaier, B.C. Dependence of the ${ }^{7} \operatorname{Li}(\mathrm{p}, \alpha)^{4} \mathrm{He}$ Minimum Yield on the Mg Concentration for Proton Channeling. Nucl. Instr. Meth. B 1994, 85, 490-493. [CrossRef]

190. Feng, X.; Wang, D.; Zhang, J. NMR Spectra of Mg Nuclei in Mg-Doped LiNbO 3 Crystals. Phys. Stat. Sol. 1990, 157, K127-K130. [CrossRef]

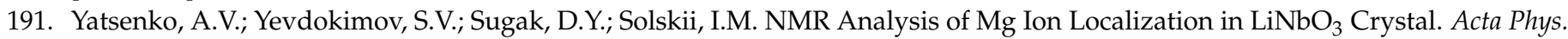
Pol. A 2010, 117, 166-169. [CrossRef]

192. Rebouta, L.; Soares, J.C.; da Silva, M.F.; Sanz-Garcia, J.A.; Diéguez, E.; Agulló-López, F. Lattice Sites for Eu, $\mathrm{Hf}$ and $\mathrm{Nd}$ in LiNbO 3 by RBS/Channeling Experiments. Nucl. Instr. Meth. B 1990, 50, 428-430. [CrossRef]

193. Marques, J.G.; Kling, A.; Rebouta, L.; da Silva, M.F.; Melo, A.A.; Soares, J.C.; Serrano, M.D.; Diéguez, E.; Agulló-López, F. Lattice Location of $\mathrm{Hf}$ in Near-stoichiometric $\mathrm{LiNbO}_{3}$ : RBS/Channeling and PAC Studies. Mat. Sci. Forum 1997, 248/249, 395-398. [CrossRef]

194. Rebouta, L.; da Silva, M.F.; Soares, J.C.; Santos, M.T.; Diéguez, E.; Agulló-López, F. Ion-Beam/Channeling Characterization of $\mathrm{LiNbO}_{3}$ : Interaction between Impurity Sites. Rad. Eff. Def. Sol. 1995, 136, 137-139. [CrossRef]

195. Rebouta, L.; da Silva, M.F.; Soares, J.C.; Santos, M.T.; Diéguez, E.; Agulló-López, F. Ion-Beam/Channeling Characterization of $\mathrm{LiNbO}_{3}$ : Interaction between Impurity Sites. Opt. Mat. 1995, 4, 174-178. [CrossRef]

196. Marques, J.G.; de Jesus, C.M.; Melo, A.A.; Soares, J.C.; Diéguez, E.; Agulló-López, F. PAC Study of the Interaction between Impurity Sites in $\mathrm{LiNbO}_{3}$ Doped with $\mathrm{Hf}$ and Mg. Hyperfine Interact. 1996, 1, 348-351.

197. Dias, S.A.; Marques, J.G.; Correia, J.G.; Sanz, J.A.; Soares, J.C. The ${ }^{181} \mathrm{Hf} /{ }^{181} \mathrm{Ta}$ Probe in the Li and $\mathrm{Nb}_{\text {Sites of }}$ Congruent LiNbO 3 Co-Doped with Mg and Cr Ions Studied by PAC. Hyperfine Interact. 2004, 158, 323-328. [CrossRef]

198. Kling, A.; Soares, J.C.; da Silva, M.F.; Rebouta, L.; Kollewe, D.; Krause, H.; Flagmeyer, R.-H.; Vogt, J. Determination of Impurity Lattice Sites in Single Crystals Using PIXE/channeling. X-Ray Spectrom. 1999, 28, 105-109. [CrossRef]

199. Kovács, L.; Rebouta, L.; Soares, J.C.; da Silva, M.F.; Hage-Ali, M.; Stoquert, J.P.; Siffert, P.; Zaldo, C.; Szaller, Z.; Polgár, K. Lattice Site of Trivalent Impurities in Mg-Doped Lithium Niobate Crystals. Mat. Sci. Eng. B 1991, 9, 505-508. [CrossRef]

200. Hesselink, L.; Orlov, S.S.; Bashaw, M.C. Holographic Data Storage Systems. Proc. IEEE 2004, 92, 1231-1280. [CrossRef]

201. McMillen, D.K.; Hudson, T.D.; Wagner, J.; Singleton, J. Holographic Recording in Specially Doped Lithium Niobate Crystals. Opt. Express 1998, 2, 491-502. [CrossRef]

202. Yue, X.; Adibi, A.; Hudson, T.; Buse, K.; Psaltis, D. Role of Cerium in Lithium Niobate for Holographic Recording. J. Appl. Phys. 2000, 87, 4051-4055. [CrossRef]

203. Kong, Y.; Liu, S.; Xu, J. Recent Advances in the Photorefraction of Doped Lithium Niobate Crystals. Materials 2012, 5, $1954-1971$. [CrossRef]

204. Buse, K.; Adibi, A.; Psaltis, D. Non-Volatile Holographic Storage in Doubly Doped Lithium Niobate Crystals. Nature 1998, 393, 665-668. [CrossRef]

205. Liu, F.; Kong, Y.; Ge, X.; Liu, H.; Liu, S.; Chen, S.; Rupp, R.; Xu, J. Improved Sensitivity of Nonvolatile Holographic Storage in Triply Doped $\mathrm{LiNbO}_{3}: \mathrm{Zr}, \mathrm{Cu}, \mathrm{Ce}$. Opt. Express 2010, 18, 6333-6339. [CrossRef] [PubMed]

206. Valyashko, E.G.; Varina, T.M.; Kuz'min, R.N.; Rubinina, N.M.; Smirnov, V.A.; Shagdarov, V.M. Spectroscopic properties of single crystals of lithium metaniobate containing iron and neodymium ions as impurity. J. Appl. Spectrosc. 1974, 21, 877-880. [CrossRef]

207. Keune, W.; Date, S.K.; Gonser, U.; Bunzel, H. Mössbauer Effect Study of $\mathrm{Fe}^{57}$ Doped $\mathrm{LiNbO}_{3}$ and LiTaO . Ferroelectrics 1976, 13, 443-445. [CrossRef]

208. Kurz, H.; Krätzig, E.; Keune, W.; Engelmann, H.; Gonser, U.; Dischler, B.; Räuber, A. Photorefractive Centres in $\mathrm{LiNbO}_{3} \mathrm{Studied}$ by Optical-, Mössbauer- and EPR-Methods. Appl. Phys. 1977, 12, 355-368. [CrossRef] 
209. Gonser, U.; Sakai, H.; Keune, W. Mössbauer Spectroscopy of ${ }^{57} \mathrm{Fe}^{2+}$ Impurities in LiNbO 3 . J. Electrochem. Soc. 1976, $123,1915-1917$. [CrossRef]

210. Becze-Deák, T.; Bottyán, L.; Corradi, G.; Korecz, L.; Nagy, D.L.; Polgár, K.; Sayed, S.; Spiering, H. Electron Trapping Centres and Cross Sections in $\mathrm{LiNbO}_{3}$ Studied by ${ }^{57} \mathrm{Co}$ Mössbauer Emission Spectroscopy. J. Phys. Condens. Matt. 1999, 11, 6239-6250. [CrossRef]

211. Becze-Deák, T.; Bottyán, L.; Corradi, G.; Korecz, L.; Nagy, D.L.; Polgár, K.; Sayed, S.; Spiering, H. ${ }^{57}$ Co Mössbauer Emission Study of $\mathrm{LiNbO}_{3}, \mathrm{Fe}: \mathrm{LiNbO}_{3}$ and $\mathrm{Mg}: \mathrm{LiNbO}_{3}$ in Various Thermochemical Reduction States. J. Radioanalyt. Nucl. Chem. 2000, 246 , 33-37. [CrossRef]

212. Rebouta, L.; da Silva, M.F.; Soares, J.C.; Hage-Ali, M.; Stoquert, J.P.; Siffert, P.; Sanz-García, J.A.; Diéguez, E.; Agulló-López, F. Lattice Site of Iron in $\mathrm{LiNbO}_{3}\left(\mathrm{Fe}^{3+}\right)$ by the PIXE/Channeling Technique. Europhys. Lett. 1991, 14, 557-561. [CrossRef]

213. Malovichko, G.I.; Grachev, V.G. Determination of Iron Group Impurity Positions in Ferroelectric $\mathrm{LiNbO}_{3}$ using nuclear-quadrupole splitting. Sov. Phys. Sol. State 1985, 27, 1678-1679.

214. Zaltron, A.; Argiolas, N.; De Salvador, D.; Bazzan, M.; Ciampolillo, M.V.; Bacci, L.; Sada, C. Iron Site Location in Fe-Diffused Lithium Niobate Crystals by Combined RBS-PIXE-NRA Analysis. Nucl. Instr. Meth. B 2012, 275, 11-15. [CrossRef]

215. Szilágy, E.; Becze-Deák, T.; Bottyán, L.; Kocsonya, A.; Kótai, E.; Nagy, D.L.; Kling, A.; Battistig, G.; Khan, N.Q.; Polgár, K. Lattice Site Determination of $\mathrm{Co}$ in Low Doped Congruent $\mathrm{LiNbO}_{3}$ Single Crystal Using PIXE/Channeling. Sol. State Commun. 2000, 115, 535-538. [CrossRef]

216. Buchal, C.; Mantl, S.; Thomas, D.K. Channeling Investigation of the Lattice Location of Ti in Ti-Implanted Optical Waveguides in $\mathrm{LiNbO}_{3}$. Mat. Res. Soc. Symp. Proc. 1987, 100, 317-324. [CrossRef]

217. Kollewe, D.; Kling, A.; Grabmaier, B.C.; Bremer, T.; Heiland, W.; Zimmermann, W. Lattice Site Location of Ti Diffused and Doped in $\mathrm{LiNbO}_{3}$. Phys. Lett. A 1992, 169, 177-180. [CrossRef]

218. Hauer, B.; Vianden, R.; da Silva, M.F.; Rebouta, L.; Soares, J.C.; Diéguez, E.; Agulló-López, F. The Lattice Site of Ti in LiNbO 3 . J. Phys. Condens. Matter 1994, 6, 267-274. [CrossRef]

219. Johnson, L.F.; Ballman, A.A. Coherent Emission from Rare Earth Ions in Electro-Optic Crystals. J. Appl. Phys. 1969, 40, $297-302$. [CrossRef]

220. Kovács, L.; Rebouta, L.; Soares, J.C.; da Silva, M.F. Lattice Site of Er in $\mathrm{LiNbO}_{3}: \mathrm{Mg}$,Er Crystals. Rad. Eff. Def. Sol. 1991, 119-121, 445-450. [CrossRef]

221. Kovács, L.; Rebouta, L.; Soares, J.C.; da Silva, M.F.; Hage-Ali, M.; Stoquert, J.P.; Siffert, P.; Sanz-García, J.A.; Corradi, G.; Szaller

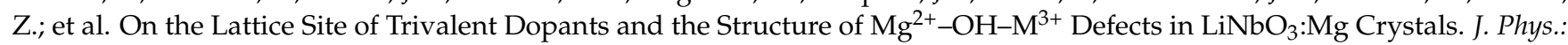
Condens. Matter 1993, 5, 781-794. [CrossRef]

222. Rebouta, L.; Soares, J.C.; da Silva, M.F.; Serrano, D.; Díeguez, E.; Agulló-López, F.; Tornero, J. Nonaxial Sites for Er in LiNbO 3 . Appl. Phys. Lett. 1997, 70, 1070-1072. [CrossRef]

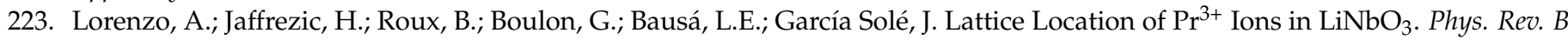
1995, 52, 6278-6284. [CrossRef] [PubMed]

224. Lorenzo, A.; Jaffrezic, H.; Roux, B.; Boulon, G.; García Solé, J. Lattice Location of Rare-Earth Ions in LiNbO 3 . Appl. Phys. Lett. 1995, 67, 3735-3737. [CrossRef]

225. Lorenzo, A.; Loro, H.; Muñoz Santiuste, J.E.; Terrile, M.C.; Boulon, G.; Bausá, L.E.; García Solé, J. RBS/Channeling to Locate Active Ions in Laser Materials: Application to Rare Earth Activated $\mathrm{LiNbO}_{3}$. Opt. Mat. 1997, 8, 55-63. [CrossRef]

226. García Solé, J.; Petit, T.; Jaffrezic, H.; Boulon, G. Lattice Location of the Non-Equivalent $\mathrm{Nd}^{3+}$ Ions in $\mathrm{LiNbO}_{3}: \mathrm{Nd}$ and $\mathrm{LiNbO}_{3}: \mathrm{MgO}: \mathrm{Nd}$. Europhys. Lett. 1993, 24, 719-724. [CrossRef]

227. García-Solé, J.; Lorenzo, A.; Petit, T.; Boulon, G.; Roux, B.; Jaffrezic, H. Site Selective Spectroscopy and RBS/Channeling in Optically Active Ion Doped $\mathrm{LiNbO}_{3}$ crystals. J. Phys. IV 1994, 4, C4-293-C4-296.

228. Rebouta, L.; Soares, J.C.; da Silva, M.F.; Sanz-García, J.A.; Diéguez, E.; Agulló-López, F. Lattice Site for Transition and Rare-Earth Impurities in $\mathrm{LiNbO}_{3}$ by Ion-Beam Methods. J. Mater. Res. 1992, 7, 130-135. [CrossRef]

229. Camarillo, E.; Tocho, J.; Vergara, I.; Díeguez, E.; García-Solé, J.; Jaque, F. Optical Bands of $\mathrm{Cr}^{3+}$ induced by $\mathrm{Mg}^{2+} \mathrm{Ions}_{\text {in }}$ $\mathrm{LiNbO}_{3}: \mathrm{Cr}, \mathrm{Mg}$. Phys. Rev. B 1992, 45, 4600-4604. [CrossRef] [PubMed]

230. Díaz-Caro, J.; García-Solé, J.; Bravo, D.; Sanz-García, A.; Lopez, F.J.; Jaque, F. MgO Codoping-Induced Change in the Site Distribution of $\mathrm{Cr}^{3+}$ Ions in $\mathrm{LiNbO}_{3}$. Phys. Rev. B 1996, 54, 13042-13046. [CrossRef] [PubMed]

231. Kling, A.; Soares, J.C.; da Silva, M.F. Optical and Structural Properties of Chromium Implanted Lithium Niobate-Cluster Formation and Substitutional Incorporation. Nucl. Instr. Meth. B 1999, 148, 1044-1048. [CrossRef]

232. Almeida, J.M.; Boyle, G.; Leite, A.P.; De La Rue, R.M.; Ironside, C.N.; Caccavale, F.; Chakraborty, P.; Mansour, I. Chromium Diffusion in Lithium Niobate for Active Optical Waveguides. J. Appl. Phys. 1995, 78, 2193-2197. [CrossRef]

233. Macfarlane, P.I.; Holliday, K.; Nicholls, J.F.H.; Henderson, B. Characterization of $\mathrm{Cr}^{3+}$ Centres in $\mathrm{LiNbO}_{3} \mathrm{Using}$ Fluorescence Line Narrowing. J. Phys. Condens. Matter 1995, 7, 9643-9656. [CrossRef]

234. Jaque, F.; García-Solé, J.; Camarillo, E.; López, F.J.; Murrieta, S.H.; Hernández, A.J. Detection of $\mathrm{Cr}^{3+}$ sites in $\mathrm{LiNbO}_{3}: \mathrm{MgO} \mathrm{Cr}^{3+}$ and $\mathrm{LiNbO}_{3}: \mathrm{Cr}^{3+}$. Phys. Rev. B 1993, 47, 5432-5434. [CrossRef]

235. Corradi, G.; Chadwick, A.V.; West, A.R.; Cruickshank, K.; Paul, M. On the substitution site of Cr and Fe in LiNbO 3 : An EXAFS study. Rad. Eff. Def. Solids 1995, 134, 219-222. [CrossRef] 
236. Kling, A.; Soares, J.C.; da Silva, M.F.; Sanz-García, J.A.; Diéguez, E.; Agulló-López, F. Lattice Site Determination of Cr in Low Doped Lithium Niobate Single Crystals Using PIXE/channeling. Nucl. Instr. Meth. B 1998, 136-138, 426-430. [CrossRef]

237. Fernández-Ruiz, R.; Bermúdez, V. Determination of the $\mathrm{Ta}$ and $\mathrm{Nb}$ ratio in $\mathrm{LiNb}_{1-\mathrm{x}} \mathrm{Ta}_{\mathrm{x}} \mathrm{O}_{3}$ by total reflection $\mathrm{X}$-ray fluorescence spectrometry. Spectrochim. Acta Part B At. Spectrosc. 2005, 60, 231-235. [CrossRef]

238. Tian, T.; Kong, Y.F.; Liu, S.G.; Li, W.; Wu, L.; Chen, S.L.; Xu, J.J. Photorefraction of molybdenum-doped lithium niobate crystals. Opt. Lett. 2012, 37, 2679-2681. [CrossRef] [PubMed]

239. Kling, A.; Marques, J.G.; Soares, J.C.; da Silva, M.F.; Diéguez, E.; Agulló-López, F. Valence Effect on the Incorporation of Tungsten Implanted into Lithium Niobate. Nucl. Instr. Meth. B 1997, 127/128, 520-523. [CrossRef]

240. Kling, A.; Marques, J.G.; da Silva, M.F.; Serrano, M.D.; Diéguez, E.; Sanz-García, J.A.; García-Solé, J.; Agulló-López, F.; Soares, J.C. Incorporation of Hexavalent Impurities into $\mathrm{LiNbO}_{3}$. Rad. Eff. Def. Solids 1999, 150, 249-253. [CrossRef]

241. Kling, A.; Valdrez, C.; Marques, J.G.; da Silva, M.F.; Soares, J.C. Incorporation of Tungsten in Lithium Niobate by Diffusion. Nucl. Instr. Meth. B 2002, 190, 524-527. [CrossRef]

242. Calvo, J.A.; Bausá, L.E.; Sanz, J.A.; Voda, M.; García-Solé, J. Spectroscopy of Uranium Ions in LiNbO $_{3}$. Ferroelectrics 1996, 185, 41-44. [CrossRef]

243. Kling, A.; da Silva, M.F.; Soares, J.C.; Sanz-García, J.A.; García-Solé, J. Change of Uranium Lattice Site in $\mathrm{LiNbO}_{3}$ Induced by Thermal Reduction Treatment. Rad. Eff. Def. Solids 2001, 155, 229-233. [CrossRef]

244. Freestone, I.; Meeks, N.; Sax, M.; Higgitt, C. The Lycurgus Cup-A Roman Nanotechnology. Gold Bull. 2007, 40, $270-277$. [CrossRef]

245. Saito, Y.; Suganomata, S. Coloration of $\mathrm{LiNbO}_{3}$ by Metal Ion Implantation. Jpn. J. Appl. Phys. 1987, 26, 1941-1942. [CrossRef]

246. Saito, Y.; Shang, D.Y.; Kitsutaka, R.; Kitahara, A. Optical Properties of Cu-Implanted LiNbO 3. J. Appl. Phys. 1997, 81, $3621-3626$. [CrossRef]

247. Shang, D.Y.; Saito, Y.; Kittaka, R.; Taniguchi, S.; Kitahara, A. Optical Properties of LiNbO 3 Implanted with Ag Ions. J. Appl. Phys. 1996, 80, 6651-6654. [CrossRef]

248. Williams, E.K.; Ila, D.; Sarkisov, S.; Curley, M.; Cochrane, J.C.; Poker, D.B.; Hensley, D.K.; Borel, C. Study of the Effects of MeV Ag and $\mathrm{Au}$ Implantation on the Optical Properties of $\mathrm{LiNbO}_{3}$. Nucl. Instr. Meth. B 1998, 141, 268-273. [CrossRef]

249. Saito, Y.; Kitahara, A. Absorption in the Visible Region of $\mathrm{LiNbO}_{3}$ Sequentially Implanted with Ag and Cu Ions. J. Appl. Phys. 2000, 87, 1276-1279. [CrossRef]

250. Shi, B.-R.; Lu, F.; Meng, M.-Q.; Wang, F.-X.; Li, W.; Liu, X.-D.; Wang, K.-M.; Wang, Z.-L. Damage Behaviours in LiNbO $\mathrm{Crystals}_{3}$ Induced by $\mathrm{MeV} \mathrm{Au}^{+}$Irradiation. Nucl. Instr. Meth. B 1998, 135, 275-279. [CrossRef]

251. Ziegler, J.F.; Ziegler, M.D.; Biersack, J.P. SRIM-The stopping and range of ions in matter. Nucl. Instr. Meth. B 2010, 268, 1818-1823. [CrossRef]

252. Takahiro, K.; Kunimatsu, A.; Nagata, S.; Yamaguchi, S.; Yamamoto, S.; Aoki, Y.; Naramoto, H. Crystal Structure and Optical Absorption of $\mathrm{Au}$ Implanted $\mathrm{MgO}, \mathrm{SrTiO}_{3}$ and $\mathrm{LiNbO}_{3}$. Nucl. Instr. Meth. B 1999, 152, 314-318. [CrossRef]

253. Dev, B.N.; Kuri, G.; Satyam, P.V.; Sundaravel, B.; Gog, T.; Materlik, G. X-ray Standing Wave and Ion Scattering Studies on Au-Implanted $\mathrm{LiNbO}_{3}$ (001) Single Crystals. Appl. Surf. Sci. 1998, 125, 163-172. [CrossRef]

254. Kling, A.; da Silva, M.F.; Soares, J.C.; Fichtner, P.F.P.; Amaral, L.; Zawislak, F.C. Formation of Coherent Gold Nanoclusters in Lithium Niobate. Nucl. Instr. Meth. B 2002, 191, 478-481. [CrossRef]

255. Kling, A.; da Silva, M.F.; Soares, J.C.; Fichtner, P.F.P.; Amaral, L.; Zawislak, F.C. Influence of Helium Co-Implantation on the Formation of Gold Nanoclusters in Lithium Niobate. Mod. Phys. Lett. B 2001, 15, 1348-1354. [CrossRef]

256. Wong-Leung, J.; Williams, J.S.; Eliman, R.G.; Nygren, E.; Eaglesham, D.J.; Jacobson, D.C.; Poate, J.M. Proximity Gettering of Au to Ion Beam Induced Defects in Silicon. Nucl. Instr. Meth. B 1995, 96, 253-256. [CrossRef]

257. Milz, S.; Rensberg, J.; Ronning, C.; Wesch, W. Correlation between damage evolution, cluster formation and optical properties of silver implanted lithium niobate. Nucl. Instr. Meth. B 2012, 286, 67-71. [CrossRef]

258. Williams, E.K.; Ila, D.; Darwish, A.; Poker, D.B.; Sarkisov, S.S.; Curley, M.J.; Wang, J.-C.; Svetchnikov, V.L.; Zandbergen, H.W. Characterization of Silver Colloids Formed in $\mathrm{LiNbO}_{3}$ by Ag and O Implantation at Room and Elevated Temperatures. Nucl. Instr. Meth. B 1999, 148, 1074-1078. [CrossRef]

259. Kling, A.; Soares, J.C.; da Silva, M.F. Platinum Implanted Lithium Niobate-Annealing Behavior and Dopant Redistribution. Nucl. Instr. Meth. B 1998, 141, 436-440. [CrossRef]

260. Kling, A.; Soares, J.C.; da Silva, M.F. Redistribution and Incorporation of Iridium Implanted into Lithium Niobate. Nucl. Instr. Meth. B 2000, 166-167, 280-283. [CrossRef]

261. Bazzan, M.; Sada, C. Optical Waveguides in Lithium Niobate: Recent Developments and Applications. Appl. Phys. Rev. 2015, 2, 040603. [CrossRef]

262. Kaminow, I.P.; Carruthers, J.R. Optical waveguiding layers in $\mathrm{LiNbO}_{3}$ and $\mathrm{LiTaO}_{3}$. Appl. Phys. Lett. 1973, 22, 326-328. [CrossRef]

263. Burns, W.K.; Klein, P.H.; West, E.J.; Plew, L.E. Ti diffusion in Ti:LiNbO 3 planar and channel optical waveguides. J. Appl. Phys. 1979, 50, 6175-6182. [CrossRef]

264. Armenise, M.N.; Canali, C.; De Sario, M.; Carnera, A.; Mazzoldi, P.; Celotti, G. Evaluation of the Ti diffusion process during fabrication of Ti: $\mathrm{LiNbO}_{3}$ optical waveguides. J. Non-Cryst. Sol. 1982, 47, 255-257. [CrossRef]

265. Armenise, M.N.; Canali, C.; De Sario, M.; Carnera, A.; Mazzoldi, P.; Celotti, G. Characterization of $\left(\mathrm{Ti}_{0.65} \mathrm{Nb}_{0.35}\right) \mathrm{O}_{2} \mathrm{Compound}$ as a Source for Ti Diffusion During Ti: $\mathrm{LiNbO}_{3}$ Optical Waveguides Fabrication. J. Appl. Phys. 1983, 54, 62-70. [CrossRef] 
266. Bremer, T.; Kollewe, D.; Koschmieder, H.; Heiland, W. SIMS Investigations of Titanium Profiles in $\mathrm{LiNbO}_{3}$ Produced by Ion Beam Mixing and Diffusion. Fresenius Z. Anal. Chem. 1989, 333, 485-487. [CrossRef]

267. Caccavale, F.; Chakraborty, P.; Quaranta, A.; Mansour, I.; Gianello, G.; Bosso, S.; Corsini, R.; Mussi, G. Secondary-Ion-Mass Spectrometry and Near-Field Studies of Ti:LiNbO 3 Optical Waveguides. J. Appl. Phys. 1995, 78, 5345-5350. [CrossRef]

268. Caccavale, F.; Gonella, F.; Quaranta, A.; Mansour, I. Analysis of Ti: $\mathrm{LiNbO}_{3}$ Waveguides Using Secondary Ion Mass Spectrometry and Near Field Method. Elect. Lett. 1995, 31, 1054-1056. [CrossRef]

269. Caccavale, F.; Sada, C.; Segato, F.; Cavuoti, F. Secondary Ion Mass Spectrometry and Optical Characterization of Ti:LiNbO 3 Optical Waveguides. Appl. Surf. Sci. 1999, 150, 195-201. [CrossRef]

270. Zhang, D.-L.; Yang, Z.; Wong, W.H.; Pun, E.Y.B. Secondary-ion-mass spectrometry study on nearstoichiometric LiNbO $_{3}$ strip waveguide fabricated by vapour transport equilibration and Ti codiffusion. Philos. Mag. 2007, 87, 63-75. [CrossRef]

271. Bremer, T.; Hertel, P.; Oelschig, S.; Sommerfeldt, R.; Heiland, W. Depth Profiling of Magnesium and Titanium-Doped LiNbO 3 Waveguides. Thin Sol. Films 1989, 175, 235-239. [CrossRef]

272. Caccavale, F.; Chakraborty, P.; Capobianco, A.; Gianello, G.; Mansour, I. Characterization and Optimization of Ti-Diffused LiNbO 3 Optical Waveguides by Second Diffusion of Magnesium. J. Appl. Phys. 1995, 78, 187-193. [CrossRef]

273. Caccavale, F.; Chakraborty, P.; Mansour, I.; Gianello, G.; Mazzoleni, M.; Elena, M. A Secondary-Ion-Mass Spectrometry Study of Magnesium Diffusion in Lithium Niobate. J. Appl. Phys. 1994, 76, 7552-7558. [CrossRef]

274. Mohan Kumar, R.; Yamamoto, F.; Ichikawa, J.; Ryoken, H.; Sakaguchi, I.; Liu, X.; Nakamura, M.; Terabe, K.; Takekawa, S.; Haneda, $\mathrm{H}$; ; et al. SIMS-depth profile and microstructure studies of Ti-diffused Mg-doped near-stoichiometric lithium niobate waveguide. J. Cryst. Growth 2006, 287, 472-477. [CrossRef]

275. Herreros, B.; Lifante, G. $\mathrm{LiNbO}_{3}$ optical waveguides by Zn diffusion from vapor phase. Appl. Phys. Lett. 1995, 66, $1449-1451$. [CrossRef]

276. Nevado, R.; Cussó, F.; Lifante, G.; Caccavale, F.; Sada, C.; Segato, F. Correlation between compositional and refractive index profiles in diffused optical waveguides. J. Appl. Phys. 2000, 88, 6183-6186. [CrossRef]

277. Nevado, R.; Cantelar, E.; Segato, F.; Caccavale, F.; Kling, A.; Soares, J.C. Compositional Characterization of Zn-Diffused Lithium Niobate Waveguides. Appl. Phys. B 2001, 73, 555-558. [CrossRef]

278. Espeso-Gil, O.; García, G.; Agulló-López, F.; Climent-Font, A.; Sajavaara, T.; Domenech, M.; Cantelar, E.; Lifante, G. Characterization of surface layers in $\mathrm{Zn}$-diffused $\mathrm{LiNbO}_{3}$ waveguides by heavy ion elastic recoil detection. Appl. Phys. Lett. 2002, 81, 1981-1983. [CrossRef]

279. Zhang, D.-L.; Qiu, C.-X.; Wong, W.-H.; Pun, E.Y.-B. Diffusion Properties of Scandium in Lithium Niobate Crystal. J. Am. Ceram. Soc. 2014, 97, 2903-2908. [CrossRef]

280. Zhang, D.-L.; Qiu, C.-X.; Zhang, W.-Z.; Hua, P.-R.; Yu, D.-Y.; Pun, E.Y.-B. Diffusion Characteristics of $\mathrm{Zr}^{4+}$ in $\mathrm{LiNbO}_{3} \mathrm{Sin}_{\mathrm{N} l e-C r y s t a l}$ J. Am. Ceram. Soc. 2013, 96, 2722-2724. [CrossRef]

281. Tsai, W.-S.; Chiang, T.-Y.; Liu, L.-Y.; Chang, P.-C.; Su, Y.-K. Time and Temperature Dependent Study of Zn and Ni Codiffused $\mathrm{LiNbO}_{3}$ Waveguides. J. Light. Technol. 2015, 33, 4850-4859. [CrossRef]

282. Zhang, D.-L.; Qiu, C.-X.; Wong, W.-H.; Du, W.-J.; Pun, E.Y.-B. $\mathrm{Zr}^{4+} / \mathrm{Ti}^{4+}$ Codiffusion Characteristics in Lithium Niobate. J. Am. Ceram. Soc. 2015, 98, 567-573. [CrossRef]

283. Zhang, D.-L.; Zhang, Q.; Qiu, C.-X.; Wong, W.-H.; Dao, Y.-Y.; Pun, E.Y.-B. Diffusion control of an ion by another in LiNbO 3 and $\mathrm{LiTaO}_{3}$ crystals. Sci. Rep. 2015, 5, 10018. [CrossRef] [PubMed]

284. De Almeida, J.M.M.M.; Marinho, F.; Alexandre, D.; Sada, C. Secondary Ion Mass Spectrometry Study of Erbium Titanium Codiffusion in Lithium Niobate. IEEE Phot. Lett. Tech. 2014, 26, 1307-1309. [CrossRef]

285. Jackel, J.J.; Rice, C.E. Topotactic $\mathrm{LiNbO}_{3}$ to Cubic Perovskite Structural Transformation in $\mathrm{LiNbO}_{3}$ and $\mathrm{LiTaO}_{3}$. Ferroelectrics 1982 , 38, 801-8040. [CrossRef]

286. Jackel, J.J.; Rice, C.E.; Veselka, J.J. Proton exchange for high-index waveguides in $\mathrm{LiNbO}_{3}$. Appl. Phys. Lett. 1982, 41,607-608. [CrossRef]

287. Cabrera, J.M.; Olivares, J.; Carrascosa, M.; Rams, J.; Müller, R.; Diéguez, E. Hydrogen in Lithium Niobate. Adv. Phys. 1996, 45, 349-392. [CrossRef]

288. Campari, A.; Ferrari, C.; Mazzi, G.; Summonte, C.; Al-Shukri, S.M.; Dawar, A.; De La Rue, R.M.; Nutt, A.C.G. Strain and Surface Damage Induced by Proton Exchange in Y-cut $\mathrm{LiNbO}_{3}$. J. Appl. Phys. 1985, 58, 4521-4524. [CrossRef]

289. De Micheli, M.; Ostrowsky, D.B.; Barety, J.P.; Mazzi, G.; Papuchon, M. Crystalline and Optical Quality of Proton Exchanged Waveguides. J. Light. Tech. 1986, LT-4, 743-745. [CrossRef]

290. Canali, C.; Carnera, A.; Della Mea, G.; Mazzoldi, P.; Al Shukri, S.M.; Nutt, A.C.G.; De La Rue, R.M. Structural Characterization of Proton Exchanged $\mathrm{LiNbO}_{3}$ Optical Waveguides. J. Appl. Phys. 1986, 59, 2643-2649. [CrossRef]

291. Olivares, J.; Cabrera, J.M.; Agulló-López, F.; Rebouta, L.; da Silva, M.F.; Soares, J.C. Structural Characterization of LiNbO 3 Proton-Exchanged Waveguides by Ion-Beam Methods. Ferroelectrics 1995, 174, 93-99. [CrossRef]

292. Hu, H.; Lu, F.; Chen, F.; Wang, F.-X.; Zhang, J.-H.; Liu, X.-D.; Wang, K.-M. Channeling Study of Proton-Exchanged LiNbO 3 Optical Waveguides. Phys. Stat. Sol. 2000, 181, 509-513. [CrossRef]

293. Cargo, J.T.; Filo, A.J.; Hughes, M.C.; Kannan, V.C.; Stevie, F.A.; Taylor, J.A.; Holmes, R.J. Characterization of Sulfuric Acid Proton-Exchanged Lithium Niobate. J. Appl. Phys. 1990, 67, 627-633. [CrossRef] 
294. Paz-Pujalt, G.R.; Tuschel, D.D.; Braunstein, G.; Blanton, T.; Tong Lee, S.; Salter, L.M. Characterization of Proton Exchange Lithium Niobate Waveguides. J. Appl. Phys. 1994, 76, 3981-3987. [CrossRef]

295. Hsu, W.-Y.; Braunstein, G.; Gopalan, V.; Willand, C.S.; Gupta, M.C. Correlation between Structural and Optical Properties in Proton-Exchanged $\mathrm{LiNbO}_{3}$. Appl. Phys. Lett. 1992, 61, 3083-3085. [CrossRef]

296. Olivares, J.; Cabrera, J.M.; Agulló-López, F.; Rebouta, L.; da Silva, M.F.; Soares, J.C. Ion-Beam Channeling Characterization of Proton-Exchanged $\mathrm{LiNbO}_{3}$. In Proceedings of the 6th European Conference on Integrated Optics and Technical Exhibit: ECIO 93, Neuchâtel, Switzerland, 18-22 April 1993; Roth, P., Parriaux, O.M., Eds.; ECIO: Neuchâtel, Switzerland, 1993; pp. 9-14-9-15.

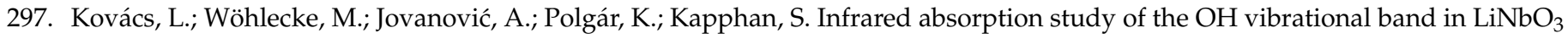
crystals. J. Phys. Chem. Solids 1991, 52, 707-803. [CrossRef]

298. Ito, K.; Kawamoto, K. Dependence of Lattice Constant Deviation and Refractive Index on Proton Concentration in ProtonExchanged Optical Waveguides on a Single Crystal of $\mathrm{LiNbO}_{3}$. Jpn. J. Appl. Phys. 1992, 31, 3882-3887. [CrossRef]

299. Rottschalk, M.; Bachmann, T.; Witzmann, A. Investigations of Proton Exchanged Optical Waveguides in $\mathrm{LiNbO}_{3} \mathrm{Using}_{\mathrm{E}} \mathrm{Elastic}$ Recoil Detection. Nucl. Instr. Meth. B 1991, 61, 91-93. [CrossRef]

300. Hagner, G.; Bachmann, T. Refractive Index Profiles and Exchange Ratios of Proton-Exchanged Waveguides in Congruent and MgO-Doped $\mathrm{LiNbO}_{3}$. Phys. Stat. Sol. 1998, 165, 205-212. [CrossRef]

301. Casey, H.C., Jr.; Chen, C.-H.; Zavada, J.M.; Novak, S.W. Analysis of Hydrogen Diffusion from Proton-Exchanged Layers in $\mathrm{LiNbO}_{3}$. Appl. Phys. Lett. 1993, 63, 718-720. [CrossRef]

302. Zavada, J.M.; Casey, H.C., Jr.; States, R.J.; Novak, S.W.; Loni, A. Correlation of Substitutional Hydrogen to Refractive Index Profiles in Annealed Proton-Exchanged Z- and X-Cut LiNbO . J. Appl. Phys. 1995, 77, 2697-2708. [CrossRef]

303. Engelsberg, M.; do Nascimento, G.C.; Pacobahyba, L.H. ${ }^{1} \mathrm{H}$ Atomic Motion in Proton-Exchanged LiNbO 3 . J. Appl. Phys. 1993, 74, 6427-6429. [CrossRef]

304. De Souza, R.E.; Engelsberg, M.; Pacobahyba, L.H.; do Nascimento, G.C. Nuclear Magnetic Resonance Study of Proton Exchanged $\mathrm{LiNbO}_{3}$. J. Appl. Phys. 1995, 77, 408-410. [CrossRef]

305. Engelsberg, M.; de Souza, R.E.; Pacobahyba, L.H.; do Nascimento, G.C. Structural Determination of Hydrogen Site Occupation in Proton-Exchanged $\mathrm{LiNbO}_{3}$ by Nuclear Magnetic Resonance. Appl. Phys. Lett. 1995, 67, 359-361. [CrossRef]

306. Yamamoto, K.; Taniuchi, T. Characteristics of Pyrophosphoric Acid Proton-Exchanged Waveguides in LiNbO 3 . J. Appl. Phys. 1991, 70, 6663-6668. [CrossRef]

307. Cheng, C.-C.; Horng, R.-C.; Chen, Y.-C. Formation and Properties of Proton-Exchanged and Annealed $\mathrm{LiNbO}_{3} \mathrm{Waveguides}_{\text {for }}$ Surface Acoustic Wave. IEEE Trans. Ultras. Ferroel. Freq. Control. 2001, 48, 387-391. [CrossRef]

308. Chen, F.; Wang, X.-L.; Wang, K.-M. Development of Ion-Implanted Optical Waveguides in Optical Materials: A Review. Opt. Mat. 2007, 29, 1523-1542. [CrossRef]

309. Peña-Rodríguez, O.; Olivares, J.; Carrascosa, M.; García-Cabañes, A.; Rivera, A.; Agulló-López, F. Optical Waveguides Fabricated by Ion Implantation/Irradiation: A Review. In Ion Implantation; Goorsky, M., Ed.; InTech: Rijeka, Croatia, 2012 ; pp. $267-314$. ISBN 978-953-51-0634-0.

310. Destefanis, G.L.; Townsend, P.D.; Gailliard, J.P. Optical Waveguides in $\mathrm{LiNbO}_{3}$ Formed by Ion Implantation of Helium. Appl. Phys. Lett. 1978, 32, 293-294. [CrossRef]

311. Barfoot, K.M.; Laursen, T.; Whitton, J.L.; Weiss, B.L.; Webb, R.P. In Situ Channeling Analysis During Thermal Annealing of ${ }^{4} \mathrm{He}^{+}$-Implanted $\mathrm{LiNbO}_{3}$. Nucl. Instr. Meth. B 1989, 44, 141-145. [CrossRef]

312. Williams, E.K.; Ila, D.; Sarkisov, S.; Venkateswarlu, P.; Poker, D.B. Application of NRA/Channeling to Study He ${ }^{+} \mathrm{Implanted}$ Waveguides. Nucl. Instr. Meth. B 1986, 118, 57-61. [CrossRef]

313. Al-Chalabi, S.A.M.; Weiss, B.L.; Barfoot, K.M.; Arnold, G.W. Analysis of He-implanted $\mathrm{LiNbO}_{3}$ by Elastic Recoil Detection. J. Appl. Phys. 1988, 63, 1032-1036. [CrossRef]

314. Kling, A.; da Silva, M.F.; Soares, J.C.; Fichtner, P.F.P.; Amaral, L.; Zawislak, F. Defect Evolution and Characterization in HeImplanted $\mathrm{LiNbO}_{3}$. Nucl. Instr. Meth. B 2001, 175-177, 394-397. [CrossRef]

315. Fichtner, P.F.P.; Kaschny, J.R.; Kling, A.; Trinkaus, H.; Yankov, R.A.; Mücklich, A.; Skorupa, W.; Zawislak, F.C.; Amaral, L.; da Silva, M.F.; et al. Nucleation and Growth of Platelet Bubble Structures in $\mathrm{He}^{+}$Implanted Silicon. Nucl. Instr. Meth. B 1998, 136-138, 460-464. [CrossRef]

316. Gischkat, T.; Schrempel, F.; Höche, T.; Wesch, W. Annealing Behavior of Lithium Niobate Irradiated with He-Ions at 100 K. Nucl. Instr. Meth. B 2009, 267, 1492-1495. [CrossRef]

317. Olivares, J.; García, G.; Agulló-López, F.; Agulló-Rueda, F.; Soares, J.C.; Kling, A. Optical Investigations of the Propagation of the Amorphous-Crystalline Boundary in Ion-beam Irradiated $\mathrm{LiNbO}_{3}$. Nucl. Instr. Meth. B 2006, 242, 534-537. [CrossRef]

318. Hu, H.; Lu, F.; Chen, F.; Wang, F.-X.; Zhang, J.-H.; Liu, X.-D.; Wang, K.-M.; Shi, B.-R. Optical waveguide formation by MeV H ${ }^{+}$ implanted into $\mathrm{LiNbO}_{3}$ crystal. Opt. Comm. 2000, 177, 189-193. [CrossRef]

319. Zhao, J.-H.; Huang, Q.; Wang, L.; Fu, G.; Qin, X.F.; Liu, P.; Guo, S.-S.; Liu, T.; Wang, X.-L. The Properties of Ion-Implanted LiNbO 3 Waveguides Measured by the RBS and Ion Beam Etching Stripping Methods. Opt. Mat. 2011, 33, 1357-1361. [CrossRef]

320. Wang, L.; Xiang, B.-X. Planar waveguides in magnesium doped stoichiometric $\mathrm{LiNbO}_{3}$ crystals formed by MeV oxygen ion implantations. Nucl. Instr. Meth. B 2012, 272, 121-124. [CrossRef]

321. Song, Q.; Lu, F.; Ma, X.; Liu, H.; Liu, X.; Zhang, R.; Wang, X. MgO:LiNbO 3 Planar Waveguide Formed by $\mathrm{MeV}^{2+} \mathrm{Implantation}$ and Its Annealing Characteristics. Laser Phys. 2008, 18, 815-818. [CrossRef] 
322. Bremer, T.; Heiland, W.; Buchal, C.; Irmscher, R.; Stritzker, B. Recrystallization and Refractive Index Profiles of Titanium-Implanted Optical Waveguides in $\mathrm{LiNbO}_{3}$. J. Appl. Phys. 1990, 67, 1183-1187. [CrossRef]

323. Zhang, S.-M.; Peng, Y.-D.; Wang, P.; Liu, Q.-X. Influences on Proton Exchange by He Ion Implantation in LiNbO 3 . Opt. Mat. Expr. 2015, 5, 1526-1531. [CrossRef]

324. Huang, Q.; Liu, P.; Liu, T.; Guo, S.-S.; Zhang, L.; Wang, X.-L. Lattice damage and waveguide properties of a proton-exchanged $\mathrm{LiNbO}_{3}$ crystal after oxygen-ion implantation. Nucl. Instr. Meth. B 2012, 286, 318-321. [CrossRef]

325. Herreros, B.; Lifante, G.; Cussó, F.; Kling, A.; Soares, J.C.; da Silva, M.F.; Townsend, P.D.; Chandler, P.J. Structural and Optical Properties of Rare-earth Doped Lithium Niobate Waveguides Formed by MeV Helium Implantation. Mat. Res. Soc. Symp. Proc. 1996, 396, 355-360. [CrossRef]

326. Herreros, B.; Lifante, G.; Cussó, F.; Sanz, J.A.; Kling, A.; Soares, J.C.; da Silva, M.F.; Townsend, P.D.; Chandler, P.J. Photolumi-

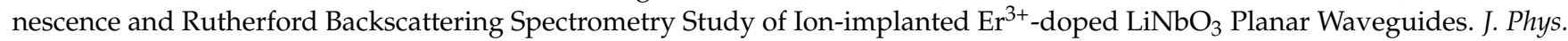
Condens. Matter 1998, 10, 3275-3283. [CrossRef]

327. Herreros, B.; Lifante, G.; Kling, A.; Soares, J.C.; da Silva, M.F.; Townsend, P.D.; Chandler, P.J.; Olivares, J.; Cabrera, J.M. RBS/channeling Study of Ion-implanted and Proton-exchanged $\mathrm{LiNbO}_{3}: \mathrm{Nd}^{3+}: \mathrm{MgO}$ Planar Waveguides. Opt. Mat. 1996, 6, 281-286. [CrossRef]

328. Cajzl, J.; Nekvindová, P.; Macková, A.; Malinský, P.; Oswald, J.; Staněk, S.; Vytykáčová, S.; Špirková, J. Optical waveguides in Er:LiNbO ${ }_{3}$ fabricated by different techniques-A Comparison. Opt. Mat. 2016, 53, 160-168. [CrossRef] 